University of Louisville

ThinkIR: The University of Louisville's Institutional Repository

Electronic Theses and Dissertations

1937

\title{
The teaching of mathematics in the junior high schools of Kentucky.
}

Frank Hall Stallings 1909-1995

University of Louisville

Follow this and additional works at: https://ir.library.louisville.edu/etd

Part of the Educational Methods Commons, and the Science and Mathematics Education Commons

\section{Recommended Citation}

Stallings, Frank Hall 1909-1995, "The teaching of mathematics in the junior high schools of Kentucky." (1937). Electronic Theses and Dissertations. Paper 1961.

https://doi.org/10.18297/etd/1961

This Master's Thesis is brought to you for free and open access by ThinkIR: The University of Louisville's Institutional Repository. It has been accepted for inclusion in Electronic Theses and Dissertations by an authorized administrator of ThinkIR: The University of Louisville's Institutional Repository. This title appears here courtesy of the author, who has retained all other copyrights. For more information, please contact thinkir@louisville.edu. 
ONIVERSITY OF LOUISVILLE.

\title{
THE TEACHING OF MATHEMATICS IN THE JUNIOR HIGH SCHOOLS OF $\quad$ KENTUCKY
}

\author{
A Dissertation \\ Submitted to the Faculty \\ Of the Graduate School of the University of Louisville \\ In Partial Fulfillment of the \\ Requirements for the Degree \\ of Master of Arts \\ Department of Education \\ By \\ FRANK HALL STALLINGS
}


FRANK HAIT STAIIINGS

IHE THACHING OF MATHFATICS IV

TER JUNIOR HIGH SCHOOIS OF KENIUCKY

Written under the direction of Dr. J.J.Oppenheimer, Head of the Department of Education and Dean of the College of Liberal Arts.

Read and approved by

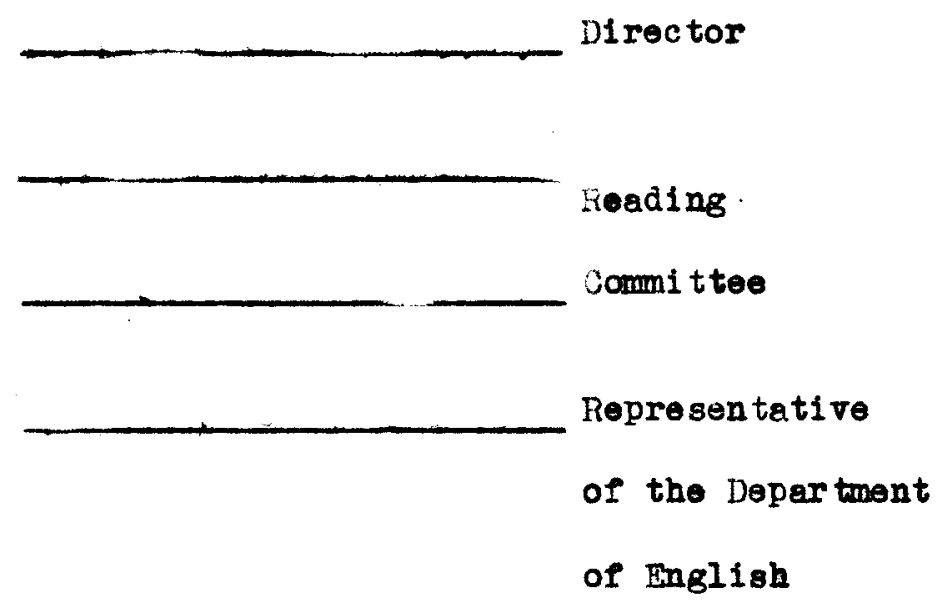

Date hay 14,1937 
TABLE OF CONTENTS

\title{
Part One
}

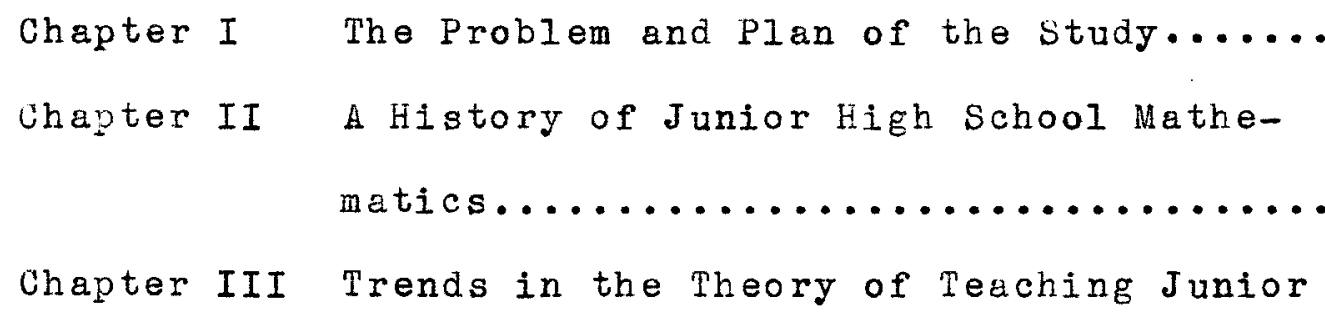

High School Mathemetics..................... 23 .

Chapter IV Trends in the Practice of Teaching Junior

High School Mathematics...................... 47 .

Chapter $V$ Criteria for Evaluating the Mathematics

of the Junior High School.................... 68 .

\section{Part Tพо}

Chapter VI The Organization of the Junior High Schools

in Kentucky and of Their offerings in

Mathematics............................. 79 .

Chapter VII An Evaluation of the Mathematics Taught

in the Junior High Schools of Kentucky...Page 104.

$$
\begin{aligned}
& \text { A - Kentucky Exclusive of Louisville...Page } 106 .
\end{aligned}
$$

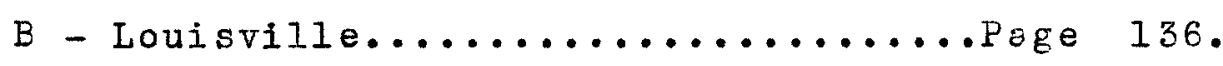

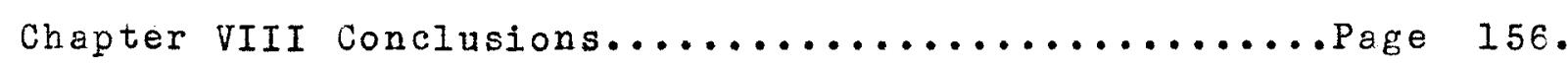

Bibliography.................................... 165 .

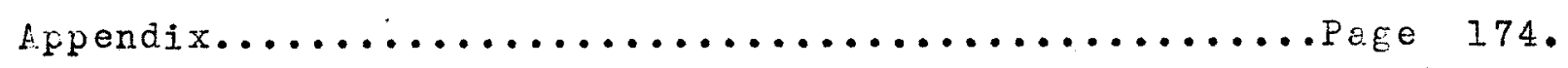




\section{PART ONE}

IRENDS IN THA TEACHING

$$
\text { OF }
$$

JUNIOR HIGH SUHOOL MATHEMATICS 
CHAPTER I

THE PROBLEM

AND PLAN

OF THE STUDY 
CHAPTER I

THE PROBLEN AND PLAN OF THE STUDY

The Problem

Education in the United States has gone through various phases of emphasis since its beginning in the colonies as a transplantation from English soil. The first phase to receive emphasis was public support. After the Revolution the old system of private and semi-private education was found inadequate for filling the needs of a young republic, and the battle for tax-supported schools was begun, a battle that reached its climax in 1872 with the Kalamazoo decision which declared it legal to divert public funds to the support of secondary education.

Next there came a period when reorganization was given the foremost place. This movement which began as an attempt on the part of colleges to shorten the period of preparation was soon taken up by educators in the elementary and secondary fields, their aim being a better adjustment of organization to the needs of the student. This emphasis culminated with the development of the junior high school, the six-six plan, and the junior $\operatorname{college}$.

Overlapping this period and closely related to it was the 
stage at which the school plant and its administration were given major attention. Numerous studies appeared regarding the construction, maintenance, and operation of school buildings in relation to the educational program, and systems everywhere underwent physical expansion. This movement was partialIy curbed by the World War although its momentum carried it well past its period of initial diminution.

The same war which curbed the emphasis upon the building program gave rise to a new emphasia on testing. Certain tests developed in connection with the administration of the personnel of the army were readily adapted to educational purposes and hence other tests were devised. The literature of this period is filled with textbooks, articles, and monographs on testing in addition to innumerable tests themselves. This movement is still in an active stage, but probably because of economic pressure a new movement has relegated it to a secondary position.

In the present period indubitably the curriculum is receiving major emphasis. Having established free education, reorganized it along lines more psychologically sound, provided it with physical facilities, and devised means of testing its product, we have decided to face seriously the problem of putting it all to some use. There is scarcely to be found, to-day, a school system which has not undertaken the problem of curriculum reorganization. Curriculum publications, courses, clinics, 
conferences, experimental centers and committees have sprung up everywhere. This phase of education is coming into its rightful inheritance, and in no part of the entire educational program has its influence been felt more than in the junior high school. This comparatively new institution has been readily open to progress, being less bound by tradition and formalism than either the elementary school on the one hand or the senior high school on the other.

The curriculum of this institution more nearly reflects the progressive trends in modern education than does either of the other two. Never-the-less, not all of the subjects which comprise its curriculum have been given equal attention. Mathematics is in many respects the step-child in the family of subject matter. Schools that have long ego declared their program of social studies obsolete are still satisfied with a traditionshrouded type of mathematics although pioneer thinkers have blazed the trail far ahead and progressive schools here and there are accepting the challenge which these leaders have laid down.

Kentucky has under way at the present time a thorough-going program of curriculum reorgenization. The commitees have been appointed to carry this work formard. It is the author's privilege to be serving at present on the Kentucky Committee on Mathematics for Grades Seven to Nine. He has also been privileged to serve on numerous mathematics committees for the Louisville 
Public schools for the same grades and it is largely because of these connections that this thesis was conceived. The work of the state commitee is still in its formative stage and while the Louisville reorganization of curriculum materials has progressed to the point where it has been put into practice and has been revised several times, further revision is planned and all the work is considered tenative as it always should be.

It is with the hope that this thesis may contribute some small part to these two undertakings and also be of some value to the interested inquirer that it is attempted.

\section{Plan of the study}

This study is divided into two parts. Part one undertakes to discover certain forces which have been at work on junior high school mathematics. These trends are discovered by tracing the historical development of the junior high school curriculum in mathematics, by citing the opinions of experts in the fields of mathematics and of the curriculum in general, and by showing how these trends are shaping themselves into actual practice in progressive schools over the country.

Part Two undertakes to give a general picture of the organization of the teaching of junior high school mathematics in Kentucky and attempts to evaluate the curriculum in the light of the trends discovered in Part one.

The data for Part one come from the following sources to 
correspond with the three means of discovering trends: historical literature, writings of experts individually and in committees, and survey studies and curriculum materials which describe practice in progressive schools elsewhere in the nation.

The date regarding the mathematics taught in Kentucky and regarding the general set up were obtained from two questionnaires sent to the principals and teachers of mathematics in twenty-two white public junior high schools. The questionnaire sent the principals regarded the general organization of the school and the organization as it affected mathematics. An exception was made of the principals of Louisville as the data required were obtainable from other sources. All of the principals who were sent the questionnaire responded. Teachers in all these schools who taught one or more classes in junior high school mathematics were sent the other questionnaire which concerned the preparation and experience of the teachers and their opinions regarding certain important issues and other information. out of 100 teachers contacted eighty-two responded to this questionnaire. Every school was represented by one or more of its teachers, and in most cases all the teachers in any given school responded.

Eight of the junior high schools are in Louisville and fourteen are elsewhere in the state. Of the eighty-two teachers responding, thirty-one are in the junior high schools of Louisville and fifty-one are elsewhere in the state. 
A Ist of the junior high schools together with their principals and teachers, except those who requested us not to divulge their names, appears in the appendix.

For data regarding the curriculum, courses of study were used where obtainable. In the absence of such, textbooks were employed.

\section{Definitions}

Many attempts have been made to define the junior high school and none of them has been wholly satisfactory. Briggs lists forty-four aspects of the movement and invites the reader to make his own definition. Davis ${ }^{2}$ lists seventeen characteristics not all of which might be deemed essential. For purposes of this study, a junior high school will be considered an institution intermediary between a six-year elementary school and a four-year or three-year seniar high school consisting of grades seven and eight or those grades together with the ninth, that practices departmentalization, that offers election of courses, and that has at least a partially distinct organization and admin1stration. It may or may not be closely connected with a senior high school provided the above characteristics are adhered to.

For sake of convenience, the curriculum will be referred to

1. Briggs, Thomas H., The Junior High School, Houghton Hifflin Company, Boston, $1920 \cdot \mathrm{pp} \cdot 54-56$

2. Davis, C. 0., Junior High School Education, World Book Company, New York, 1925. pp. 13-14 
as the planned educational experiences provided, while the course of study will be referred to as the document recording these experiences.

The adjective "functional" has two meanings, one found in general curriculum literature meaning, "useful in lifen and one confined to mathematics meaning, "pertaining to a correspondence between tro variables." In order to avoid confusion, when the term is used in the general sense it will be preceded by the word "Iifen thus making the expression "life-functional". The single word nfunctionaln will refer to the mathematical concept.

By the term, "progressive schools" is not meant necessarily those belonging to the movement commonly referred as the Progressive Movement, but simply those schools which reflect the more recent trends in their curriculum in mathematics.

\section{Limits of the study}

The principal aim of the study is to present a view of the Kentucky junior high school curriculum in mathematics, to evaluate it in the light of the tendencies evident in the opinions of experts in the field of junior high school mathematics and in actual practice in progressive schools elsewhere, and to make recommendations for its improvement. The organization of the junior high schools in Kentucky and of their offerings in mathematics is described largely to throw light upon the problem of the curriculum although it ought to be of some value in itself. 
It is not the purpose of this study to construct a course of study but to try to show defects in the present curriculum and make recommendations that would assist those into whose hands the task of curriculum reorganization falls. 


\section{CHAP'IER II}

A HISTORY OF THE DEVELOPMENT OF JUNIOR HIGH SCHOOL MATHEMATICS 
A HISTORY OF THE DEVELOPMENT OF JONIOR HIGH SUHOOL MATHEMATICS

Before an evaluation of present practices in the field of junior high school mathematies can be made or recommendations offered for their improvement, it will be necessary to try to understand how these practices came into being. Because they are the outcome of a slow evolution an historical approach is necessary.

Generally speaking, the secondary education of the Nineteenth Century as found in the Latin Schools and later the Academies and the High Schools was not designed for the masses but for the select few. It had for its aim not the training for both present and future living but rather preparation for the entrance examinations of the colleges and universities.

Naturally, the curriculum of these early secondary schools was designed to accomplish this aim. Secondary mathematics, when offered, was formalized and disciplinary in keeping with the demands of the colleges whose entrance examinations the students would likely essay.

At first the only mathematics offered in the secondary 
schools was arithmetic, since this was all that the colleges required for admission, and it was only after the colleges raised their standards that the secondary schools increased their offerings. Harvard first required algebra (to the end of simple equations) in 1820, Columbia in 1821, Yale in 1847, and Princeton in 1848. Harvard was the first to require geometry for admission and that in 1844.1

A glance at \& typical text of this period will show the extent to which the college had influenced secondary instruction in mathematics. John Farrar's text in arithmetic ${ }^{2}$ devoted separate and unrelated chapters to each topic in arithmetic. Some of them were: "Numeration," "Addition, " Nubtraction," "Partnership," "Fellowship," etc. Each chapter began with a complicated set of definitions which were to be completely mastered before any useful pursuit of the chapter could be made on the assumption that, as Professor David Eugene Smith has pointed out, the word "elephant" must necessarily be defined before visiting a menagerie. Before learning to count the student had to learn the definitions of "magnitude," "number," "continued quantity," "discrete," and "discontinued quantity," and before he could Iearn to add he must know that addition is the noperation

1. Cf. Whitcraft, L. H., Some Influences of the Requirements and Examinations of the College Entrance Examination Bogrd on Mathe= matics in Secondary Schools of the Onited States, Contribution to Education No. 557, Bureau of Publications, Teachers College, Columbia University, New York, 1933.

2. Farrar, John, An Elementary Treatise on Arithmetic, Hilliard, Gray and Company, Boston, 1834 . 
which has for its object the uniting of several numbers in onen and that it is, in the last analysis, "an abbreviation of the formation of numbers by the successive union of units." The grade placement of this text was indefinite but it was often used in the second and third years of the preparatory schools. When algebra and geometry were introduced into the secondary schools, they were equally formal and disciplinary, each being taught as if the other did not exist.

This strictly logical approach and especially this "watertight compartmentalization" was peculiar to American schools. European schools had already begun fusion and were making a decidedly more psychological approach. To be sure there were pioneers in this country who felt the need of change and who early advocated many of the features now characteristic of junior high school mathematics. One of these was Warren Colburn, a popular textbook writer who, in 1825, published a work entitled

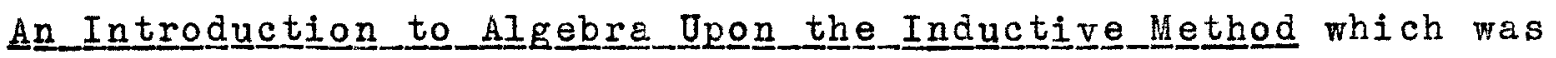
used extensively in the third and fourth years of secondary schools. In this book he attempted to make the break between arithretic and algebra less pronounced. To quote from his preface: nThe first object of the author of the following treatise had been to make the transition from arithmetic to algebre as gradual as possible. The book, therefore, commences with practical questions in simple equations such as the teacher might readily solve without the aid of algebra. This reguires only the explanation of 
the signs plus and minus, the mode of expressing multiplication and division, the sign of equality together with the use of a letter to express the unknown quantity.n 3

Another pioneer, Charles Davies, had somewhat the same idea and carried it out rather consistently. In the preface of his Elementary Algebra he said: "In this work it has been the intention to form a connecting link between arithmetic and algebra; to unite and blend, as far as possible, the reasoning of numbers with the more abstruse methods of analysis." 4 Davies utilized a startling innovation by introducing the student to some simple problems that presented practical situations in which algebra would be useful before commencing any formal attack upon definitions or carrying him through lengthy drill. This work was published in 1854 and went through several editions. It was used in the middle years and senior year of the preparatory schools. However, such exceptions were rare, and they slowly influenced general practice.

Late in the nineteenth century, there began in this country a movement to shorten the span of time required for preparation for college entrance under the leadership of President Eliot of Harvard. In 1893 the Report of the Committee on Secondary School

3. Colburn, Warren, An Introduction to Algebra Upon the Inductivive Method, Hiliiard and Company, Boston, 1825. Preface.

4. Davies, Charles, Elementary Algebra, A. S. Barnes and Company, New York, 1854. Preface. 
Studies recommended that a course in concrete geometry be given in the grammar schools: "In the lower grades instruction to be given informally and in the upper grades a separate course one hour a week." 5 Emphasis was to be placed upon concrete examples and practice in the use of the protractor and compasses. This recommendation was not intended primarily for the purpose of making the grades more vital to the student but was made as an attempt to further the interests of the colleges by enabling students to acquire the credits necessary for entrance at an earlier age. Similarly, the Committee of Ten in the following year proposed that the child be introduced at a very early age to the geometric figures and that he should experiment with these and gradually form short chains of arguements concerning their properties. Thus, while trying to foster its own ends the college contributed toward improved practice in secondary and elementary education.

In keeping with these recommendations W. T. Campbell published in 1899 one of the first texts in this country based upon the idea of what is commonly called intuitive geometry. The name of campbell's text was Qvservational Geometry ${ }^{6}$ and it was the culmination of an experiment conducted by the author at the Boston Latin School where a course of the intuitive type had

5. Eliot, Charles W., and Others, Report of the Committee on Secondary School Studies, Bureau of Education, washington, D.C., 1893.

6. Campbell, W. T., Observational Geometry, American Book Company, New york, 1899. 
been conducted over a period of several years. However, the Idea of intuitive geometry was slow to gain any considerable hold for some time.

The big impetus given to the type of mathematics now found in the junior high school came from President Moore of the American Mathematical Society in 1902. In his address to that body he said: "The separation between pure mathematics and applied mathematics is grievous even in the domain of elementary mathematics." 7 He continued his address by urging that barriers between the various fields of mathematics be broken down and that important concepts be taken from all the branches and taught in the upper grades in a thoroughly concrete and captivating manner. The fact that this utterance came from a man so prominent in the field of pure mathematics gave tremendous weight to his opinion in the sight of educators in this country. Moore was accuainted with the work of Perry in England and of C. R. Mann and others in this country to whom he gave due credit.

One of the experiments with which Moore was familiar was that conducted by Miss Edith Long at Lincoln Nebraska. This experiment described by Miss Long in the School Reviem 80 consisted of an arrangement whereby incoming students at the Lincoln High

7. Moore, E. H., "On the Foundations of Mathematics", A General Survey of Progress in the Last Twenty-five Years: First Yearbook of the National Council of Ieachers of Mathematics. $1926, p \cdot 39$.

8. Long, Edith, "Correlation of Algebra, Geometry and Physics", School Review XXIV (0ctober, 1902) pp. 209-211. 
School were introduced simultaneously to algebra and geometry. It was so successful that it was continued for a number of years and caused wide comment. Another experiment, in many ways similar to that of Miss Long, was conducted at the Horace Mann School for Girls in New York City. It is said that visitors to that school could not tell on certain days whether the mathematics being taught was algebra or goometry so closely were they interwoven. At about the same tine, the public schools of New York City introduced a course in "Inventional Geometry" in the seventh grade using a textbook of that name written by I. N. Failor.9 The first text to fuse algebra and geomatry to any considerable extent was a book used in the ninth grade at the University High School of the University of Chicago written by G. W. Meyers. 10 The preliminary edition came out in 1906.

From these accounts we see that largely through the influence of the colleges and universities, two definite forces were developing: that of fusion and that of pushing down to a lower grade level subjects which were required for college entrance. Soon, other groups were awakened to the need for a new type of secondary mathematics. In 1906 the Mathematics section of the Central Association of Science and Mathematics Teachers was organized and a committee of five was appointed to prepare a course

9. Failor, I. N., Inventiongl Geometry, A. S. Barnes \& Company, New York, 1904 .

10. Meyers, G. W., First Year Mathematics for Secondary Schools, University of chicago Press, Uhicago, 1906. 
of study in algebra. In its discussions this committee came to the conclusion that: "To bring the different branches of mathematics into closer relation and to preserve the unity of mathematical work is so much to be desired in secondary schools that simultaneous teaching of arithmetic, algebra, and geometry would seem indispensible. By this is not meant thet so many hours per week be devoted to one subject and the remaining hours to anothernot parallel teaching-but the actual blending of the subjects wherever the relations are so close that such blending shall not be forced." 11

In 1911 the Provisional Report of the National Committee of f Five_ong Geometry Syllabus again urged fuston, especially of algebra and geometry.

W. D. Reeve taught a course in general mathematics at the University of Minnesota High School in the ninth grade as early as 1915 which seems to have had many of the characteristics of present-day junior high school courses. He later published several texts which were the outgrowth of his experiences there and these were widely used in early junior high schools throughout the country.

Not a great deal has been said so far about the changes

11. Ammerman, Charles and Others, "Preliminary Report of the Committee of the Central Association on Algebra in the Secondary Schools", School_Science and Mathematies, VII (September, 1907) pp. 674-85. 
that have taken place regarding arithmetic. As stated earlier in this chapter, arithmetic was almost the only mathematics taught in the secondary schools until about 1820 when Harvard first required algebra as an entrance requirement.

The arithmetic taught up to this time included the four fundamentals, simple notation, reduction to the end of the single rule of three, and work with the metric system and with other systems of weights and measurements.12 As has already been pointed out, the treatment of the subject was formal and deductive.

At about this tine notable changes began to take place in arithmetic. It was largely due to the Pestalozian influence that Warren Colburn was prompted to write his Intellectual Arithmetic Opon the Inductive Method of Instruction. This work abandoned rules and attempted to create situetions in problem solving which would lead the pupil to make his own generalizations. While this work was intended for the elementary level it prodoundly influenced arithmetic in the academy, and soon Colburn wrote the "Sequeln to that work for secondary schools on the same principle. Other texts followed suit and from 1821 to 1857, there appeared 195 new texts in arithmetic which, if they did not abandon rules, at least gave them only secondary

12. Cf. Cajori, F., The Teaching and History of Mathematics in the United States, J. S. Bureau of Education, Washington, D. C., 1890. pp. 55-56. 
place to problem work of a concrete nature.

Around 1865 the rule of three began to disappear from progressive texts and other eliminations gradually came about. In 1889 The Boston School Committee was persuaded to eliminate such topics as mensuration of unusual solids and surfaces, compound interest, equation of payments, exchanges, the metric system, and compound partnershig. Other schools gradually followed suit.

In 1895 the Committee of Fifteen made further proposals for elimination and at a period somewhat later than this, the studies of I. D. Coffman and WaIter A. Jessup appeared which greatly affected the teaching of arithmetic. These studies summarized by Jessup in the Fourteenth Yearbook of the National Society for the Study of Education recommended the elimination of apothecaries' weights, alligation, allquot parts, annual interest, cube root, cases in percentage, compound and complex fractions of more than two digits and other topics too numerous to mention. 13 While these proposals were made for the elementary school, they apply to a great extent to the junior high school arithmetic since grades seven and eight of the former are typically included in junior high schools.

More recently much emphasis has been placed, in arithmetic,

13. Minimum Essentials in Elementary School Subjects: Fourteenth Yearbook of the National society for the Study of Education, Part I, 1915. Chapter VIII. 
upon diagnostic testing and upon setting up definite goals of attainment. Many studies have appeared regarding these two phases within the last decade. Typical of the former are the well-known studies of Buswell of the University of Uhicago and of the latter are those of Fashburne and his coworkers at Winnetka. Other tendencies which are becoming evident in the teaching of arithmetic are: more concrete problem situations, more attention to informational aspects, and more life-functioning materials.

These forces in arithmetic and in mathematics in general could not find full expression in the traditional type of school organization. It was not until the junior high school came into being that the recommendations from various sources regarding mathematics reorganization were given serious consideration.

The junior high school movement is commonly said to have begun with the Berkley, California reorganization in 1910. Briggs l4 Iists two junior high schools as having begun before 1900, eight between that time and 1910, ninety-two between 1910 and 1915, but refers to the California reorganization as the beginning of the active phase of the movement.

The first junior high school to be established in Rentucky was organized at Lexington in 1917. As early as 1913 the superintendent had proposed such a move because of the need for

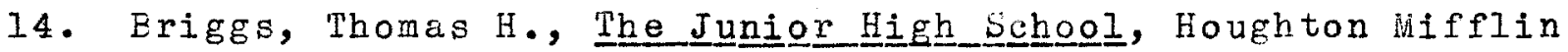
Company, Boston, 1920. p. 32. 
more adequate housing facilities. Some time after this the problem of reorganization was discussed at shelbyville but no action was taken. Holmes High School of Covington which is a six year high school was so reorganized in 1927.15

In Louisville the junior high school is a rather recent thing although a step toward such a reorganization was made rather early. In 1912 Superintendent Ernest 0. Holland reported the establishment of fifteen departmental centers for grades seven and eight. This plan was chosen instead of the junior high school plan which was much discussed because of certain local problems. In 1927 the question of the junior high school was again raised by Superintendent 0 . I. Reid who, while saying much in favor of this plan, believed that the time was not yet ripe.

In 1927 the length of the school day in the departmental schools was increased and shop work and many other features including exploratory courses were added. Superintendent Guy Whithead planned the present reorganization program and the year 1928 saw the first two junior high schools open. They were Highland and Eastern. 16

At present there are twenty-two junior high schools in Ken-

15. Cf. Judy, R. P., The Reorganization of Secondary Education, a master's thesis on file at the University of Kentucky, 1929. 115 .

16. Cf. Brom, R. T., History of the Public Secondary Schools of Louisville, Kentuckz, $a$ master's thesis on file at the University of Kentucky, 1935. pp. 92-93. 
tucky, eight of which are in Louisville.

The junior high school not only represents a new type of organization, it reflects a new philosophy. It is an attempt to adjust the school to the child, to provide for his present as well as for his future needs, and to help the child find himself and adjust himself. Hence, in it are found the sincerest attempts to evolve a curriculum that is fitted to his nature. It was the first organization to espouse the cause of a reconstructed mathematics. The tendencies evident in the thinking of experts have been adopted more whole heartedly by the junior high school than by any other department of public education. It has been less bound by tradition and less dependent upon college entrance requirements than the senior high school and more open to change than the elementary school.

In mathematics the most potent factor for determining the curriculum of this new institution was the report of the National Committee on Mathematical Requirements which was published in 1923. This committee, first appointed by the Matheratical Association of America in 1916, was finally given financial assistance by the General Education Board of New York. Its findings have become classical. Some of the committee's outstanding members were David Eugene Smith of Columbia University, E. H. Moore of the University of Chicago, J. A. Foeberg of the State Department of Education of Pennsylvania, Raleigh Schorling of the Lincoln School, New York, and Vevia Blair of the Horace Mann School. 
This committee endorsed the junior high school type of reorganization and made specific recommendations for its curriculum. Since constant reference will be made to its report, it will not be necessary to elaborate upon its findings at this point.

From this brief sketch of the development of junior high school mathematics the following trends are evicient:

There has been a gradual pushing down to the secondary level mathematics which was taught formerly only in higher education. Ihis necessitated a new approach in the teaching of mathematics and hence fused or general courses came into being.

Obsolete topics in arithmetic were replaced with intuitive geometry and simple algebra.

The junior high school readily adopted these changes since its philosophy stressed the psychologieal nature of the child rather than the logical nature of traditional subject-matter.

With this background in mind an attempt will next be made to demonstrate that these general trends have found expression in specific recommendations of experts concerning junior high school mathematics. 
CHAPTER III

TRENDS IN THE THEORY OF TEACHING

JUNIOR HIGH SCHOOL MATHEATICS 
CHAPTER III

TRENDS IN THE THEORY OF TEACHING JUNIOR HIGH SCHOOL MATHEMATICS

$$
\text { Introduction to Chapter }
$$

The foregoing chapter traced junior high school mathematics through its early development period. The present chapter attempts to delineate certain features of contemporary opinion and establish them as trends, thus continuing to lay a background against which to evaluate present practices in junior high school mathematics in Kentucky.

This is a justifiable arrangement since trends arising out of the natural evolution of conditions are first voiced in the opinions of far-seeing individuals and next become recognized in actual practice. The chapter which follows this present one takes up this last step.

Needless to say, opinions of experts do not always agree. However, certain factors have been so constantly pointed out that their position as trends in thought cannot well be questioned. Even if the experts disagree on what expressions these trends should assume they generally share common beliefs that outweigh their differentiated modes of attack. This chapter, while attempting to cite the common elements of these opinions will, at the same time, attempt to show the varying ways which experts propose 
that these trends be applied.

Certain sources have been carefully studied in ascertaining these trends. Naturally they were the sources most likely to yield the desired information, principally as regards junior high school mathematics and the junior high school situation in general. These sources will be referred to in the sections to which they relate but special mention is due those most frequentIy referred to. They were:

\section{Books}

The Reorganization of Mathematics in Secondary Education, a report of the National Committee on Mathematical Recuirements of the Mathematical Association of America. The writer was fortunate in obtaining a copy of the original publication as it appeared in 1923. Since that is now out of print, all page references are to the partial reprint of 1927 published by Houghton Miffin Company.

The Iearbooks of the National Council of Teachers of Mathematics from the first (now out of print) which was published in 1926 to the ninth which appeared in 1934.

High School Curriculum Reorgsnization a report of the NorthCentral Association of Colleges and Secondary Schools, published by that organization in 1933. 
Periodicals

The Mathematics Teacher, from 1917 to the present time.

Bulletin of the Department of Secondary School_Principels, of January, 1936.

In adition to these principal sources there are many more in which usable material was found less frequently for this study but which were carefully studied in ascertaining the trends.

The Trend Toward Fusion

One of the most significant trends in education to-day is toward fusion of subject matter. As it concerns junior high school mathematics, it began first as a movement to unite algebra and geometry ${ }^{l}$, and then was extended to include arithmetic, trigonometry, statistics, and to a more limited extent, physics. Now the same movement has found expression in a growing tendency to unite all the various fields of subject matter into large social-psychological units. The underlying causes of this tendency are based on a theory of integration which cannot be fully discussed here. It is but the purpose of this section to direct the reader's attention to some expert opinion about the implications of this movement for junior high school mathematics.

The National Committee on Mathenatical Requirements recog-

1. Cf. Chapter II. 
nized this tendency only in so far as it implied the uniting the several branches of a single subject. It stated: "In recent years there has developed among many progressive teachers a very significant movement away from the older rigid divisions into "subjects" such as arithmetic, algebra, and geometry, each of which shall be completed before another is begun, and toward a rational breaking down of the barriers separating these subjects, in the interest of an organization of subject matter that will offer a psychologically and pedagogically more effective approach to the study of mathematics. ${ }^{2}$

Mr. E. R. Breslich of the Oniversity of Chicago argued for a general course in mathematics as early as 1915. In 1933 he summed up the advantages of such an arrangement in the following terms:

11. When several subjects are touched upon it is possible to arouse the interests of a large number of pupils.

2. Psychological arrangement is facilitated.

3. Complexity may be gradually increased.

4. Pupil progress may be gradually assimilated.

5. Abstract processes in algebra may be made concrete by use of geometric material.

6. Provision is made for repetition and reviews.

7. Pupil resourcefulness is increased.

8. Measured results seem to favor the plan." 3

Mr. W. D. Reeve, an outstanding writer in the field of

2. National Committee on Mathematical Requirements, The Reorganization of Mathematics in Secondary Education, Reprint, Houghton Mifflin Company, New York, 1927. pp.16-17.

3. Breslich, E. R., "The Changing Curriculum", Mathematics Teacher, XXVI: 6 (0ctober, 1933) p.345. 
secondary mathematics, stated the case for general courses as follows: "My proposal is that wherever conditions permit we arrange our mathematics so that we shall not have courses in algebra, geometry, or in trigonometry, as such, but a definitely arranged and psychologically ordered course in mathematics. 4

Marie Gugle, former president of the National Council has this to say: "The unified or general mathematics, as reorganized for the junior high school, is far more satisfactory and effective than the old plan of arithmetic in grades seven and eight, and algebra in the ninth." 5

More recently this tendency has been manifest in organizing all or nearly all instruction in a school grade around great central units which cut across all subject lines. A discussion of the actual practice along this line will be postponed to a later chapter and only expert opinion will be referred to here.

To quote from the Committee on the orientetion of Secondary Education: "The traditional curriculum, which breaks up knowledge into separate compartments instead of drawing at any time upon any part of it which suits the pupil's needs, is neither in accord with the laws of learning nor the function of the school.

4. Reeve, W. D., "The Case for General Mathematics", Mathematics Teacher, $X V: 7$ (November, 1922) . pp.381-91.

5. Gugle, Marie, "Revision of College Preparatory Mathematics", Mathemetics Teacher, XXIX:6 (October, 1926). pp.z2I-28. 
We need a new curriculum-one consciously designed and organized to serve the purpose of the school in the best way." 6 The fact that this committee accepted the question of fusion as one of the ten major issues of secondary education is enough to establish its place as a trend of significance.

In summary, it may be said that fusion in expert opinion ranges all the way from the uniting of two or more branches of a single subject to complete abolition of subject matter lines.

Expert Opinion Regarding Content

While the fusion tendency will, of course, affect content it does not prescribe what actual teaching topics shall be included in courses. This section attempts to cite instructional materials in junior high school mathematics which experts consider appropriate for that level.

The most widely recognized authoritative statement regarding the content of junior high school mathematics came from the National Committee on Mathematical fequirements. Only one major criticism can be made of its recommendations. It dia not make provision for drill and remedial work in the fundamentals of arithmetic which present conditions make necessary. In other respects, it still stands as the outstanding commitment of experts

6. Report of the Committee on the Orientation of Secondary Ed= ucation, Bulletin of the Department of Secondary School Principals, $\mathrm{XX}: 59$ (January, 1936) p.258. 
in the field.

Very wisely the committee did not go into great details or designate the order of topics but presented five plans, not recommending one as superior to another. They were:

$$
\text { PIan A }
$$

First Year: Applications of arithmetic, particularly in such lines as relate to the home, to thrift, and to the various school subjects; intuitive geometry.

Second Year: Algebra; applied arithmetic, particularly in such lines as relate to commercial, industrial and social needs. Third Year: Algebra; trigonometry; demonstrative geometry.

\section{$P I$ an $B$}

First Year: Applied arithmetic (as in plan A); intuitive geometry.

Second Year: Algebra; intuitive geometry; trigonometry. Third Year: Applied arithmetic; algebra, trigonometry, demonstrative geometry.

PIan C

Eirst Year: Applied arithmetic (as in plan A); intuitive geometry; algebra.

Second Year: Algebra; intuitive geometry.

Third Year: Trigonometry; demonstrative geometry; applied arithmetic.

PI\&n D

First Year: Applied arithmetic (as in plan A); intuitive geometry. Second Year: Intuitive geometry; algebra. Third Year: Algebra; trigonometry; applied arithmetic.n7

These plans were made with the assumption that elective work would not begin until the tenth grade and that the above should be required of all students.

7. National Committee on Mathematical Requirements, The Reorganization of Mathemetics in Secondary Educetion, Reprint, Houghton Miffin Company, New York, I927. pp. 4I-42. 
Another authoritative recomendation concerning the content of junior high school mathematics came from the Committee on Standards for Use in the Reorganization of Secondary School Currucula in 1933.8 This committee of the North-Central Association of Colleges and Secondary schools has been working on the content of secondary school studies for more than twelve years. The sub-committee on mathematics was under the direction of Dr. Kaleigh schorling. The findings of this commitee were placed in the hands of a reviewing comittee of eminent authorities before being published.

The materials were chosen or rejected as they met or failed to meet the aims set forth in the Cardinal objectives of secondary Education and were divided into the following elements from the standpoint of the pupil:"(A) Acquiring fruitful knowledge. (B) Developing interests, motives, ideals, attitudes, and appreciations. (C) Developing mental techniques in memory, imagination, judgement, and reasoning. (D) Acquiring right habits of conduct and useful skills." "The actual curriculum materials suggested by this report are in such detail that it would be impossible to reproduce all them here but certain general statements can be made. The content for the seventh grade includes percentage and its application, intuitive geometry, simple statistics, and a considerable amount of informational arithmetic including topics on the relation of mathematics to health, invest-

8. North-Central Association of Colleges and secondary schools, High School curriculum Reorganization, ed. L. W. Webb, l'he Association, Ann Arbor, Nichigan, 1935. Chapter XIV. 
ment, architecture, and to the general development of mankind.

The content for the eighth grade includes variation, ratio and proportion, scale drawing, positive and negative numbers, simple trigonometry, the Pythagorean theorem, informational arithmetic stressing business forms and practices, statistics, and the appreciation side of mathematics with special applications to certain vocations.

The content for the ninth grade includes a major portion of algebra of a very practical nature, together with numerical trigonometry, statistics of a type more advanced than that found in the previous courses, and numerical computation with approximate data.

The Trend Toward Quantitative Thinking As Opposed To Manipulation

There is a marked tendency toward teaching important concepts and away from meaningless manipulation. Not that anyone argues for a discontinuation of drill work but this as an end in itself without basic understanding is rapidly losing its former hold upon secondary mathematics.

Judd has been one of the outstanding critics of the traditional mathematics of the secondary school on this score. He believes that basic understandings have been woefully neglected as the following quotation will show: "I am told that the school 
should teach children to make change, measure wall paper and how to tell time and that sections of arithmetic should be devoted to these specific topics, but I look in vain for any appreciation of the fact that the school ought to load pupils who have only a hazy and unsystematic notion of the world to see the value of arrangement and order in all thinking and to cultivate the general idea of regularity and precision. ${ }^{9}$

The National Committee on Mathematical Requirements stated: "Continued emphasis throughout the course must be placed on the development of ability to grasp and utilize ideas, processes, and principles in the solution of concrete problems rather than on the acquisition of mere facility or skill in manipulation." 10

In special reference to manipulation as opposed to quantitative thinking in algebra, John P. Hverett states in the Serenth Yearbook: "He who has been exposed only to the routine of repetition or whose experiences have been limited to repetition of numbers or to manipulative tasks may see in algebra "a bag of tricks." Many, alas, have gone no further."ll

9. Judd, Charles H., "The Fallacy of Treating School Subjects as Tool Subjectsn, Selected Topics in Teaching Mathematics: Third Yearbook of the Nationel Council of Teachers of Mathematics, 1928. p.7.

10. The Reorganization of Mathematics in Secondary Education, p. 14 .

11. Everett, John P., "Algebra and Mental Perspective", The Teaching of Algebra: Seventh Yearbook of the National Council of Teachers of Mathematics, 1932 . p. 28 . 
E. R. Hedrick, former president of the American Mathematical Society, put the case for conceptual mathematics even stronger: "If you, the teachers of mathematics, do not do these things, if formal symbolistic exercises continue to shut out the real mathematics for which they are only a preparation, then mathematics in the schools is doomed, doomed by your own acts."12

As a part of the Eight-Year Study of The Progressive Education Association, the Committee on Evaluation have done outstanding work in organizing source units and suitable tests which emphasize mathematics as a way of thinking. They have definitely attempted to relate mathematics to the general objectives of education by stressing functional thinking, stctistics, and the nature of proof. They have relegated manipulation to a position secondary to these fundamental objectives and while they consider their work tenative, it is a long step toward relating quantitative thinking to the important issues of life. ${ }^{13}$

The Trend Toward Utilitarianism

A statenent of this trend should be made with a word of caution. To some, "utilitarianism" means teaching only those

12. Hedrick, E. R., nCrises in Economics, Education, and Mathematics", Mathematics Teacher, XXIX:3 (March, 1936). p. 114 .

13. Progressive Education Association, Mathematics, Report of the Mathematics Group of the Sumer Institute of 1936, Bulletin No. 591, Committee on Evaluation in the Eight-Year Study, Ohio State University, Columbus, Ohio, 1936. 
skills and facts in mathematics or any other so called ntool subject" that the "man in the street" has been found to use in his daily pursuits. Most assuredly, this is one part of it and expert opinion would not deny that this is true. However, the tendency toward utilitarianism is much broader than this conception. Education is an investment made by society for perpetuating and improving its effectiveness, and in the light of this fact society expects returns from its investment commensurable with the amount expended. To educate the individual merely for his own advantage over his fellows is an idea utterly foreign to the intention of society.14 since society is concerned primarily about the making of citizens as such and not primarily the making of individuals, "utilitarianism" should simply mean the tendency to make mathematics function in society rather than to confine it to cloistered walls. In seconarary education, this means that the school should be concerned with its own courses primarily rather than to consider them merely a preparation for more advanced courses.

The Report of the National Committee on Mathematical Requirements stated: "In the junior high school, comprising grades seven, eight, and nine, the course should be planned as a unit with the purpose of giving each pupiI the most valuable mathematical training he is capable of receiving in those years, with

14. Cf. Report of the Committee on the orientation of Secondary Education: Bulletin of the Department of Secondary School Principals, XX:59 (January, 1936) Issue III. 
little or no regard for courses which he may or may not take in succeeding years. ${ }^{15}$

Mr. Breslich, in speaking of the junior high school mathematics curriculum, said: "Such material should be selected as proves its worth by actual service in the life of the pupil and such facts should be included as the pupil needs in his other studies." 16

E. R. Hedrick recently declared: "There was a slogan of education that is now half-forgotten in the wilter of opposing propaganda. It is that education, properly speaking, is preparation for life, or, indeed, life itself. For such a program I have hearty sympathy, 17

The Trend Toward Emphasis Jpon The Concept of Function

No student of the literature of secondary mathematics can deny that the concept of function merits a plece among the growing tendencies in secondary mathematics. Since in a dynamic society, factors are subject to change, the inter-dependence of these factors, as they change, expressed quantitatively is one of the chief, if not the chief contribution which mathematics

15. The Reorganization of Mathematics in Secondary Education, p. 19 .

16. Breslich, E. R., "Junior High School Methematics", School Review, XXVIII: 5 (May, 1920). .374.

17. Hedrick, E. R., op. cit. p.z. 
has to offer to society.

For many years the concept of function in secondary mathematics was confined to manipulation of algebraic formulas and to graphical representation of these formulae in a symbolic setting. At present the trend is toward employing function to explain concrete social and economic and physical phenomena as the following quotations will show.

E. R. Hedrick challenged the teachers of secondary mathematics in no uncertain terms. He said: "Have you, will you, teach how quantities may be related to other quantities, in the actual world, in preference to many pages of formalized problems in factoring? 18

W. D. Reeve declared in the Fourth Yeargbook: "A significant trend in the teaching of algebra, not yet fully realized, but well under way is to put meaning into the subject by replacing the emphasis upon formal symbolism by the function concept. $n 19$

The National Committee on Mathematical Reouirements stated: "The one great idea which is best adapted to unify the course is that of the functional relation. The concept of a variable and

18. Hedrick, E. R., op. cit. p. 113 .

19. Reeve, N. D., "Significant Trends in the United States", Significant Changes and Trends in the Teaching of Mathematics Throughout the World Since l 910 : Fourth Ye al Council of Teachers of Mathematics, 1929. p. 160 . 
of the dependence of one variable upon another is of fundamental importance to everyone." 20 The course referred to here was that of the junior high school level. This report goes on to say that no theory of function need be taught but that there should be an abundance of concrete illustration as to how one factor is affected by another.

Definitions of function are many and range all the way from highly technical phrases to the simple one I propose here. A

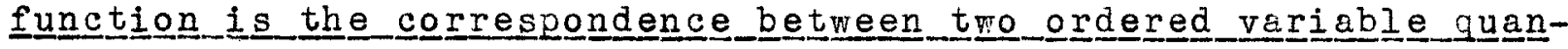
tities.

Suggestions of how this concept may be taught are fully treated in a proposed course of study in the Ninth Yearbook. 21 Some of the ways suggested in this source are:

(1) By tabulation of related data in such a way as to bring out the correspondence.

(2) By substitution in and transposition of formulas.

(3) By graphical representation of formulas and of related series of data.

(4) By the principle of congruence.

(5) By the use of the trigonometric functions.

(6) By use of the Pythagorean Theorem.

20. The Reorganization of Mathematics in Secondary Education, p. 15 .

21. Relational and Functional Thinking: Ninth Yearbook of National_Council of Teachers_of Mathematics, 1934 . 
(7) By inverse and direct proportion.

(8) By similarity of geometric figures.

(9) By scale drawing.

(10) By use of the concept of symmetry.

Thus, it may be seen that junior high school mathematics provides abundant opportunity for teaching this important concept and also that it need not be confined to any particular branch of mathematics.

The Trend Toward Providing For Individual Differences

One has only to survey modern educational literature to be convinced that educators are agreed that the provision for individual differences is a definite tendency.

Mort22 points out the fact that the great ideal of equality of educational opportunity is a farce without an attempt to provide for the individual needs and abilities of pupils. His is one of the most comprehensive treatments yet published on the subject and abounds in suggestions of a practical nature.

While the teacher is one of the most important factors in making individual adjustments, much responsibility rests with the course of study. To quote 0tto: "When teachers are called

22. Mort, Paul R., The Individual Pupil in the Management of Class and School, American Book Company, New York, 1928. pp.17-25 
upon to cover specifically outlined units of the course of study in a specified time, or when teaching methods are prescribed in detail, there is little time or opportunity to teach children, each according to his particular needs." 23

Thus, flexibility should be an important characteristic of the course of study.

Further, expert opinion indicates that definite provision should be made in the course of study for both retarded and accelerated groups. To quote from the Ninth Yearbook of the Department of Superintendence: "It is estimated that the most gifted child will in comparison with the least gifted child of the same age do six times as much in the same time or do the same amount with less than a sixth as many errors. 24

The Trend Toward Unit Organization of Subject Matter

Closely allied with provision for individual differences is unit organization of subject matter.

The unit has become such an integral part of modern educational theory that it is scarcely necessary to present proof of its status as a trend. While the preponderance of expert

23. Otto, Henry J., Elementary School organization , AppletonCentury Company, New York, 1934. 24. Morrison, H. C., The Prictice of Teaching in the Secondary Schools, The University of Chicago Press, Uhicago, second Edition, 1931. pp.24, 25. 
opinion favors unit organization, there is wide disagreement as to what constitutes a unit.

Morrison defines a unit as: "... a comprehensive and significant aspect of the environment, of an organized science, of an art, or of conduct, which being learned results in an adaptation in personality." $\approx 5$

Harap stresses the characteristic of describing experiences as contrasted to setting forth subject matter as an essential of the unit. He also states: "It should reproduce life situations and utilize materials in the classroom as they occur in life. It should include much pupil activity and involve a variety of.direct sense experiences. The pupils should be brought into friendly, informal relations. " 26

Caswell and Campbell, after reviewing the above definitions and a number of others, conclude that the term, "unit" is used in two broad senses. Some writers, they believe, consider the unit a mere division of subject matter. Such a unit might be further placed in one of the following sub-types: topical unit, generalization unit, or a unit that explains a significant aspect of cutture or environment. Other writers consider the unit as being experiential and that it is, for the pupil, either a center of interest a pupil purpose or one meeting a pupil need. 27

E. Morrison, $\mathrm{H} \cdot \mathrm{C}$., The Practice of leaching in the secondary School, The University of Chicago Press, Second Edition,1931,p.24.

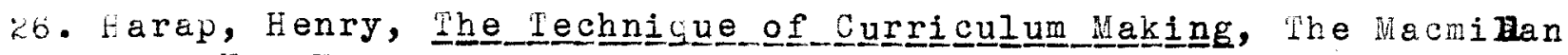
Company, New York, 1928. p. 273 .

27. Caswell, H.I. and Campbell, D.S. , Curriculu American Book Company, New York, 1935. Chapter XV. 
Breslich's characteristics of a unit are especially pertinent as they were formulated with special reference to mathematics. He says of the unit:

(a) It is a body of closely related facts and principles so organized as to contribute to the understanding of an important aspoct of the course.

(b) It must be possible to present the unit as a whole, in a form so concise as to give the learner a clear conception of it before he undertakes the study of it.

(c) The objectives must be so definitoly stated that they are clear not only to the teacher but also to the pupil. The learning product must be known.

(d) All pupils properly qualified to take the course must be able to master the minimum essentials necessary and sufficient to attain a complete understanding of the unit. In addition to this minimum, the unit must contain supplementary material to allow freedom in adapting the work to the individual differences of the pupils.

(e) It must be possible to devise tests which sqgure objective evidence of the understanding of the unit." 28

Thus it is evident that there are wide differences as to what constitutes a unit. The following characteristics, however, seem to the author to be compatible with those given by at least most of the experts:

Psychological rather than logical arrangement. Definitely stated objectives.

Work adjusted to the individual differences of the pupils.

The idea of completeness or wholeness.

28. Breslich, E. R., "The Jnit in Mathematics", Junior-Senior

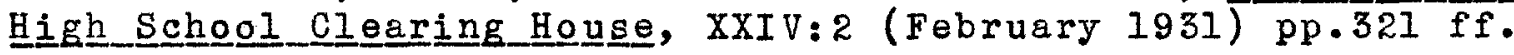


The Trend Toward Assuming Responsibility For Emotionalized Attitudes and Ideals

While this tendency is not peculiar to mathematics it has not escaped, nor should it escape its influence. Briggs has had much to say on this subject and included its accertance or rejection as a major issue of secondary education. The committee on Orientation argued irrefutably for education's assuming responsibility for attitudes and ideals and it may be truthfully said that this is a basic assumption underlying the progressive education program in this country and throughout the world.

Mathematicians have not dodged the issue, but they have been slow to realize the full Implications of it in actuel practice. To quote a mathematician of national reputation, W. D. Reeve declared: "We need to give more attention to the influence of emotionalized attitudes in learning.", and again: "We should know more about how such attitudes are developed and how they mey reenforce our teaching. 29

In mathematics, the expression of this trend first took the form of advocating an appreciation of mathematics and its contribution to the progress of mankind. The National Committee's report stated that all mathematical instruction should be permeated with the idea of appreciation and divided thus into three parts:

29. Reeve, W. D., op. cit. p. I38. 
(one) Appreciation of beauty in the geometric forms of nature, art, and industry.

(Two) Ideals of perfection as to logical structure, precision of statement and of thought, logical reasoning, discrimination between true and false etc. and

(Three) Appreciation of the power of mathematics.... and the role that mathematics and abstract thinking in general have played in the development of civilization...... 30

More recently, however, emotionalized attitudes are coming to mean more than a mere appreciation of the usefulness of a subject, they have come to imply a classroom setting that is definitely planned for pupil participation, pupil leadership, pupil exercise of the rights of democracy. It is through activity, not passivity, that attitudes and ideals are formed. To again quote from the Committee of Orientation: "Since this process is always going on, it is clearly important for those who present organized knowledge to be concerned about how it is going on. Attitudes are developed through all the experiences and activities of the child." 31

Thus, in reviewing actual practice from progressive schools,

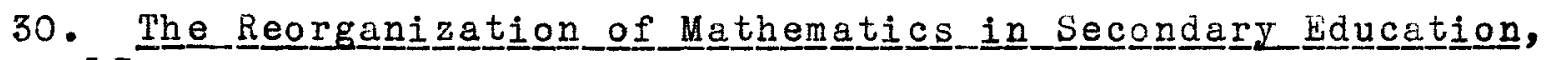
p. 13 .

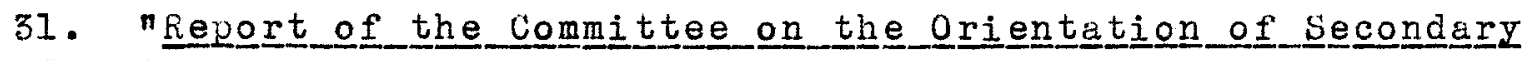
Education", p. 300 . 
as will be done in the next chapter, and in evaluating practice in Kentucky later on and in making recommendations for the improvement of practice we shall look for activities that are definitely planned for the purpose of forming emotionalized attitudes and iderls as well as a mere statement of these as aims.

Summary of The Trends As Expressed In Expert Opinion

The Trend Toward Fusion. Many advocates of fusion including the National Committee would not extend this notion further than combining the several branches of mathematics into unified courses. others including the Committee on Orientation believe that large life-functioning units should be organized that would not recognize subjects as such but would draw upon all subjects as they can contribute to the units.

Trends in Expertopinion Regarding Content. Authorities believe that the content of junior high school mathematics should include arithmetic, intuitive geometry, algebra, trigonometry, and demonstrative geometry. They agree that algebra, intuitive geometry and trigonometry apply in grades eight and nine but not in grade seven. Here emphasis should be upon arithmetic and intuitive geometry. Other than these, no recommendations were advocated in preference to others as to grade placement.

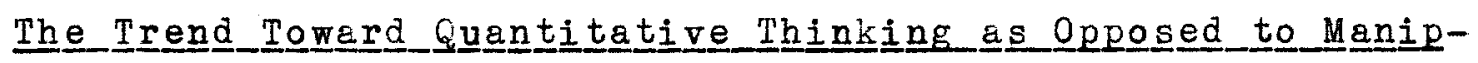
ulation. No authority argues for dispensing with drill altogether, but this without basic understanding should be eliminated as should 
work which has no virtue other than mental discipline.

The Trend Toward Otilitarianism. Utilitarianism is to be considered in its broader sense. The Committee on Reorganization believed that little regard should be had for future courses and that the student should be given mathematics that is useful to him and to society in the present.

The Trend Towar d Emphasis Upon the Concept_of Function. The National Committee believed that this concept was of paramount importance and should constitute the unifying factor in mathematics teaching. 0ther authorities are in agreement. It has been shown that there are ample opportunities for teaching function in all the branches of mathematics at the junior high school level.

The Trend Toward Providing_for_Individual_Differences. This cannot be left entirely in the hands of the Teacher. She should be equipped with a course of study which is flexible and which provides materials simple enough, on the one hand, to be within the reach of slow groups and enriched enough to challenge exceptional students, on the other. Wherever possible separate courses of study should be provided.

The Irend Toward Unit many so-called 'units' would not stand up under careful scrutiny the following characteristics are essential to this tendency: psychological arrangement, definitely stated objectives, adjustwent of the work to include all levels of ability, and the idea 
of wholeness.

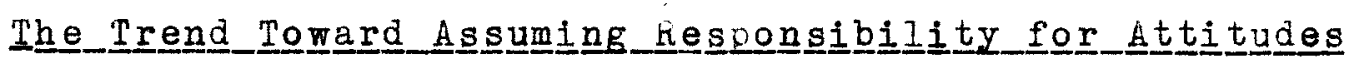
and Ideals. At first this tendency was expressed by merely showing how mathematics contributes to the progress of mankind and attempting to build up an appreciation of this fact together with a disciplinary drive on fixing in the pupil such habits as neatness, orderliness, etc. The tendency now is toward accepting this responsibility in a broader sense. The attempt should be made, it is proposed, to set up active participation for the pupll in which desirable attitudes will be brought about by the social situation thus created. 


\section{CHAPTER IV}

TRENDS IN THE PRACTICE OF TEACHING

JUNIOR HIGH SUHOOL MATHEMATICS 
CHAPTER IV

\author{
TRENDS IN THE PRACTICE OF TEACHING \\ JUNIOR HIGH SCHOOL VATHEMATICS
}

Introduction

Chapter II attempted to show that certain definite trends are evident in expert opinion. This chapter will try to show that they are also evident in the actual practice of progressive schools in this country and to give concrete illustrations.

It is not to be expected that these trends have been accorded equal consideration in actual practice. Some have received wide adoption while others have been recognized only by a few schools and to a limited extent.

A number of sources have been studied in an attempt to detect the extent and nature of the application of these tendencies. Principal among these is the Office of Education's bulletin, Instruction In Mathematics, in connection with the ivational survey of secondary Lducation. Also there were other survey studies and a number of recent courses of study, which are used to illustrate the manner in which the trends are being put into actual practice in progressive schools elsewhere than in Kentucky.

The reader is again reminded that the expression, "progressive schools" does not necessarily mean those connected with the 
Progressive Movement but simply refers to schools which have put into practice to a greater or lesser degree the implications of these trends.

The fact that the schools represented in the National Survey are in this sense progressive is indicated by the following statement in the monograph on mathematics from that survey: "This report presents practices, therefore, in what may be considered a selected group of schools in the United States. Although analysis was made of all outlines submitted, the fact that a school publishes its course of study and releases it for analysis is indicative of efforts to produce a better course of study than obtains in the average school. $n^{1}$

Of the courses of study directly referred to in this chapter, all but one have been published during or since 1930, and nearly all represent revisions of previous courses. other materials descriptive of the curriculum such as bulletins, articles from periodicals, etc. have all been published during or since 1935.

Such schools as those of Bronxville, New York; Lakewood, Ohio; the State of Virginia; the Experimental school of ohio State University; the University of Wisconsin High School; and the University of Chicago High School are well known for their

1. Lide, E. S., Instruction In Mathematics, Bulletin, 1932, No. 13, Monograph No. 17, U. S. Office of Education, Washington, D. C. Introduction. 
curriculum work. The other schools referred to have done something in mathematics worthy of notice.

The Trend Toward Fusion

As stated in the foregoing chapter, one of the most characteristic attributes of junior high schocl mathematics is the idea of fused or general courses. The studies cited in this section will demonstrate that this is true in actual practice as well as in theory.

William Leonard schaaf ${ }^{2}$ examined eight series of textbooks for junior high school mathematics which were in wide use throughout the country as basic texts and accepted general mathematics as the typical mathematics for the junior high school.

The National Survey ${ }^{3}$ indicates that out of forty-four courses of study examined for the seventh and eighth grades only seventeen are still requiring arithmetic, and that even these so-called arithmetic courses contain much material that would be more fairly described as general mathematics.

In the ninth grade, the tendency is less pronounced although

2. Schaaf, W. L., A Course for Teachers of Junior High School Mathematics, Contribution to Education No. $3 \bar{J}_{3}$, Bureau of Fublications, Teachers College, Columbia Dniversity, New York, 1929. 3. Lide, E. S., op. cit. p. 21 . 
readily evident. McCormick ${ }^{4}$ examined forty-one courses of study in ninth grade mathematics and found that even at that time, 1929, general mathematics was the prevailing type of mathematics in the more progressive schools for that level. He further found that twelve most commonly used algebra texts for the ninth grade devoted an average of approximately one-fourth of their space to other-than-algebra topics.

A few illustrations showing the varying extent to which fusion has taken place will be appropriate at this point. The oklahoma ${ }^{5}$ course of study for ninth grade algebra represents almost the minimum of fusion. To a traditional arrangement of algebra has been added a separate chapter on Trigonometry, one on Variation, and a few optional exercises in demonstrative geometry. Little attempt has apparently been made to inter-relate the various fields since all non-algebraic topics have been assigned to separate chapters.

At the other extreme is the Virginie course ${ }^{6}$ which offers mathematics in the seventh and eighth grades only as a part of large, general units which disregard all subject-matter lines.

4. McCormick, Clarence, The Teaching of General Mathematics in the Secondary Schools of the United States, Contribution to Education No. 386, Bureau of Publications, Columbia University, New York, 1929 .

5. High School Courses of Study in Mathemati도으. Bulletin \#123A, Department of Education, Oklahoma, 1932 .

6. Eighth Grade Course of Study, Virginia, 1934 . 
For example, the eighth grade unit or center of interest is "Adaptation of Our Living Through Social and Mechanical Inventions and Discoveries." This center of interest is divided up into eleven problems corresponding to eleven aspects of social living. The mathematics taught comes in only as it contributes along with the other subjects to these problems.

Similarly, but in a more informal manner mathematics is utiIized at the Ohio State Jniversity Experimental School ${ }^{7}$ only as it is needed by the pupil in carrying out some project.

These illustrations present the extremes. Typically, junior high school mathematics is taught as a separate subject but with the various branches combined and inter-woven into a general course. To quote from the survey: "The analysis of topics for grades seven, eight, and nine has indicated a very considerable correlation of arithmetic with algebra and intuitive geometry as well as with the social and economic fields in which the fundamental processes are applied." 8

Content in Actual Practice

While the previous section showed the tendency toward fusion of mathematics, actual content materials were not consid-

7. Educational Research Bulletin of Ohio State Univergity, February 12, 1936 .

8. Lide, E. S., op. cit. p.61. 
ered to ang great extent. This section will draw certain conclusions from the data presented regarding content in actual practice.

Since the text-book is often the most closely followed guide in actual practice, a brief resume of two studies of the content of texts will be included at this point. McCormick's study included an examination of general mathematics texts for the junior high school grades seven and eight as compared with arithmetic texts for the same grades. He concluded: "The junior high school text-books for the grades now being considered contained about the same amount of statistical graphs as the books written for the eight-year elementary schools. In every other branch there was a very noticeable difference. Arithmetic dropped from an average of about eighty per cent in the arithmetics of the elementary schools to about fifty-five per cent in the junior high school text-books. Algebra increased from five and one-half per cent to fifteen and three-tenths per cent and intuitive geometry from sixteen per cent to twenty-one and three-tenths per cent. ${ }^{9}$

Mrs. David R. Davis reported a study of the content of ten junior high school text-book series in 1931. She found the following ranges in the percentages of space devoted to the various branches for grades seven, eight and nine:

9. McCormick, Clarence, op. cit. p.61. 


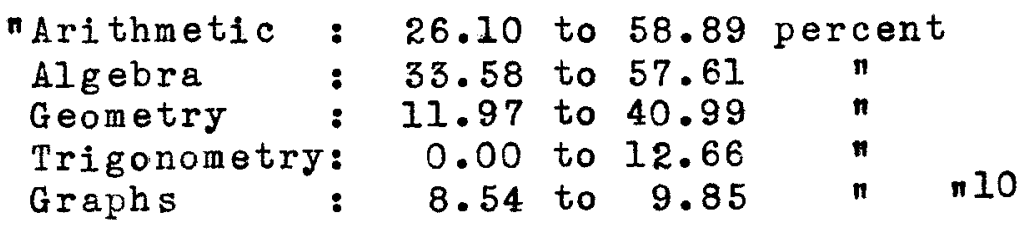

The National Survey included an analysis of forty courses of study for seventh grade general mathematics and forty-two for the eighth grade to ascertain in how many certain topics appesred. The table below is adapted from the one in the bulletin of the survey.

ir Topic:

Percentage of Seventh Grade outiines Including the Topic:
Percentage of Eighth Grade outines Including the Topic:

Arithmetic:

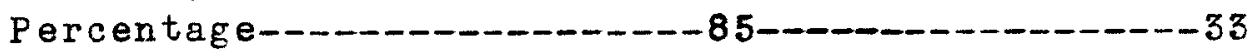

Fundamental operations----- 53-

Business-_-

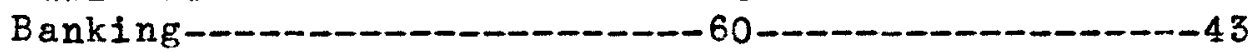

H om e- - -

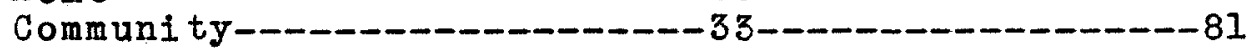

Investments-_-

Graphs-- -

Intuitive Geometry:

Direct Measurement_-

Areas, Circumferences,

Volumes-- -

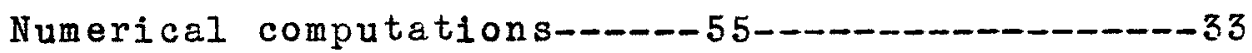

Indirect Measurements-_-

Construction-

Familiarity with FormsAlgebra:

Formulas, meaning, use of---30-

Positive and $\mathrm{Neg}$. Nos.....

Equations, use of-

(Note: No topic was included which appeared in less than thirty per cent of the courses of study.)

10. Davis, Mrs. David R.: "A Comparative Study of Textbooks in Junior High School Mathematics", The High School, VIII:2 (February, 1931) pp. 103-114.

11. Lide, E. S., op. ci. p. 24. Adapted from table 9. 
Certain general conclusions may be drawn from the above tabulation:

(a) Arithmetic, except for community and investment topics, is given more prominence in the seventh grade and less in the eighth.

(b) The simpler parts of intuitive geometry are presented in the seventh grade while indirect measurement, a more difficult topic is postponed until the eighth.

(c) Except for formulas, nearly all the algebra is first presented in the eighth grade.

McCormick made a further study in content for grade nine both in general mathematics and algebra textbooks. (There were eight of the former and twelve of the latter.) The table below reveals the mean percentages by which different branches are incluad in the texts eximined:

at

Arithmetic
Statistics, computationa
Statistics, graphs
Algebra
Algebra, graphs
Geometry, intuitive
Geometry, demonstrative
Trigonometry

hlgebras General Mathematics

\section{Summary}

Junior high school mathematics includes arithmetic in diminishing amounts from the seventh grade through the ninth grade. Intuitive geometry is presented and given considercble treatment 
in the seventh grade and less in the eighth. The more difficult topics are left for the eighth and ninth grades. Indirect measurement began in the eighth.

In the ninth grade, McCormick's study showed twenty-five per cent, appraximately, of non-aleebraic topics in the algebra texts, and forty per cent non-algebraic topics in the general mathematics text. Principal among these non-algebraic topics is intuitive geometry. Other topics included in the ninth grade are graphs, demonstrative geometry, and trigonometry.

The recommendations of the National Committee on Mathematical Requirements have been put into practice to a remarkable extent as far as content is concerned.

The Trend Toward cuantitative Thinking As Opposed To Manipulation

Generally speaking this tendency is more evident in opinion than in actual practice. However, more and more attention is being given to this question, and there is every evidence that in time practice will approach theory in this respect. The more recent courses of study are already giving attention to this important idea.

For example, in the preface to the Beaumont, liexas course of study the following statement appears: "An attempt has been made to consider the general uses of mathematics to the general 
run of people-largely the interpretation of function and the ability to do quantitative thinking.n13

In personal correspondence with the author of this thesis Dr. Maurice L. Hartung of the University of Wisconsin School of Education, an educator at present active in the Eight-Year Experimental Program of the Progressive Education Association, stated: "In my own classes in recent years the emphasis has tended more and more toward generalized objectives. In algebra the emphasis is upon inductive reasoning and understanding of the scientific method." This statement represents a trend away from mechanical drill toward quantitative-mindedness.

George A. Boyce of the Bronxville High School of Bronxville, New York, has done the most outstanding piece of work along this line. After several preliminary editions which have served in actual practice, his units are now available in regularly pubIished form under the title: nquatitative Thinking Series for Junior High Schools." In his preface to unit one he states: "The point of view behind this experimental work has been to prepare a course in quantitative thinking which would not only be interesting but which would actually meet the real needs of boys and girls of to-daj. ${ }^{14}$

13. Mathematics For_Junior High Schools, Beaumont, Texas, City Schools. Preface.

14. Boyce, George A., and Beatty, Willard W., Mathematics of Everyday Life: Quantitative Thinking Series for Juniór Schools, Bronxvilie, New York, School Store, 1935 . 
The Bostonl5 course of study places emphasis upon developing of "number sense" by adapting drill work to practical situations and by encouraging accurate conceptions of answers by reverse multiplication, checking all results, and by estimating answers.

The National Survey analyzed the objectives in the courses of study obtained and found that well over half of them included as an aim the nKnowledge and Power to Apply Mathematical Concepts.n' These concepts included: concepts of mathematical laws; number sense; symbolic notation; mathematical terms; and others.

The Trend Toward Utilitarianism

The National Survey ${ }^{17}$ shows that out of forty-seven courses in mathematics for grade seven, forty-seven for grade eight, and forty-one for grade nine, those listing as an objective, "specific knowledge useful in lifen, were thirty-seven, thirty-four, and twenty-eight respectively. This is in sharp contrast to the number of courses offering as an objective, "preparation for later courses". These were only five for the seventh, five for the eighth, and four for the ninth.

15. Course of Study in Mathemetics: Grädes VII_- VIII_Revised, Boston, $19 \overline{3} 0$.

16. Lide, E. S., op. cit. p. 19.

17. Cf., Lide, E. S., op. cit. p. 19. 
The emphasis on utility is further evinced by the many practical topics included in the outlines. Fifty-three per cent of them included a unit of mathematics in the home, sixty per cent on banking, and seventy-three per cent on business practice in grades seven. 18

Not only were these topics frequent but also much was made of the practical application of mathematics in social problems. To quote from summary of the Survey: "In both arithmetic and general mathematics there is considerable application of mathematics to such economic and social uses as are afforded in the community and the business world." 19

At the Experimental School of the Ohio State University usefulness is the major criteria. Examples from a description of seventh grade activities will be quoted to illustrate this:

"Two boys determined how to arrange seats and tables for 200 persons in a room of given size for a program of known content.

Two girls determined how many pounds of seed were needed to resow an area of the physical education playground.

Two boys constructed a device to determine the value of, and two devices to determine the area of a circle.

Four boys constructed graphs, recording the data of heights and weights of the seventh grade group.

Two girls in theif study of a social science problem constructed a graph." 20

18. Ibid. p. 24 .

19. Ibid. p. 67 .

20. Educational kesearch Bulletin, Ohio State University, (February, 1936) p. 59 . 
There still exists considerable emphasis upon the disciplinary values of mathematics, but there is unquestionably a gradual breaking away from the notion that mathematics must be diffucult for difficulty's sake and also that secondary education must be molded for the select few who will pursue higher education.

The Trend Toward Emphasis Jpon The Concept of Function

Practice has been slow to follow theory in this respect. To quote from the Survey: "Except for the development of the function concept, the objectives formulated by the National Committee seem to have exerted considerable influence on those appearing in local outlines." 21

Several quite recent outlines have, however, given careful consideration to this conept.

Dr. E. R. Breslich 22 , of the University of Chicago, in describing the junior high school course offered in the University High School mentioned functional thinking as one of the chief features of the course. He has devised a comprehensive test by which to measure functional thinking under the following divisions:

21. Lide, E. S., op. cit. p.20.

22. Breslich, E. R., NHathematics for Grades Seven, Eight and Nine", School Science and Mathematics, XXXV (May, 1935) pp.526-536. 
one, recognizing relationships; two, how a change of one variable in a formula affects the others; three, interpreting graphs; four, changes in equations; five, reorganizing linear and quadratic equations; six, dependence in formulas; seven, variation; eight, expressing relationships in mathematical symbols. The test is devised for use in grades from nine to twelve. Hovever, some of the parts may well be used for lower grades.

A recent bulletin on mathematics from the State of Washingtion $^{23}$ which was prepared under the direction of $L$. 0 . Swenson presents a thorough treatment of the subject. The following topics are treated: the notion of dependence; the ratio method of showing relationship between two quantities; direct variation; inverse variation; other types of variation such as variation in proportion to squares and cubes. Some of the recent textbooks are including the subject of dependence or function with reference to concrete problems. The criticism might be made that the concept is usually confined to a single chapter rather than being interwoven into the entire offerings.

The Trend Toward Providing For Individual Differences

The National Survey included a study of provisions for individual differences as they exist in actual practice. A questionnaire was sent out regarding devices for providing for in-

23. A Plan for Reorganization of High School Mathematics, State of Washington, 1935 . 
dividual differences and eight thousand five hundred and ninetyfour forms were accepted for tabulation.

There were twenty-eight provisions for individual differences to be checked. These were later combined so as to form but seven: homogeneous grouping; special classes; plans characterized by the unit assignment; scientific study of problem cases; variation in pupil load; out-of-school projects and studies; and advisory and guidance programs. To quote from the Survey: "of the seven, the first three-homogeneous grouping, special classes, and the unit assignment-have been found to be the core elements in a typically successful program to provide for individual differences." 24

While the first two of these are administrative measures, all three of them have definite and weighty implications for the curriculum. If homogeneous grouping is to be practiced, certainly the curriculum should be affected and the same is true for special classes. The idea of unit assignment must be taken cognizance of by the curriculum.

The survey further revealed that in mathematics for grades seven, eight and nine, the respective percentages of schools segregating classes according to ability were ninety-six, eightynine, seventy-four and that in no other subject except English

24. Billett, Roy 0., Provisions for Individual Differences, Makㅡㄹㅡ. and Promotion, Bulletin, 1932. No. 17, Monograph No. 13, U. S. Office of Education. 
was ability grouping so extensively'practiced.

The Trend Toward Unit Organization of Subject-Matter

As stated in an early chapter, most so-called units would not qualify under the strictest definitions of "unit, n and yet any attempt to break away from logical arrangement of subjectmatter in favor of psychological arrangement is tending toward unit organization.

out of fifty-seven courses of study included in the survey ${ }^{25}$, sixteen were declared to be organized according to the unit plan but over half of the entire number were adjudged psychologically arranged rather than logically.

Schar's questionneire study of 152 schools and systems found that forty-six per cent of the respondents considered their courses arranged according to the psychological plan and an equal percentage reported their arrangement as logical. Eight per cent were doubtful.

The Pennsylvania course of study of $1927^{26}$ divided the content of junior high school mathematics into its logical branches of arithmetic, algebra, intuitive geometry and trigonometry. This represents almost the minimum of unit organization. It is

25. Lide, E. S., op. cit. pp. 9, 10 .

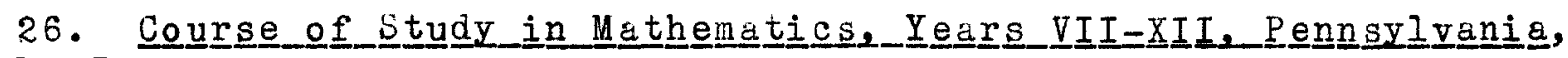
1927 . 
distinctly logical.

A course which shows some advance in this respect but which by no means represents the maximum of psychological arrangement is that of Houston, Texas. 27 Some of the "units" are "Heasurements," "Graphs, " and "Geometry in Architecture."

The South Dakota course 28 recognizes the need for childadjusted divisions of subject-matter and hence goes a step further and subdivides the large teacher units into pupil units with aims in terms of pupil accomplishments.

For a fourth illustration of unit organization, reference will again be made to the Bronxville course. The following appear good examples from actual practice of psychological units within a subject-matter area:

"The Financial Relationships of Children to Parents.

The Economics of Health.

The Economics of Leisure.

Measuring Land, Sky, and Sea.n $\approx 9$

An example of larger and more comprehensive units cen be found in the Virginia course of study already referred to.

27. The Scope of the Curriculum, Houston, Texas, 1932.

28. Mathematics for secondary Schools: Course of Study Number 9. South Dakota, 1936.

29. Boyce, George A., and Beatty, Willard W., op. cit. p.4. 
The Trend Toward Assuming Responsibility For Emotionalized Attitudes And Ideals

There is still a preponderance of factual material in junior high mathematics in actual practice and a paucity of planning for emotionalized attitudes and ideals. one is startled, in examining the objectives tabulated in the survey, to find that even those attitudes and ideals which mathematics has boasted of fostering are mentioned only in a fow courses. The one mentioned most frequently, "precision of thought and of statement", is included on the objectives of less than one-third of the outlines and one as socially important as "Interest in the Nature of Community kxpensen is mentioned in less than onefifth of the outlines. 30

There are, of course, exceptions in individual situations. The Indianapolis course 31 devotes an entire introductory chapter to traits of character and personality. The treatment, if formalized and lacking in practical suggestions, is vastly to be preferred to no treatment at all.

The Lakewood, Ohio, course provides numerous activities in connection with the various units which ought to aid in the de-

30. Lide, E. S., p. 19.

31. Course of Study in Mathematics: Junior High School Di-

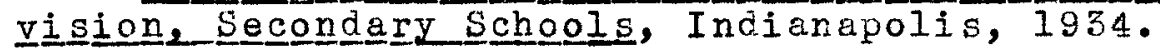


velopment of these attitudes and ideals. For example, under unit one, "The Origin of Mathematics and a Review of the Fundamentals," the child's own experiences in learning to use figures are hooked up with the development of number in the early civilizations and in primitive civilizations of today. Suggested activities under this unit are:

"(1) Recall personal experiences of learning to count.

(2) Read stories of early methods of counting.

(3) Discuss methods of writing numbers which are known to the class.

(4) Oral report on the witing materials used in early civilizations.

(5) Oral report on the forms used by the ancients in writing numbers." 32

Much emphasis is placed upon group cooperation in the Lakewood course and upon pupil participetion.

At the John Burroughs School33, Clayton, Missouri, integration by means of a unit course contributed to by teachers of several subjects is emphasized. The dependence of man upon quantitative measurement is impressed upon the pupils by means of dramatization. Through this course the pupil gets a new conception of how mathematical laws control social and economic progress from the stone age to the age of machinery. Dramatization seems peculiarly adapted to the development of attitudes and ideals.

32. Mathematics: A Tentative Course of Studyd Grades Seven, Eight and Nine, Lakewood, Ohio. I932.

33. Cf. Lide, E. S., op. cit. pp. 3I-32. 
Summary of the Trends in Actual Practice Elsewhere

The Trend Toward Fusion. Fusion ranges in actual practice all the way from combining two or more branches of mathematics to the uniting of all subject fields into large life-functioning units. More typically, however, fusion has meant courses in general mathematics with considerable correlation of arithmetic, algebra, and geometry.

Content in Actual Practice. Arithmetic is typically offered in diminishing amounts from the seventh grade through the ninth. Intuitive geometry is given considerable emphasis in the seventh grade although the more difficult parts are left for the eighth and ninth grades. Indirect measurement and algebra begin in the eighth. In the ninth grade, algebra constituted forty per cent of the material offered in general mathematics textbooks and in algebra textbooks twenty-five per cent of the topics were non-algebraic according to McCormick's study.

The Trend Toward Quantitative Thinking A ulation. This tendency is less evident in practice than in theory. However, several progressive schools are giving it serious consideration. Number sense, one phase of this tendency has been a chief object in at least one course of study. Over half of the courses analysed in connection with the Survey included the aim: "Knowledge and Power to Apply Mathematical Concepts."

The Trend Toward Utilitarianism. The Survey showed that 
"Specific knowledge useful in life" is replacing "preparation for later courses" as an aim. Mathematics of the home, of banking, and of business is given prominence as vell as emphasis upon social phases of mathematics.

The Trend Toward Emphasis Upon the Concept of Function. This concept has not been given the prominence in practice that it has been accorded by opinion. However, several more progressive courses are giving emphasis to function.

The Trend Toward Providing for Individual Differences. Homogeneous grouping, special classes, and some form of the unit assignment are the three most widely used means of providing for individual differences. All three have broad implications for the curriculum.

The Trend Toward Unit organization of Subject Matter. While few courses of study even from progressive schools are organized into units in the strictest sense, more of them tend to a psychological arrangement than otherwise.

The Trend Toward Assuming Responsibility for Emotionalized Attitudes and Ideals. There is still a preponderance of factual material. In more progressive situations more emphasis is being placed upon pupil leadership and responsibility as a means of developing attitudes and ideals. 
CHAPTER V

CRITERIA FOR EVALUATING THE MATHEMATICS

OF THE JUNIOR HIGH SCHOOL 
CHAPEK V

\section{CRITERIA FOR EVAJUACNG THE VATHERATCS \\ OF LHE JUNIOR HIGH SCHOOL}

In order to evaluate the curriculum more systematically it will be necessary to set up certain criteria for each of the trends. There will doubtless be some overlapping in the criteria as there is, indeed, in the trends which they measure. irends are primarily tendencies in emphasis and hence two trends may imply something of the same procedure while being, at the same time, distinct within themselves.

Let the reader be reminded that the criteria are limited by the sources from which they were obtained, namely, opinions of experts and practices in forward-looking schools.

\section{Griteria For tialuating Fusion}

Eriterion one. The basic recommendation of the National Committee on Mathematical Requirements was thet such subjects as arithmetic, algebra, and geometry be taught not separately and in succession but in fused or general mathematics courses. Ihat this, tendency has been put into actual practice is evinced by the already mentioned National Survey. Hence, the first criterion for evaluating fusion in the junior high school curriculum: Are the courses offered in mathematics of the general type 
rather than of the type that treats but a single branch of mathematics?

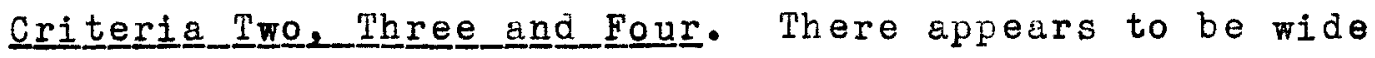
agreement both in theory and in practice that arithmetic, algebra, and intuitive geonetry, and the simpler ideas of statistics, particularly graphs, should constitute the bulk of the junior high school offering. These latter, algebra, intuitive geometry, and statistics should be interwoven with the basic arithmetic which has historically been given precedence at the junior high school level. Therefore the following criteria would seem valid:

Are the algebraic formula and equation used throughout the course rather than confined to isolated topics?

Are graphs and other statistical procedures used throughout the course rather than confined to isolated chapters?

Are the geometric figures and constructions used throughout the course rather than confined to isolated topics?

\section{Criteria For Evaluating Content}

Criterion 0ne. Since all computational work is dependent upon a mastery of the fundamental arithmetic operations, it is essential that they should be given primacy in evaluating content. Therefore, the criterion:

Are the fundamentals adequately provided for? 
Criterion,Two. Computation, however, is subject to the ever present danger of becoming mechanical. It is useless for the child to learn processes if he does not know when and how to apply them. Therefore, there are appearing in junior high school mathematics textbooks and courses of study more and more informational topics. Therefore, this criterion seems justifiable as measuring a definite trend in content:

Is informational arithmetic stressed?

Criterion Three. Since next to arithmetic, the most prominent branch of mathematics recommended for the junior high school is intuitive geometry we are justified in asking:

Is a considerable proportion of the mathematics for the three years intuitive geometry?

Criteria Four and Five. The five plans proposed by the National Comittee on Hathematical Requirements all included some trigonometry and demonstrative geometry in either the eighth or ninth year general course. It has also been shown that a number of the courses of study and textbooks include these topics. Hence, the questions may be asiced:

Is some trigonometry included either in the eighth or ninth grade?

Is some demonstrative geometry included in the eighth or ninth grade?

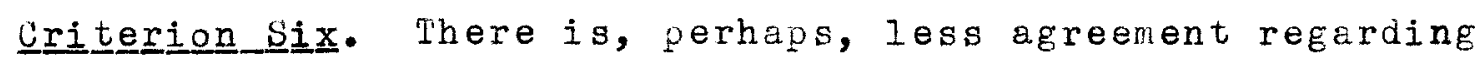


the amount of algebra to be offered than regarding the other branches. Some authorities would have the ninth grade course almost wholly algebra while others would not emphasize it above other phases of mathematics. This division is evident in practice as well as in theory, but it seems safe to ask:

Is a considerable proportion of the work for the three years algebra?

Criteria For Evaluating Quantitative Thinking

Criterion one. As it has already been stated, the trend toward quantitative thinking is a tendency toward a goal which is the antithesis of blind manipulation. There is an increasing insistance that pupils should understand why they should perform a given operation as well as how it should be performed. This means that they should be given problems that are worth solving, that have true social significance. Therefore the first criterion: Are significant social data presented for quantitative treatment?

Criterion Iro. A second factor essential to quantitative thinking is that techniques be provided the student with which to treat data. Aside from the fundamental processes of arithmetic, undoubtedly the most useful tool is simple statistical procedure. Therefore, we may inquire:

Are statistical procedures stressed? 
Criterion Three. Since one of the greatest safeguards against blind manipulation is the inter-change of ideas among a group, the cuestion may be asked:

Is provision made for class discussion of socially important concepts from a quantitative standpoint?

Criteria Four, Five and Six. Still another requisite for quatitative thinking is what has been called "number sense." only by experience do the symbols which are called numbers take on real meaning. While it may be argued that all figuring adds to this number consciousness, there are certainly some exercises that give the pupil more definite skill in forming number ideas than others. Prominent among these are exercises in estimating answers before deriving them, rounding off numbers, and rearranging disorderly arrays of figures. From these we have the following criteria:

Are pupils provided with techniques for estinating answers before deriving them in order to develop "number sense?"

Is nnuber sensen developed by providing practice in rounding off numbers?

Is work in rearrønging disoräerly arrays of figures included?

Criterion Seven. The most glaring manipulative device sometimes employed in junior high school mathematics is transposition of the terms of an equation. This could have no meaning to the beginner in algebra; therefore, it should be taught only after the student has had considerable experience with equations. Be- 
cause of this we submit the criterion:

Is transposition, a purely manipulative device to the pupil, taught only after the concept of balance in the ecuation has been stressed?

Criteria For Evaluating Utilitarianism

Criterion one. The first step toward making mathematics useful was the elimination of useless topics in the basic subject, arithmetic. Therefore, a necessary criterion is:

Have impractical materials such as the following been eliminated? (a) Unusual weights and measures, (b) unwieldy decimals, (c) unusual aliquot parts, and (d) unusual geometric figures.

Criterion Two. In algebra there should be problems of a nature such as to illustrate the usefulness of the subject to the pupil and the "puzzle" type of problem such as, "ihree-fifths of my money less seven dollars equals one-fourth of my money," should be eliminated if utility is a desirable factor in a curriculum. Therefore, the criterion seems pertinent:

Have the puzzle types of problems been eliminated?

Criterion Three. A number of the more recent courses of study, as was shown in Chapter IV, urge the pupils to bring to class problems which they have encountered that are capable of mathematical solution, and obviously this greatly contributed to the usefulness of the course. The criterion may well be included 
for evaluating utilitarianism:

Are pupils encouraged to bring in problems about which they are concerned for solution?

Criterion Four. While members of the school community, pupils are also citizens of the home and this affords rich opportunity for making mathematics socially useful to them. Hence the inquiry may be made:

Is the Mathematics of the home stressed?

Criterion Five. Since another present use that the student has for mathematics is in his other school subjects, and since the more progressive courses of study are taking cognizance of this opportunity for making mathematics useful, we may well ask: Is there content which is definitely useful. to the student in other subjects?

\section{Criteria For Lvalueting Function}

Criterie one, Two and Three. While almost every numerical relation implies function perhaps the three technicues most apt for illustrating this concept to junior high school pupils are: the tabulation of related data, the formula, end graphs. These are the simplest and most easily understood instances of dependence. Therefore, we may inguire:

Is provision made for the tabulation of related data in such a way as to bring out the correspondence?

In the formula is the affect of one variable upon another 
stressed?

Are functional graphs stressed?

Criterion Four. While there are these peculiar opportunities for illustrating the functional relation, this concept should be emphasized throughout the entire course and the question should be asked:

Is the dependence of one variable upon another stressed throughout the course?

Criterion Five. It cannot be repeated too often that the degree to which pupils are made conscious of the dependence of one variable upon another depends upon the frequency with which concrete examples of this dependence are brought to their attention, and since this relation is of prime importance there might well be a separate unit or portion of unit in which it is given careful attention. Because the pupil should be led to generalize the piecemeal impressions he has acquired of function, we inquire:

Is there a special unit or section of a unit devoted to dependence?

Criteria For Evaluating Provision For Individual Differences

Criteria one, Two, Three, Four and Five. As has already been stated, the National Survey of Secondary biducation concluded thet, "...homogeneous grouping, special classes, and the unit 
assignment have been found to be the core elements in a typicalIy successful program to provide for individual differences." 1

Unit organization implies long-term assignments with drill work more or less individualized; homogeneous grouping implies differentiated courses of study; and special classes call for courses of study peculiarly adapted to their needs. Therefore, the following criteria would appear to measure the basic requirements which the curriculum should meet in providing for individual differences:

Is the remedial work readily adaptable to individual instruction?

Is the work so arranged as to make practical directed study? Are long-term assignments possible?

Is the work adaptable to groups which have been differentiated on the basis of ability?

Are special classes provided for?

Criteria For Evaluating Unit Organization of Subject Matter

Criteria one and Tro. Although the term "unit" is subject to many interpretations, there appear to be certain common elements in these to which at least most authorities would agree. The most obvious of these common elements is the idea of a psychological approach. This undoubtedly means that the child's

1. Billett, Roy 0., Provisions for Individual Differences, Marking and Promotion, Bulletin, 1932. No. 17, Monograph No. 13, U. S. Office of Education. 
needs and interests should be exploited in effecting learning. This in turn implies that the child should know the goal for which he is striving for it would be impossible to elicit his interest without his knowing it. Hence, two important criteria are:

Are the units of an experiential (or psychological) nature rather than logical divisions of subject matter?

Are the objectives of the unit definitely stated?

Criterion Ihree. Since another point on which all advocates of unit organization would seem to agree is that there should be in the unit the sense of wholeness, we may ask:

Are the units centered around some central theme or purpose?

Criterion Four. A final characteristic of a unit to which most authorities would subscribe is one which is implied in criterion two and which is emphasized in the criterion:

Can the lesining products of the unit be measured?

Criteria For Measuring The Assumption of Responsibility For Attitudes And Ideals

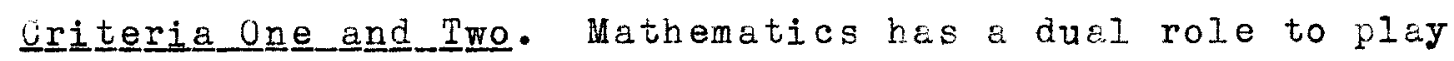
in attempting to form desirable attitudes and ideals in the pupil. First, there is the responsibility for giving the pupil an appreciation of the place mathematics has taken in nature, and in the 
progress of mankind. The following criteria are designed to evaluate the curriculum in this regard.

Is the aesthetic side of mathematics stressed by such topics as geometry in nature, in design of buildings, etc.?

Is attempt made to show how mathematics has contributed in the past and is contributing to the progress of mankind?

Criteria Threee, Four and Five. Then, there is the more general role that mathematics should play along with other subjects in attempting to form attitudes and ideals. Such traits as initiative, ability to cooperate with others, and the habit of forming conclusions independently should be kept constantly in mind in planning the curriculum. Because of this, the following criteria are proposed:

Is pupil initiative stressed?

Is the work adaptable to group cooperation?

Are important social problems presented in such a way as to encourage the pupil to think for himself?

Criterion Six. Finally, the pupil cannot have a wholesome attitude if his work is either too easy to challenge his best effort or too difficult to permit him to experience a reasonable degree of success. Therefore, we may ask:

Is there material simple enough so that the slow pupil may experience a reasonable degree of success and, at the same time, is the superior pupil supplied with work that will challenge his best effort? 
PART II

THE TEACHING OF MATHEMATICS

IN . THE

JONIOR HIGH SCHOOLS OF RENTUCKY 
CHAPTER VI

THE ORGANIZATION OF THE JUNIOR HIGH SCHOOLS

IN KENTUCKY

AND

OF THEIR OFFERINGS IN MATHEMATICS 
CHAPTER VI

THE ORGANIZATION OF THE JONIOR HIGH SCHOOLS IN KENTUCKY AND OF THEIR OFFEKINGS IN MATHEHATCS

\section{Introduction}

Before a detailed examination of the curriculum in mathematics can be attempted it will be necessary to consider certain factors in the junior high schools of Kentucky. The general organization of the schools, the training and experience of their teachers, the offerings in mathematics, courses of study, and textbooks cannot be overlooked either in forming an evaluation of present practice or in making suggestions for improvement. The data used in this chapter were obtained from the questionnaires* sent principals and teachers and from records from the Louisville Public schools.

\section{General Organization}

Kentucky has almost every imaginable type of school organization. There are systems based on the eight-four plen, which is in predominance in the state, others on the six-three-three plan, still others on the six-two-four plan, and a few systems which provide for an eight-jear elementary school from which students enter a three-year senior high school.

* Note: Specimens of the questionnaires appear in the eppendix. 
Junior High Schools

There are twenty-two white public junior high schools which qualify under the definition offered on page seven of this thesis. * Seven of these are junior divisions of six-year high schools but maintain distinct administration and organization. There is every indication that this number will be rapidly increased with in the next few years. The survey of 1933 recommended the junior high school type of organization and the program of curriculum study set up by former.Superintendent James H. Richmond was organized with this plan in mind.

\section{Size of Junior High Schools}

The following table shows the present junior high schools classified according to size of enrollment.

\section{Table I}

White Public Junior High Schools Classified According to Size

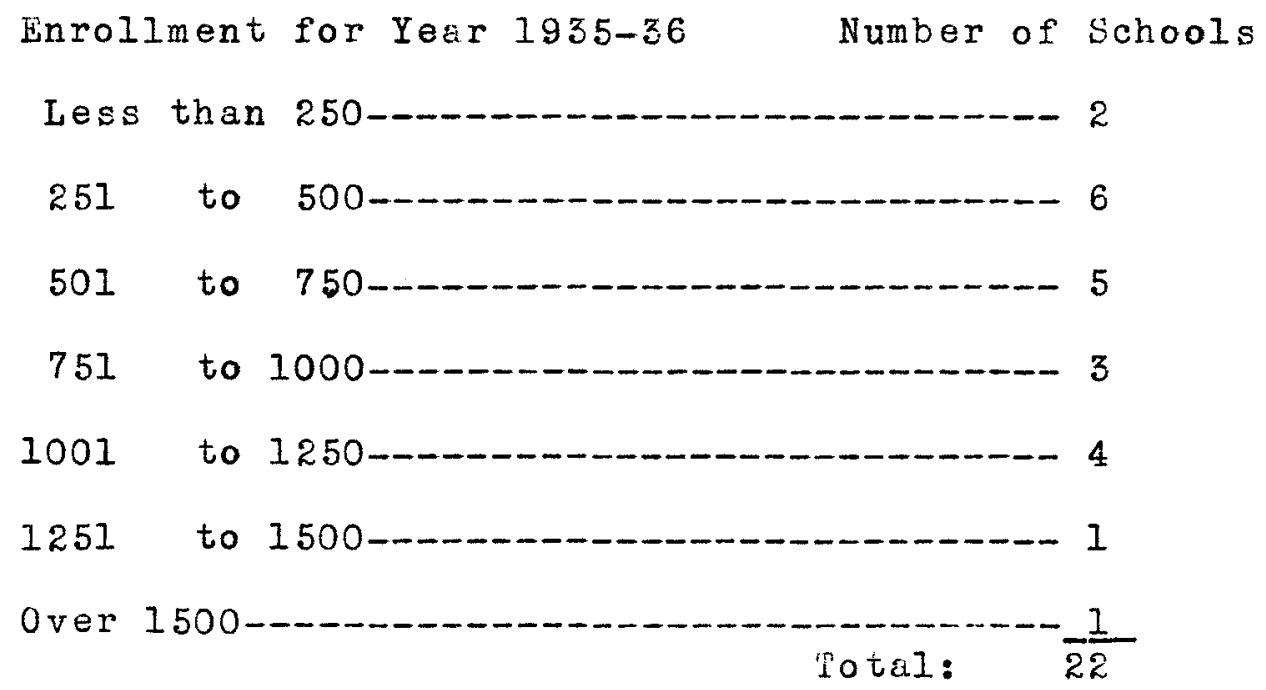

* A list of the schools together with their enrollments and the names of their principals and teachers of mathematics appears in the appendix. 
81

While Louisville had its share of larger schools, the tendency was also toward medium or large schools throughout the state. There were three schools in the state over 600 but less than 800 , one over 800 but less than 1200, and one above 1200.

\section{Units of Organization}

of these twenty-two schools, twenty-one are connected with city systems. One, Bryan Station Junior High School, is a part of the Fayette County organization. Of the remaining, eight are in Louisville, three in Paducah, two in Lexington, and one each in Covington, Ashland, Ovensboro, Hopkinsville, Madisonville, Harlan, Maysville, and Bowling Green.

\section{Grades Included}

Three of these schools, those of 0 wensboro, Henderson, and Madisonville include only grades seven and eight. The others comprise grades seven, eight and nine.

\section{Length of Term}

The schools are nearly ecually divided between nine-month terms and ten-month terms, ten schools with the former and twelve with the latter. This is in normal years. Because of epidemics or for other reasons some of the schools found it necessary to shorten the length of the 1955-'36 term. 
Segregation of CIasses

Sixteen of these junior high schools assign pupils to groups within a given grade level according to ability or general achievement. One school, Owensboro, segregates according to the ability to read. One, Bryan Station, according to ability and, in the seventh and eighth grades, according to sex. Four schools do not segregate. This might be explained in one instance because of the smaliness of enrollment but in the other three schools there is a sufficient number of students to warrant segregation.

The offering in Mathematics

General Mathematics is the typical offering for the seventh and eighth grades. With but one exception all schools are using textbooks* of the general type. The one excepted school uses an arithmetic in those grades.

In the ninth grade, general mathematics has not become the one required course which the National Committee believed it should be. The table below shows the offerings in the ninth grade.

* A list of the textbooks appears in the bibliography. 
Table II

Offerings in Mathematics for the Ninth Grade Courses Offered Number of Schools

Algebra only - 8

Algebra and General Mathematics - - - 10

Algebra and Commercial Arithmetic - - $\frac{1}{19}$

(Note: Three schools do not have a ninth grade.)

Policy of Requirements

All schools require mathematics for the seventh and eighth grades. In the ninth grade requirements are as follows:

\section{Table III}

Requirements in Mathematics for the Ninth Grade

Policy of Requirements Number of Schools

Algebra required of all 6

Either algebra or general mathematics required - 10

Commercial mathematics required for commercial

students, algebra required of ell others - - - 1

No mathematics required

(Note: See note above.)

Number of Periods per Week and Length of Periods

In all these schools mathematics courses meet five times a week. Since the average length of these periods is uniform within a given school for the years comprising the junior high school period, it is unnecessary to show the grades separately. 
Table IV

Length of Periods

Average Length of Periods Number of Schools

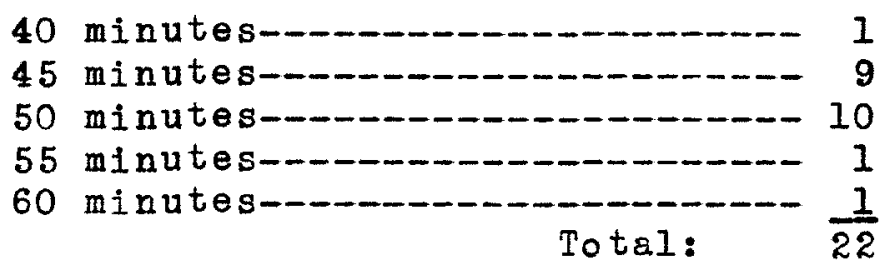

This represents a wide range since the longest period is 150\% of the shortest. Forty-five and fifty-minute periods seem the prevailing practice.

Provision for Retarded Pupils in Mathemetics

Eleven of the schools have a special or ungraded class for retarded pupils. Eight schools, those of Louisville, have a separate course of study for pupils who do not belong in special rooms and yet who need remedial work in mathematics. A number of respondents to the questionnaire for teachers indicated that the work in mathematics is adapted to retarded pupils as the need arises.

There is little doubt that both retarded and normal pupils are benefited by carefully providing for backward learners.

The Teachers of Mathematics

There are approximately 100 teachers in the twenty-two junior high schools considered in this study. Of these, eighty- 
two responded to the questionnaire sent them. They are divided according to sex as follows: thirty men and fifty-two momen.

\section{Full and Part-time Teachers of Mathematics}

Out of the eighty-two teachers responding to the questionnaire, forty-four devote their full teaching time to mathematics while thirty-eight teach mathematics in addition to one or more other subjects or duties.

The subject most often taught in adition to mathematics is science (by nine teachers). Others include Latin, commercial, physical education, health, and art. In a few cases teachers of mathematics have been assigned administrative duties such as those of assistant principal, health counselor, guidance director, etc. In one instance the principal teaches some mathematics.

\section{Training of Teachers}

The levels of training reached by eighth of these teachers (two did not give this information) are indicated in the following table.

Table V

Levels of Training

Level Reached Number of Teachers

Men Women Total

Two-year College Level:-- 6

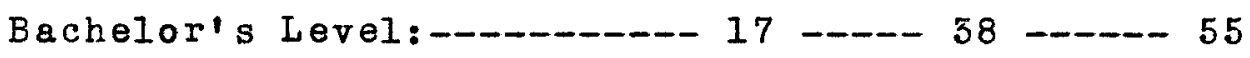

Master's Level:-_-_- $12 \ldots-\ldots$

Doctor's Level:--- - - - $\frac{1}{30}----\frac{-1}{50}-\cdots--\frac{1}{80}$ 


\section{Training in Mathematics}

The following table shows the number of hours earned in mathematics by seventy-seven of the teachers. Five teachers did not give information regarding the number of hours earned in mathematics.

\section{Table VI}

Semester Hours Earned in Mathematics

Number of Hours Larned

$$
\text { Men Women Total }
$$

Six hours or less, ---

Seven to twelve hours, -- - $-\ldots-4-\ldots-15-\ldots$

Thirteen to eighteen hours, ----- $2-\cdots-12-\ldots--14$

Nineteen to twenty-four hours, - - $2 \ldots-\ldots$

Twenty-five to thirty hours, - $\ldots$ - $7 \ldots 11$

Thirty-one to thirty-six hours, -- $2 \ldots-\ldots-3-\ldots-\ldots$

Thirty-seven to forty-two hours, -- $3 \ldots---1 \ldots-\ldots$

Forty-three to forty-eight hours, - 5 - 5

Over forty-eight hours. - - - - - $\frac{-2}{30}-\cdots-\frac{3}{47}-\cdots-\frac{5}{77}$

Two extremes are to be noted. Twenty-seven teachers or more than twenty-five per cent of the total have but twelve hours or less in mathematics. On the other extreme there were practicalIy thirty-nine per cent who have more than twenty-four hours in mathematics. It is very probable that the range in between these two extremes is more desirable for junior high school mathematics than either of the extremes. 
Training in iducation

Because of the certification recuirements in Kentucky in the peist, more emphasis has been placed upon the subject of education than upon specific training in subject metter in the preparation of teachers. The range of semester hours earned begins higher and, on the whole, more hours have been earned in mathematics.

\section{Table VII}

Semester Hours tarned in tuducation

Number of Hours tarned Number of Teachers
Wen Tomen Total

Less than twelve, _.......... 1

I'welve to eighteen, -

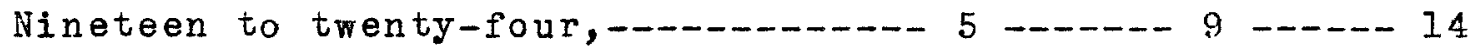

Twenty-five to thirty, -

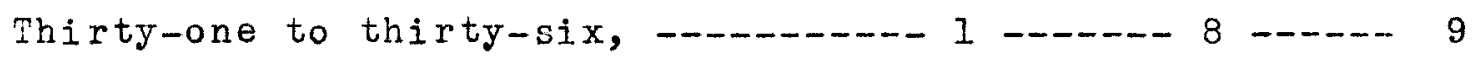

Thirty-seven to forty-two, -

Forty-three to forty-eight, .....- $1 \ldots \ldots$

Forty-nine to fifty-four, _._._._. $3 \ldots \ldots$

Fifty-five to sixty, - 1

殿ore than sixty. -

Eight teachers responding to the questionnaire did not give information regarding the number of hours ecirned in education.

\section{Summáry}

The men have, on the whole, achieved more advanced train- 
ing than the women. Although not shown above, Louisville teachers are slightly more advanced in this respect than those teaching elsewhere in the state.

Two extremes were noted regarding specific training in mathematics. Thirty-five per cent of the teachers have twelve hours or less in mathematics, and thirty-eight per cent of them have more than twenty-four hours.

Typically more stress has been laid upon education courses than upon training in mathematics.

\section{Teaching Experience}

For seventy-four teachers who submitted data regarding to their teaching experience, the following tabulation is made.

\section{TabIe VIII}

Number of Years

(Including 1935-'36)
Number of Teachers

Men Women Total

One to two years,

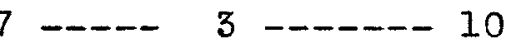

Three to four years,

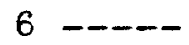

7 15

Five to six years, $6----4$ 10

Seven to eight years,

5

$---1$

$-\cdots--6$

Nine to ten years, 3

$2-----5$

Eleven to twelve years,

1

$4-----5$

Thirteen to fourteen years, -

Fifteen to sixteen years, 1 5 6

Seventeen to eighteen years, $3-\cdots---3$

Nineteen to twenty years,

More than twenty years. 
The women have, on the whole, more years of experience than the men. Although not indicated in the table, Louisville teachers have taught for a slightly shorter period than those elsewhere in the state.

Experience in Teaching Mathematics

As regards specific experience in teaching mathematics, the average number of years is ten. The women have taught mathematics on an average of seven and eight-tenths years longer than the men.

$$
\text { Experience in the Junior High School }
$$

The average length of experience in the junior high school for all teachers is five and nine-tenths years thus indicating that much of the experience obtained is in other types of schools.

$$
\text { Summary of Experience }
$$

Women teachers have, on the whole, been teaching longer than the men. Although not indicated in the tables, Louisville teachers have had slightly less experience than those elsewhere in the state. Much of the experience of these teachers has been obtained elsewhere than in the junior high school.

\section{Teachers' Opinions}

In characterizing a group of teachers, equally important with knowing the amount of training ana experience that they have 
had is an attempt to ascertain their attitude toward important problems confronting education today and towarc the problems pertaining to the subject which they teach.

In making such an attempt a number of questions were asked on the questionnaire sent the teachers in regard to both the practical aspects of mathematics and pertaining to the more theoretical aspects of the curriculum. One of the practical questions asked was whether or not all students should be required to take algebra in the ninth grade. Of the eighty teachers responding to this question forty-four said, "no," seventeen said "yes with reservations," and nineteen said "yes." While there was a diversity of responses there was an indication that most teachers would not set up algebra as a rigid requirement in the ninth grade.

Another practical problem presented to the teachers on the questionnaire was that of content materials. For each of the three years they were asked to indicate the number of class periods which they felt should be devoted to each of seven branches of mathematics in the general courses. In order to avoid confusion, the teachers were asked to assume that the school year should consist of 180 school days with one period per day devoted to mathematics. The following table records the results. 


\section{Table IX}

The Number of Ulass Periods Which Teachers Feel should Be Devoted To Each of Seven Branches of Mathematics Instruction Branch of Mathematics $\begin{array}{lll}\text { Number of Class Period } & \text { Peventh Eighth } & \text { Ninth }\end{array}$

Fundamentals of Arithmetic

$\begin{array}{cccc}\text { Range } & 15-180 & 10-135 & 0-105 \\ \text { Median } & 90 & 40 & 20\end{array}$

Informational Topics

$\begin{array}{lcccc}\text { Range } & 0- & 80 & 10-110 & 0-89 \\ \text { Median } & 20 & 45 & 30\end{array}$

Intuitive Geometry

$\begin{array}{lcccc}\text { Range } & 0-100 & 0-70 & 0-70 \\ \text { Median } & 36 & 40 & 20\end{array}$

Algebra

$\begin{array}{lcccc}\text { Range } & 0- & 30 & 0-65 & 0-150 \\ \text { Median } & 0 & 20 & 40\end{array}$

History and Appreciation

of Mathematics

$\begin{array}{lrccccc}\text { Range } & 0- & 30 & 0- & 20 & 0 & -40 \\ \text { Median } & 5 & 5 & 5\end{array}$

Statistics and

Statistical Graphs

$\begin{array}{lcccc}\text { Range } & 0-40 & 0-40 & 0-40 \\ \text { Median } & 10 & 10 & 10\end{array}$

Trigonometry

$\begin{array}{lccccc}\text { Range } & 0- & 15 & 0- & 20 & 0-30 \\ \text { Median } & 0 & 0 & 0\end{array}$


There were fifty teachers who, gave their opinion regarding the number of class periods that should be devoted to each of the above branches for the seventh and eighth grades and thirty-six who gave the same information for grade nine. While the ranges are quite broad the modians would appear to be in line with the opinions of authorities and with practice in forward looking schools elsewhere except that most authorities advocate some trigonometry in the second and third years (grades eight and nine) or in one of these years.

The teachers were likewise asked their opinion as to whether or not they considered the present interests of pupils an adequate basis for the formation of a curriculum. One teacher agreed that he would without reservation, thirteen agreed nlargely," thirtyseven agreed nto a considerable extent, $n$ twenty-five agreed nto a very limited extent," and four agreed "not at all." This is wide divergence of opinion with the tendency between the two extremes.

In order to sound out teachers further on the more theoretical problems of the curriculum the Ten Major Issues of Secondary Education as enunciated by Briggs and by the Committee on the Orientation of Secondary Education of the Department of Secondary School Principals were delimited so as to apply to junior high school mathematics specifically. It was believed that this would bring the issues closer home to teachers by enabling them to think in terms of their own experience. The issues were converted into statements in order that the teachers might indicate by placing 
plus and minus marks whether they were: one, in full agreement with the statement; two, in agreement but with a few reservations; three, in agreement but with many reservations; four, in disagreement but with many reservations; five, in disagreement but with a few reservations; and six, in complete disagreement. It was hoped to obtain by this plan how teachers individually reacted and also the general sentiment, if such existed, of the teachers of junior high school mathematics regarding these vital issues. Further, by comparing their reactions with those of the Committee on Orientation an interesting side light would be thrown upon the issues as well as upon the teachers themselves.

In order to be more readily understood by the reader, the reactions of the teachers are presented in graphs. As indicated above there were six positions from which to choose ranging from total agreement with the statement to total disagreement. These positions range from left to right in the graphs. A high column at the left indicates that a large portion of the teachers agreed with the statement; a high column at the right means that most teachers disagreed. A comparative uniformity in the heights of the columns indicates that there was no marked consensus of opinion.

The horizontal red line indicates the total number of teachers responding. This total varies among the issues from seventy-eight to eighty-two. The horizontal blue line indicates the mid-point. Thus if any column extends above this line it means that over half of the teachers marked the statement alike. The vertical red line separates the most conservative stand in agreement from the most conservative in disagreement. 
Teachers' Reactions to Ten Issues of Secondary Education As They Affect Junior High School Mathematics

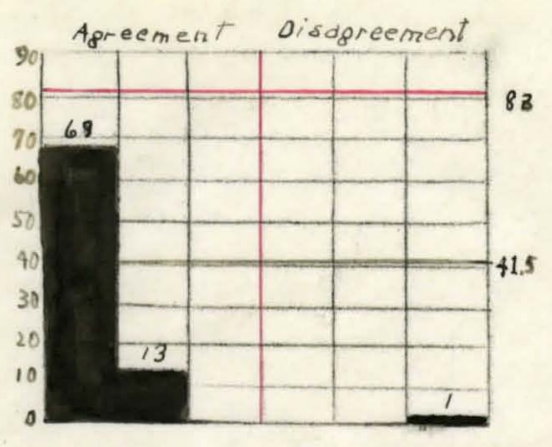

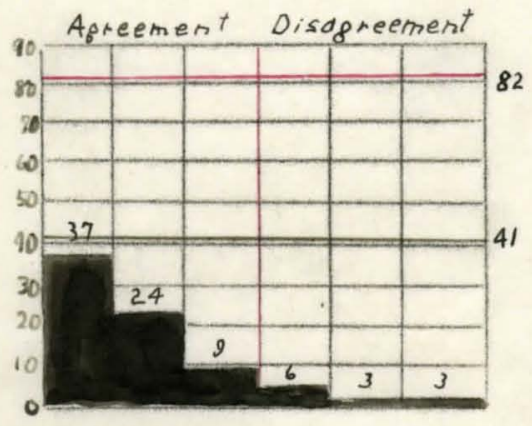

\section{Issue I}

"The junior high school mathematics curriculum should be planned with the aim of providing for all normal individuals and not merely for a select group."

Teachers showed a marked agreement with this statement. Sixty-nine agreed without reservations and only one disagreed.

\section{Issue II}

"The work of certain pupils, who because of inability or indifference do not show progress after every effort has been made to adjust the curriculum to their needs, should be terminated with a completion of the fundamentals."

There was considerable agreement with this statement although many agreed with reservations and a few disagreed.

\section{Issue III}

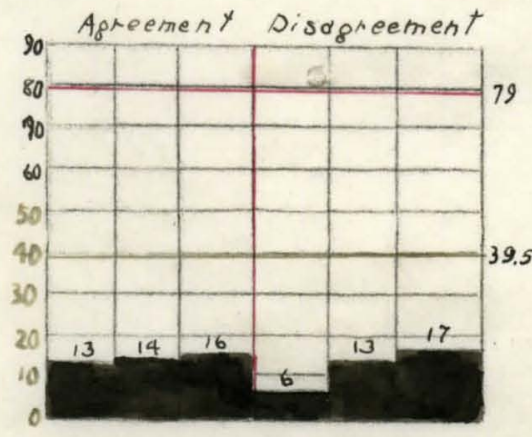

"Junior high school mathematics should be concerned only with the welfare and progress of the individual rather than with those only as they promise to contribute to the welfare and progress of society."

$$
\text { Opinion was about equally divided. }
$$




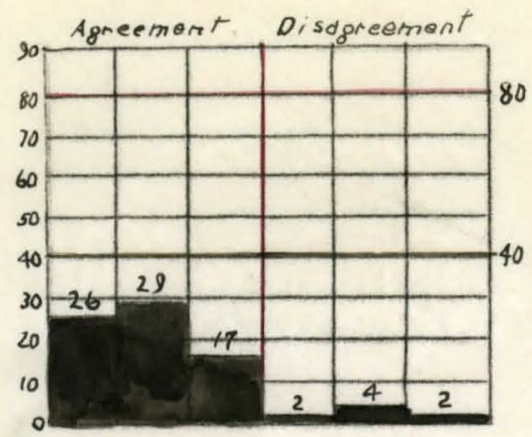

\section{Issue IV}

"The junior high school mathematics curriculum should be based on the common needs of the students rather than on their differentiated needs."

A majority agreed with the statement but most with reservations. Few disagreed.

\section{Issue $\mathrm{V}$}

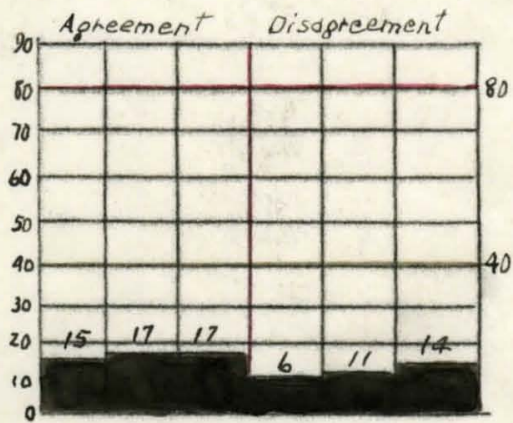

"The junior high school mathematics courses should exploit every opportunity to provide for vocational training and not be confined to the training that might come under the heading of "general education."

Opinion was fairly well distributed concerning this issue. A slight majority was in agreement with the statement.

\section{Issue VI}

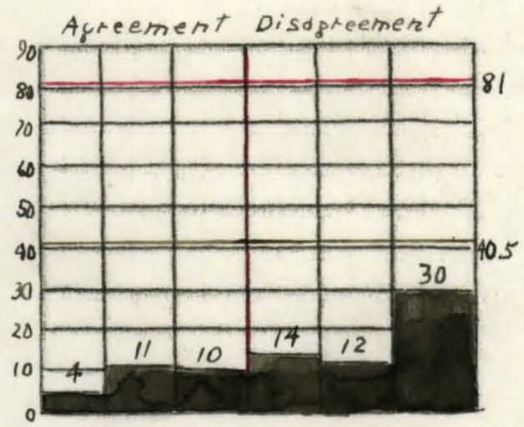

"The junior high school mathematics curriculum should be primarily directed toward preparation for advanced courses rather than directed primarily toward the value of its own courses."

The majority disagreed with this statement wholly or with reservations. A few agreed mostly with reservations.

\section{Issue VII}

"It would be wise to organize the

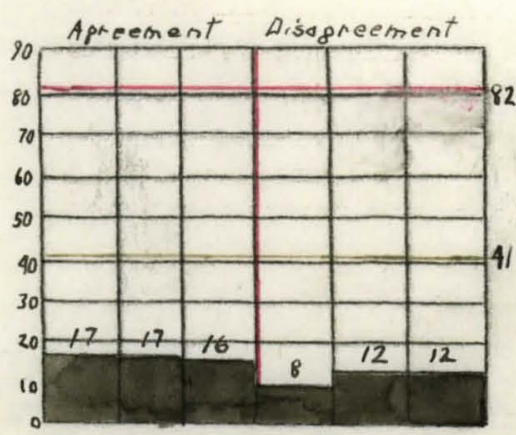
experiences of the junior high school period of education around life-functioning aims such as socio-civic, economic, health, leisure time, etc. rather than adhere to the traditional subject-matter divisions such as mathematics, English, etc."

Opinion was divided regarding this issue. Slightly more agreed than disagreed. 


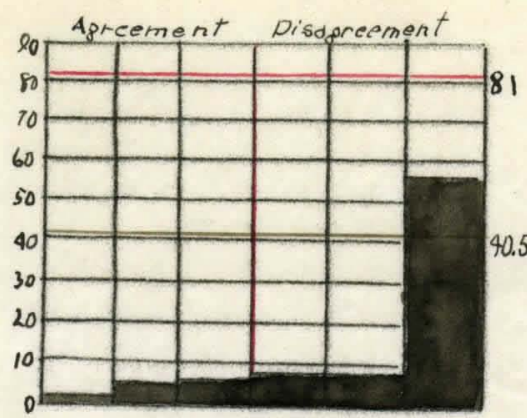

\section{Issue VIII}

"Junior high school mathematics should present merely organized facts and should not assume responsibility 0.5 for attitudes and ideals."

There was a marked disagreement with the statement as well over half of the teachers totally dissented.

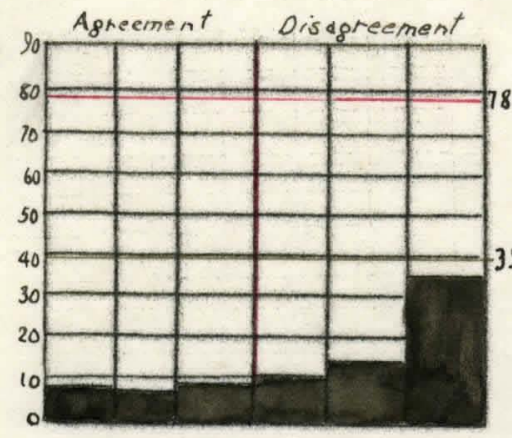

\section{Issue IX}

"The junior high school mathematics curriculum should have as its aim merely the adjustment of students to prevailing social ideals and should not seek the reconstruction of these ideals."

There was some disagreement with the statement. Although opinions ranged from complete agreement to complete disagreement the tendency was well toward the latter.

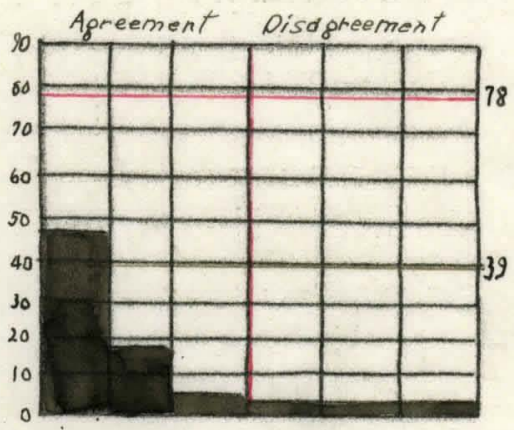

\section{Issue $\mathrm{X}$}

"Junior high school mathematics should be thought of as a distinct but closely articulating part of the entire mathematics program of the schools rather than as a mere phase of that program with few or no distinguishing characteristics of its own."

There was a marked agreement with the statement with few who disagreed.

As has been stated elsewhere, the Ten Issues of Secondary Education were delimited to apply more specifically to the curriculum of the junior high school in mathematics. Attempt was made to change the basic idea as little as possible and still have the principles applicable. 
Issue I

The first issue as accepted by the Committee on Orientation read: "Shall secondary education be provided at public expense for all normal individuals or for only a limited number?" The issue as presented to the teachers mas: "The junior high school mathematics curriculum should be planned with the aim of providing for all normal individuals and not merely for a select group." Both ideas are based on the principle of equality of educational opportunity which, if idealistic, is at least a goal to be striven for. Teachers were in agreement with the committee that this is at least a desirable and logical goal.

\section{Iseue II}

The second issue may seem to be at variance with the statement submitted to the teachers but a careful study of the committee's discussion will reveal that the issue as stated by them would imply that presented to the teachers for a particular subject. To quote the Committee: "once a pupil has mastered the minimum essentials, therefore, and has been given full opportunity under adequate guidance to try himself out in the various major types of work which the secondary school has to offer his continued failure to attain or to make progress toward valuable competence in some one of these types of work represents just grounds for considering that he has reached a level of diminishing returns from continued schooling." 
The teachers agreed with the Comittee's stand although with some reservations.

\section{Issue III}

The third issue as presented to the teachers was practically identical with the original except that the words "the junior high school mathematics curriculum" were substituted for "secondary education". The Committee on Orientation took the stand that public education is an investment made by society to promote social living and that therefore education was concerned with the individual only as he promised to contributed to society. There was no marked consensus of opinion on the part of the teachers.

\section{Issue IV}

Issue four contrasted providing for the common needs of the pupils with providing for their differentiated needs. The Committee strongly favored differentiation whereas teachers mostly took the opposite stand. However, in restricting the issue to the junior high school some injustice was done the original proposition since differentiation is more pronounced in the upper years of secondary education than in the lower.

\section{Issue V}

Issue five, likewise, was considerably restricted when delimited to include only the junior high school. This institu- 
tion has been thought of as an agency for exploration of many fields but as of one not designed to produce specialists in any vocation. Perhaps this accounts for the fact that teachers as a whole did not take a decided stand in favor of vocational training as did the Committee.

\section{Issue VI}

Issue six regarded the question of whether the junior high school should be concerned primarily with its own courses or should rather be concerned primarily with preparation for future courses. The Committee favored secondary education's being primarily concerned with its own courses in the belief that if it established standards of its own, higher institutions would find them adequate for entrance requirements. The teachers were mostly in agreement with the stand of the committee.

\section{Issue VII}

Issue seven called forth a reaction on the part of the committee in favor of large fundamental categories rather than subject-matter divisions of curriculum organization. There was no consensus of opinion on the part of the teachers but a few more agreed with this than disagreed.

\section{Issue VIII}

On issue eight the teachers agreed with the committee that the school must assume responsibility for attitudes and ideals. 


\section{Issue IX}

Issue nine called forth a reaction on the part of the teachers opposed to the stand taken by the Committee. The teachers believed that the school should seek to reconstruct society.

\section{Issue $X$}

Teachers agreed with the committee on issue ten that the secondary school should have distinctive characteristics of its own.

\section{Summary}

On five of the issues (issues one, two, six, eight, and ten) there was substantial agreement between the Committee and the teachers.

On two (issues four and nine) there was maried disagreement between opinions of teachers and that of the Committee.

On three of the issues (issues three, five and seven) there was no consensus of opinions on the part of the teachers.

Teachers showed marked agreement among themselves on seven of the issues. On three of them, opinion was about equally divided. 
Summary, of Chapter

Twenty-two junior high schools in Kentucky qualify under the definition assumed by this study. The enrollment of fourteen of these schools exceeds 500 pupils. All but one are connected with city systems. Three of these schools contain only grades seven and eight while the remaining contain these grades and, in addition, the ninth. The schools are about equally divided between nine and ten-month terms. Sixteen of these junior high schools practice homogeneous grouping on some basis.

General mathematics is the typical offering in the seventh and eighth grades and texts of the general mathematics type are typically used. In the ninth grade about half of the schools offer only algebra while about the same proportion offer a choice between algebra and general mathematics. Only one school offers commercial arithmetic. Forty-five and fifty-minute periods for mathematics are typical. Eleven of the schools have speciel or ungraded classes for retarded pupils.

Only six teachers reporting have less training than is required by the bachelor's degree and a considerable number of teachers had reached or exceeded the training represented by the master's degree. Training of teachers in the subject of mathematics is represented by two extremes with thirty-five per cent of the teachers having had less than twelve hours in mathematics and thirty-eight per cent having had more than twenty-four hours. 
On the whole teachers have had more work in education than in their subject field.

In round figures sixty-nine per cent of the teachers have had five or more years of teaching experience although typicalIy much of this has been elsewhere than on the junior high school level.

Teachers opinions regarding the ten major issues of secondary education as applied to junior high school mathematics show a marked agreement among themselves. On half of the issues teachers agreed with the Committee on orientation. On two issues they disagreed with the Committee and on three issues there was no concert of opinion among the teachers.

\section{Conclusions}

While Kentucky is typically on the eight-four plan now there are indications that the junior high school type of organization will more and more come into prominence. Therefore its curriculum should be given serious consideration.

The junior high schools now in existence are typically large enough and are sufficiently well organized to carry out many of the implications involved in the tendencies as outlined in Part One of this study. The teaching personnel is sufficiently trained and has had sufficient experience to permit the application of these tendencies to the curriculum and their opinions, for 
the most part, indicate that they are aware of important prob1 ems confronting education.

It would seem that Kentucky is ready to move forward in the problem of a reorganized mathematics curriculum for the junior high school. 
CHAPTER VII

AN EVALUATION OF THE MATHEMATICS TAUGHT IN

THE JUNIOR HIGH SCHOOLS OF KENTUCKY

A. KENTUCKY EXCLUSIVE OF LOUISVILLE

B. LOUISVILLE 
CHAPTER VII

AN EVALUATION OF THE MATHEMATCS TAUGH IN

THE JUNIOE HIGH SCHOOLS OF KENTUCKY

\section{Introduction}

Part one of this thesis attempted to establish certain forces as trends and to set up criteria for judging the application of these trends to a given situation. The first chapter of Part Two attempted to give an overview of the situation regarding mathematics in the junior high schools of Kentucky. It remains for this present chapter to try to evaluate the curriculum of these schools in terms of the criteria.

In the absence of courses of study, textbooks would seem to furnish the best description of curriculum materials. These together with lists of omissions* as indicated on the questionnaire for teachers have been used in this present chapter as the source of data.

Since Louisville is the only system from which courses of study were available and since the author has been active in mathematics curriculum work in that city for the past several years it was decided to treat the Louisville curriculum separately.

\footnotetext{
* A tabulation of these omissions appears in the appendix.
} 
It is recognized that the textbook does not give a complete picture of the curriculum even when teachers have indicated what topics they omit but it is apparent that instruction is dependent upon the textboor to a large degree and especially so where there is no course of study. Teachers who are exceptionally competent will not confine their materials to the textbook but more typicalIy the teacher will rely on the textbook for guidance when other guides are not provided.

In evaluating the curriculum as revealed by the textbooks the author has tried to be as objective as possible. He has had at hand every textbook used in the seventh, eighth, and ninth grades of the schools considered in this study in arithmetic, algebra, and general mathematics. A list of these textbooks with their authors, publishers, and dates of publication will be found in the bibliography of this thesis.

In applying some of the criteria the author has taken each book and studied it page by page. In other instances he has found the desired information by reference to the indices and by tracing down the leads given there. In applying other criteria he has used the answer sections of the textbooks and the tables of contents.

It should be pointed out in the beginning that it is not the purpose of this chapter to compare the various textbooks one with another, but to make a general evaluation of the curriculum as it is revealed by them as a whole. 
While it is outside the soope of this study to construct courses of study it is pertinent in evaluating present practices to point out opportunities for and suggest means of improvement.

\section{The Curriculum in Kentucky Exclusive of Louisville as Revealed By the Textbooks}

\section{Fusion}

Criterion One: Are the courses offered in mathematics of the general. type rather than of the type that treats but a single branch of mathematics?

With but one exception all the textbooks for grades seven and eight are of the general type. The one exception, a single book used for both these grades, is principally an arithmetic although it gives some consideration to intuitive geometry and to the algebraic equation.

For the ninth grade, only two schools outside of Louisville are offering general courses. One of these schools is using a regular general mathematies textbook and the other is using an eighth grade generel mathematics textbook for the ninth grede course. The other textbooks for the ninth grade are algebras.

Thus it will be seen that general mathematics is the typical offering in grades seven and eight in Kentucky and that al- 
gebra is the typical offering for the ninth grade. The National Committee on the Reorganization of Mathematics in Secondary Education advocated general courses for each of the three years and urged that these courses be required of all. Since the general mathematics course is of a more practical nature and since it contains sufficient algebra for common uses and in addition to this offers much other valuable material it seems reasonable to recommend that where only one course is to be offered it should be the general course. If, in addition to this, specialized courses could be offered as electives there should be no objection to doing so.

Criterion Two: Are the algebraic formula and equation used throughout the course rather than confined to isolated topics?

In all the textbooks where presented at all the formula and equation are confined almost wholly to isolated chapters. Their use elsewhere is so seldom that the course would still be complete if they were entirely omitted. Percentage offers a most appropriate setting for the equation and yet only two textbooks on any level employ the equation in teaching that topic.

This isolation is unfortunate from the standpoint of fusion. Fusion does not mean presenting topics in tandem order but rather it means blending the various branches together.

Criterion Three: Are graphs and other statistical procedures used throughout the course rather than confined to isolated chapters? 
What was said of the algebraic equation and formula may be said also of graphs. This important technique is taught as a separate topic and then dropped. Outside those referring to the special chapters on graphs, the indices of the entire fifteen textbooks list only eleven references to graphs. As a later section will show, little statistics other than graphs are included.

Criterion Four: Are the geometric figures and constructions used through the course rather than confined to isolated topics?

A page by page analysis of eleven textbooks (all except the algebras) revealed that the square is mentioned only twenty-three times, the rectangle only eighteen times, and the circle only eighteen times except in those chapters devoted to the special topic of geometric figures and constructions. Doubtless the less common figures even referred to even more seldom.

Content

Criterion one: Are the fundamentals adequately provided for?

While all the seventh and eighth grade textbooks make some provision for drill in the fundamentals, treatments on the whole are rather inadequate. Of the five textbooks for the seventh grade the greatest number of pages that any textbook devotes to fundamental drill is twenty-five and the others range downward 
to twelve. Of the five textbooks for the eighth grade the greatest number of pages that any book devotes to drill work in fundamentals is fifteen and one-half and the others range downward to three.

Criterion Two: Is informational arithmetic stressed?

The five books for grade seven contain thirty-one chapters on such informational subjects as banking, insurance, taxation, business practice, etc. making an average of slightly over six chapters per book. The books for the eighth grade contain a total of twenty-six chapters making an average of slightly over five chapters per book and the one general mathematics textbook for the ninth grade contains eight chapters of an informative nature. The algebras contain almost no informational subjects.

The treatment seems to be adequate as to the amount offered but the criticism may well be made that the informative topics are considered too little from the standroint of the consumer and too much from the standpoint of the employee. It is not nearly so important, for instance, for the average person to be able to compute insurance premiums as it is for him to understand the basic assumptions of insurance and to know what type afforas him greatest protection.

Criterion Three: Is a consideruble proportion of the mathematics for the three years intuitive geometry? 
The mean percent of number of pages devoted to intuitive Eeometry for grades seven and eight is nineteen and two tenths. This approaches the percent found by McCormick with eleven seventh and eight-grade textbooks which was twenty-one and three tenths.

The one ninth grade general mathematics textbook devotes approximately eleven per cent of its space to intuitive geometry.

Criterion Four: Is some trigonometry included either in the eighth or ninth grade?

In none of the seventh grade textbooks is trigonometry included. This is probably as it should be. It should be left for the two succeeding grades. Only one eighth grade textbook treats it, however, and the ninth grade general mathemetics treats it only in considering the tangent function. All the algebra textbooks include trigonometry and treat other functions as vell as the tangent. Teachers indicated on the questionnaire that this is a favorite topic for omission.

Criterion Five: Is some demonstrative geometry included in the eighth or ninth grades?

One ninth grade algebra includes some demonstrative geometry whereas all the other books omit it. While a great amount of demonstration cannot be justified on the junior high school level, pupils do profit from an understanding of the nature of proof which 
it affords. It also serves the exploratory aim of the junior high school.

Criterion six: Is a consideruble proportion of the work for the three years algebra?

None of the seventh grade books include algebra except as it is used in the mensuration formulas. Approximately twenty per cent of the space in the eighth grade textbooks is devoted to algebra and the ninth grade general mathematics contains approximately fifteen per cent of algebra. To be sure the ninth grade algebra textbooks are almost wholly algebra although some few other subjects are given slight attention.

\section{Summary}

The content revealed by the textbooks compares favorably with the recommendations of experts and with practice elsewhere. There is, however, too slight provision for the fundamentals. Also, the informational arithmetic should be taught more from the consumer's point of view and more of the textbooks for the eighth and ninth grades should include some demonstrative geometry.

\section{Quantitative Thinking}

Criterion 0ne: Are significant social data presented for quantitative trestment?

Since unquestionably graphs offer the greatest opportunity 
for presenting socially significant data in junior high school mathematics a careful study was made of the subjects both of the graphs printed in the textbooks and of the data presented in the textbooks from which children are told to make graphs. Many of the subjects obviously have little if any social value. "John's Baseball Score," is an example of this type. Of those which presume to treat socially important subjects the following are typical. Five textbooks treat the size of agricultural crops or compare these crops one with another. Four treat the comparative size of the states in area. Three compare the continents as to area. Only one textbook gives statistics regarding fatal accidents from automobiles or from other causes, only one compares the number of deaths from various diseases, and none treats unemployment, taxation, relief, or any of the other really important issues of the present time.

Criterion Two: Are statistical procedures stressed?

With the exception of graphs little attention to statistical procedure is in evidence. Only three seventh grade books mention even so common a statistical term as average or mean and In no one of these three books are more than four problems devoted to this concept. Only one eighth and one ninth grade book mention either of these terms.

Only three seventh grade books mention "median" and no book uses it except for purposes of finding the class median on tests. 
No eighth grade book mentions median and only one ninth. Only one book at any level mentions mode, frequency table, or frequency distribution.

Criterion Three: Is provision made for class discussion of socially important concepts from a quantitative standpoint?

In the hands of a skillful teacher such topies as the history of numbers, insurance, taxation, investment, etc. might precipitate important discussion, but unfortunately in the textbooks the emphasis is largely upon manipulative work rather than upon the big concepts.

Uriterion Four: Are pupils provided with techniques for estimating answers before deriving them in order to develop "number sense?"

Only one of the five seventh grade textbooks provide means of estimating answers before deriving them and that is in connection with a single type of problem in decimals.

Two of the five eighth grade texts make mention of techniques for estimating answers, each only once. Only one ninth grade text supplies techniques for estimating answers. This text devotes one page to the matter.

Criterion Five: Is number sense developed by practice in rounding off numbers? 
Three of the five seventh grade textbooks provide some slight work in rounding off numbers. No textbook devotes more than three pages to such exercises. Only one eighth and one ninth grade textbook mention the topic.

Criterion Six: Is work in rearranging disorderly arrays of figures included?

Practically no serious attention is given this matter. Only one textbook treats it at all and that book gives but eight arrays to be put into orderly fashion.

Criterion Seven: Is transposition (a purely manipulatived device to the child) taught only after the concept of balance in the equation has been stressed?

Since none of the seventh grade textbooks take up the equation the analysis was confined to eighth and ninth grade books. None of the eighth grade books teach transposition and the ninth grade books teach it only after the concept of balance in the equation has been stressed.

\section{Utilitarianism}

Criterion One: Have impractical materials such as the following been eliminated?

(a) Unusual weights and measures?

Only one book deals with apothecaries weights, troy weights, and only two with foreign money. 
All the books treat the metric system but this would seem to be of practical value at least from the appreciatory standpoint.

(b) Unwieldy decimals?

By analyzing the answers and the problems in the chapters devoted to decimals it was found that practically none of the problems demand the use of more than four decimal places and that the vast majority of the problems require only two places.

(c) Unusual aliquot parts?

The work in aliquot parts is confined almost wholly to halves, thirds, fourths, fifths, sixths, and eighths. One book gives sevenths, thirteenths, and fifteenths but does not require the pupil to commit them to menory.

(d) Unusual figures and solids?

Little mention is made of such unusual figures as irregular polygons, trapezoidal prisms, frustrums, or other unusual figures or solids. Irregular polygons are referred to but nine times in all the books, trapezoidal prisms but seven, and frustrums of pyramids and cones but five times.

(e) Highest and least common multiple?

These terms are not mentioned in any of the books. 


\section{6}

Criterion Two: Have the puzzle types of problems been elim- . Inated in teaching algebra?

The problems in eleven chapters on the equation from as many books (all the books containing such chapters) were read and it was found that 204 out of 431 problems using the algebraic equation are of these two purely puzzle types: age problems and missing number problems. An example of each will be given to illustrate the nature of these problems which one would never use outside the mathematics class room. An example of the first type is: "The sum of the ages of Frank and his sister is eighteen years. Frank is five times as old as his sister. How old is each?" An example of the second type is: nIf four times a number is four more than the number, what is the number?"

Criterion Three: Are pupils encouraged to bring in problems about which they are concerned for solution?

This is a feature almost totally lacking from the textbooks. One text asks pupils to make up some problems and another asks them to bring in business forms obtained from business houses and banks but the idea of having the pupils bring to class problems with which they are concerned is foreign to the textbooks. lomments on the questionnaire for teachers, however, indicate that a number of teachers do this.

Criterion Four: Is the mathematics of the home stressed? 
All the seventh grade books, all the eighth grade books, and the ninth grade general mathematics textbook devote one or more chapters to mathematics of the home. The work is confined almost wholly to these three topics: thrift, reading gas and electric meters, and home budgets and accounts. The work is largely manipulative.

Criterion Five: Is there content which is definitely useful to the student in other subjects?

\section{(a) Science}

Lever problems are treated in each of the algebras although other simple machines such as the incline plane, wheel and axle, etc. are omitted.

Graphs do not treat of scientific topics other than weather, age-height relations and plant growth.

One textbook points out that the trigonometric functions are used in estimating distances of planets and stars.

Other than the lever, formulas do not include scientific applications to any appreciable extent.

Chapters on geometry in nature mention the snow crystal. Other crystals are neglected.

Six of the textbooks teach the reading of gas and 
electric meters. In five of these books the only electrical term mentioned is the kilowatt. The other book mentions volts and amperes.

(b) Social Studies

While graphical representation and interpretation are useful to the student in social studies the actual graphs included in the textbooks are not socially significant as it has already been pointed out.

Taxation, insurance, business organization, installment buying, budgeting, building and loan associations are all topics which should contribute to one's social understanding.

The geography taught is neglegible and history is not dealt with except in treating the nistory of mathematics. This ought to be of some value.

(c) English

Except for incidental practice in oral and written expression and in reading the contribution to the study of English is neglegible.

(d) Shop Work, Mechanical Drawing and Domestic Arts Mensuration should aid the shop student in a gen- 
eral way although specific applications to shop problems are rare. This is also true of geonetry constructions.

The student of mechanical drawing should be aided by the work in the textbooks of mathematics on scale drawing and by such concepts as symmetry, congruence, and proportion.

A number of problems in each of the textbooks deal with recipes, mersurement of cloth, and selection and purchasing of foods. Caloric measures were mentioned in several of the textbooks but teachers from the schools where these books are in use indicated on the questionnaire that this topic is omitted.

(e) Art and Music

The geometric figures should assist the pupil to appreciate art and should assist him in the pursuit of drawing, painting and carving. 'lhere are no applications of mathematics to music in the textbooks.

The Concept of Function

Criterion one: Is provision made for the tabulation of 
related data in such a way as to bring out the correspondence?

of the five seventh grade books only two tabulate data so as to impress the student with the relation of the quantities. only one eighth grade text does so. In the ninth grade textbooks, such tabulations are confined to those related to equations which, while being of some value for stressing function, do not deal with important data. The treatment is slight in all these books.

Criterion Two: In the formula is the affect of one variable upon another stressed?

Except for one ninth grade text little attention is given the matter of defendence in the formula. The treatment in this text is slight.

Criterion Three: Are functional graphs stressed?

Since all of the tabulations mentioned under criterion one are in connection with graphs the comments made there will apply to graphs. The treatment of functional graphs is slight. This is to be lamented since the graph offers one of the best means of showing correspondence between related data.

Criterion Four: Is the dependence of one variable upon another stressed throughout the course?

It is questionable whether or not the pupil gets the full 


\section{1}

meaning of function unless it is definitely pointed out, explained and constantly referred to. The statement of the National Committee on the Reorganization of Hathematics in Secondary bducation that no theory of function need be taught has been taken by textbook writers to mean that even definitions of the terms function, dependence, and variation need not be given the pupil. Only one textbook at any level gives a general definition of function. Four texts mention it in a single connection and only two mention either dependence or variation.

Criterion Five: Is there a special unit or section of a unit devoted to dependence?

One of the textbooks includes a chapter on Making comparisons and Studying Related Changen. Others do not contain chapters or sections of chapters on the subject.

\section{Summary}

The function concept has not become the one unifying factor which the National Committee believed it should be for the junior high school curriculum in Kentucky at least as it is revealed by the textbooks. Few truly functional graphs are provided in the textbooks examined and the same is true for functional tabulations. Definitions are lacking and only one textbook gave any extended treatment to the subject of dependence. 
Provision for Individual Differences

Criterion one: Is the remedial work readily adaptable to individual instruction?

It was shown in the section regarding content that there is a dearth of remedial material in these textbooks. What is given is, however, readily adaptable to individual instruction. Examples are given of how to work the more difficult problems and all of the books were obtainable with answer sections in order that the pupil might check his work. It is unfortunate that the textbooks do not provide more self-checking devices in order that the pupil may be able to check his answers without reference to the answer sections of the textbooks.

Criterion Two: Is the work so arranged as to make practical directed study?

The typical procedure in introducing $\varepsilon$ new topic in the textbooks is: One, To say something about the topic that will draw the pupil's attention to what is about to be presented; Two, work one or more examples; Three, present exercises that will assist the pupil to acquire the needed techniques; and Four, give the pupil problems in which to apply the technicues learned. This type of procedure is readily adaptable to the directed study method of instruction. 
Criterion Three: Are long term assignments possible?

There are two factors necessary for long term assignments. One is the actual length of the unit and the other is the factor of unity within the unit. That is to say, if a unit is brief no matter how complete within itself it is not capable of long term assignment. On the other hand, if the unit does not move toward a constant goal, the teacher will not be able to tell the class in advance what is expected of them even if the unit does contain sufficient material to warrant long term assignments. The units found in the textbooks fail under the first qualification. They are too brief for long term assignments. The average length of the topics (obtained by dividing the total number of pages in each book by the number of chapters or topics and then averaging these averages) is eleven pages. Putting it another way there are, on an average, twenty-eight units per book. This means that the year's work is divided up into twenty-eight parts and in an 180-day school year this would allow something around six days per unit which is not sufficient for long term assignments.

Criterion Four: Is the work adaptable to groups which have been differentiated on the basis of ability?

Only two of the seventh-grade books, two of the eighth, and one of the ninth, make provision for adapting the instruction to groups.

Criterion Five: Are special classes provided for? 
The textbooks do not provide for the work of special classes. Several of the schools do, as was indicated on the questionnaire, provide for special classes by supplying materials adapted to their needs.

\section{Unit Organization}

Criterion one: Are the units of an experiential nature rather than logical divisions of subject matter?

Since Caswell's and Campbell's clessification covers practically every type of unit, the various topics in the textbooks were subjected to their classification. It should be pointed out that the headings given in the table below do not always correspond exactly to those in the textbooks. For example the heading, "Positive and Negative Numbers," includes chapters whose exact title is, "Directed Numbers." It is believed, however, that the headings below represent the dominant theme of the topics and in doubtful cases care was exercised to make sure that the organization of the material itself, as well as the title, is predominantly logical or psychological before assigning the topic to either of these categories.

The classification here referred to consists of two principal categories with three subdivisions under each category. These are as follows: 
Caswell's and Campbell's Classification of Units ${ }^{l}$

I. Subject inatter Units

A. Topical

B. lieneralization

C. Significant Aspects of Culture or Environment

II. Experiential Units

A. Center of Interest

B. Pupil Purpose

C. Pupil Need

1. Cf. Caswell, H. L., and Campbell, D. S., Currriculum Levelopment, American Book Company, New York, 1935. Chapter $\bar{X} V$. 
Classification of the Units of Instruction Appearing in the sntire Fifteen Textbooks

I. Subject Matter Units (A) Topical, (B) Generalization, (C) Significant Aspect of Culture or Environment

II. Experiential Units (A') Center of Interest, ( $\mathrm{B}^{\prime}$ ) Pupil Purpose, (c') Pupil Need.

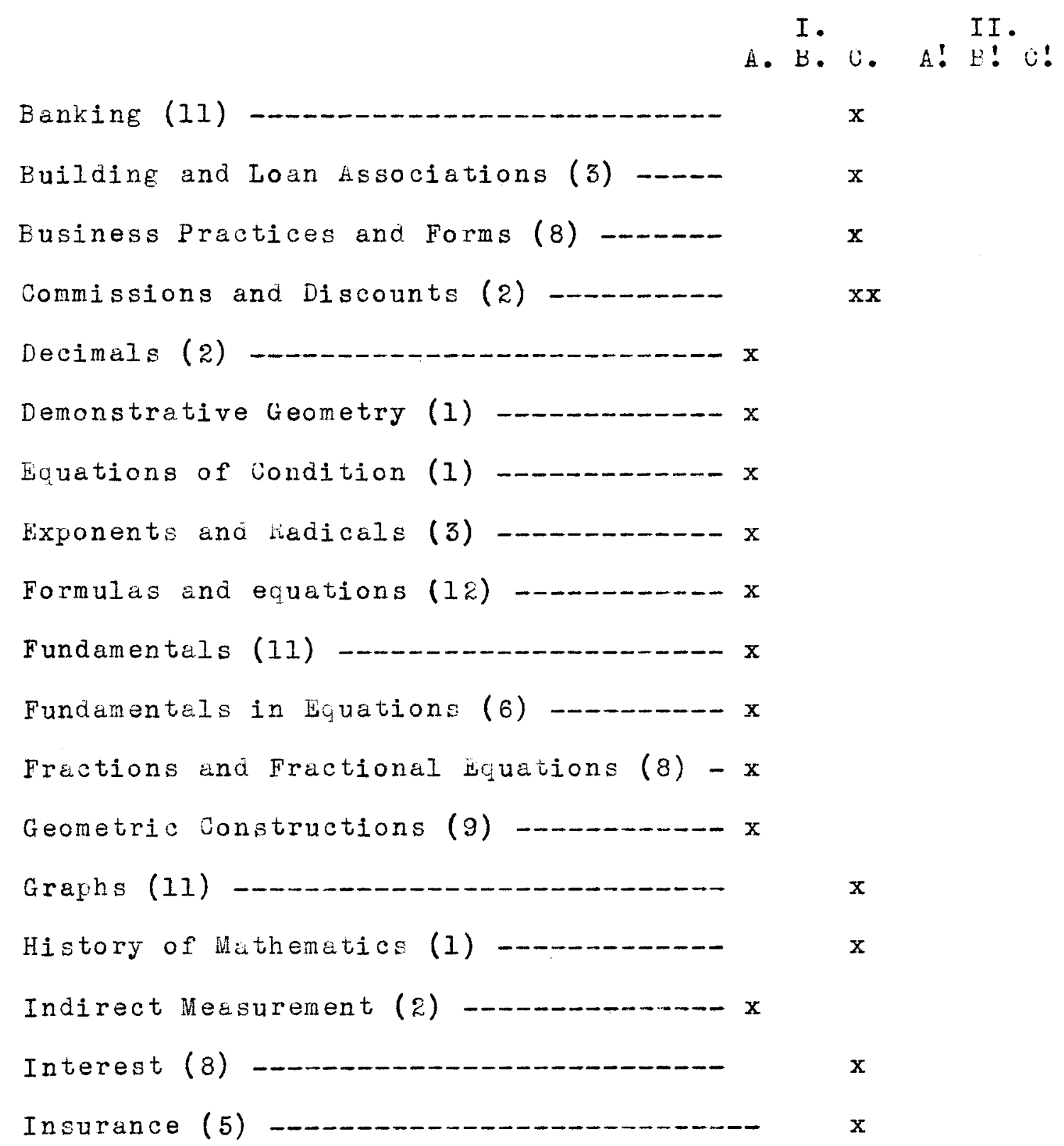


Classification of the Units of Instruction Appearing in the Entire fifteen Textbooks continued

I. Subject Matter Units (A) Topical, (B) Generalization, (c) Significant Aspect of Culture or Environment

II. Experiential Units (A') Center of Interest, (B') Pupil Purpose, (C') Pupil Need.

$$
\text { A. B. C. A II. } U \text { ! }
$$

Investments (

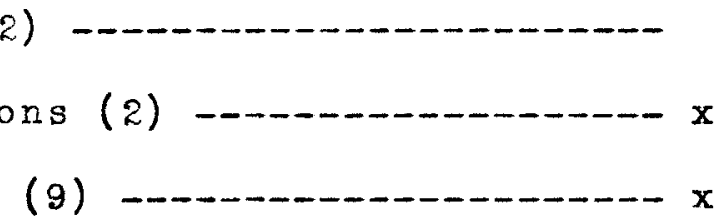

Lines, Angles (9) _....................

Literal Numbers (9) _..................... Means of Communication and Trsnsporta-

tion (3) -

Parentheses (3) -

Percentage (14) -

Postal Information (I) -

Problem Solving (7) _.

Problems of the fome -

Problems of the Farm and Forest _..... $x$

Ratio and Proportion (6) -

Simultaneous Equations (3) - . -

Special Products and Factoring (4) -... $x$

Squares and Square Roots (6) -

Taxation (5) - $\quad x$

Trigonometry (2) - 
It can readily be seen from the above table that practically all the units fall under the general heading of the subject matter type of unit and that most of them fall under the topical subdivision of this category. Only two units ere of the psychological type.

Uriterion Two: Are the objectives of the unit definitely stated?

Although some of the textbooks made general statements $r e-$ garding the purpose of each topic, none state definite, well defined aims.

Criterion Ihree: Are the units centered around some central theme or purpose?

As will be seen from the table in which the units are classified they are centered around central themes which are, however, small, isolated bits of learning.

Criterion Four: Can the learning products of the units be measured?

The units are largely factual, and this type of unit is by far the easiest to measure.

Assuming Responsibility for Attitudes and Ideals

Criterion 0ne: Is the aesthetic side of mathematics stressed by such topics as geometry in nature, in design of buildings, etc.? 
Such topics are confined almost wholly to the seventh and eighth grade textbooks. One seventh grade text devotes eight pages to such topics, another three pages, another two, another four, and the other textbook gives a rather adequate treatment of sixty-two pages. Of the eighth grade textbooks, one contains five pages of such material and another twenty-five pages. The others take almost no cognizance of the matter.

Criterion Two: Is attempt made to show how mathematics has contributed in the past and is contributing to the progress of mankind?

One seventh grade textbook contains three pages of the history of mathematics and another eight. Besides these two, only one textbook on any level deals with the history of mathematics and that book confines its treatment to the metric system.

As to attempting to show how mathematics is now contributing to progress, only one textbook on any level does so directly.

Criterion Three: Is pupil initiative stressed by providing optional or honor work?

Two seventh grade textbooks and two eighth grade texts make such provisions. Two ninth grade algebras and the general mathematics also provide for optional work. The other nine textbooks did not provide optional work.

Criterion Four: Is the rork adaptable to group cooperation? 
Except for the several topics already mentioned on informational subjects which might, in the hands of a skillful teacher, precipitate some class discussion, the work in these textbooks is largely an individual matter with the teacher-pupil relation dominant almost to the exclusion of class cooperation. To be sure any textbook can be used in cooperative work but definite provisions for such are not made in the textbooks.

Criterion Five: Are important social problems presented in such a way as to encourage the pupil to think for himself?

As has been shown in a previous section, socially important problems are largely lacking. When treatment is made at all it is largely from the computational rather than the conceptual standpoint.

Griterion Six: Is there material simple enough so that the slow pupil may experience a reasonable degree of success and, at the same time, is the superior pupil supplied with work that will challenge his best effort?

While some attempt has apparently been made to adjust the work to various levels of ability in some of the textbooks, it has not been done on a scientific basis. Also it is very doubtful whether or not the slow pupil will ever be able to experience success with textbooks which require such a large amount of reading. The brighter pupil hos been provided with more difficult problem work, but nothing has been done to determine whether such 
work challenges his effort.

Summary and Recommendations

While it is admitted that an analysis of textbooks used in the junior high schools of Kentucky does not give a complete picture of the curriculum it would seem to be the best available in the absence of courses of study. In this study comments made by the teachers on the questionnaire submitted to them were used to supplement the picture of the curriculum given by the textbooks.

Each of the tendencies will be summarized separately. The more general conclusions will be left for the final chapter of this study.

Fusion. Fusion has taken place in the junior high school mathematics curriculum for hentucky to about the same extent that it has throughout the nation as a whole. The seventh and eighth grade courses are typically general courses while the ninth grade courses are typically algebra. As pointed out elsewhere, it is probable that where a junior high school can offer only one course in the ninth grade it should be general mathematics rather than a specialized course.

It is further recommended that there should be a more genuine attempt to fuse the various branches of mathematics in these general courses rather than segregate them as is now done. Arith- 
metic, algebra, geometry, trigonometry, and statistics should be interwoven and blended rather than presented in tandem order.

Gontent. In planning a curriculum for junior high school mathematics, more attention should be given the matter of drill in the fundamental operations. No single textbook contains adequate provision for the development of these skills. Not only should the drill work be extended in quantity, but attempt should be made in preparing courses of study to scientifically construct this material. Informational topics should be taught more from the standpoint of the consumer. The emphasis should be more on the conceptual and less on the mechanical.

The various branches of mathematics are represented in the general courses in about the same proportion that is typical of the nation as a whole as revealed by the studies mentioned. However, trigonometry and demonstrative geometry should be given some place in planning courses of study as they have not been done in most of the textbooks.

The content of the algebra textbooks is typical of practice elsewhere.

Suantitative Thinking. Neither have socially significant problems been presented nor have proper techniques been offered to deal with such problems. More socially significant data should be supplied the pupil and such computational and statistical technicues as will enable him to comprehend these problems should also 
be furnished. Graphs afford a splendid opportunity for presenting social problems and such simple statistical devices as means, median, mode, frequency tables, etc. should be emphasized.

It is evident from the textbooks that little attention has been paid to what may be termed "number sense." In constructing new courses of study such devices as rounding off numbers, arranging disorderly arrays of figures of both whole numbers and fractions, and estimating answers before deriving them should be abundant.

Utilitarianinism. The textbooks revealed that the topics recommended for elimination by the various committees have been carefully omitted. The decimals rarely exceeded four places and obsolete terms and tables do not appear.

Problems involving the algebraic equation should be of a more practical nature in accordance with the criterion of utility. Puzzle problems should be largely eliminated. Percentage affords a splendid opportunity for employing the equation in a practical situation.

Mathematics of the home is largely confined to a fert types of problems and the vork is too largely manipulative. More of the larger concepts of home life should be considered such as the financial relationship between parents and children, the economic relationship between the home end the community, etc. 
While some attempt at correlation between mathematics and the other school subjects has apparently been made there is a large opportunity for further correlation. It is probable that transfer of training is dependent upon indentical elements and therefore there should be introduced into the mathematics courses specific problems that relate to the other subjects rather than teaching the pupil general technicues in the hope that he will be able to apply them to any new situation. Shop problems, problems from the social studies and from the fine arts should be considered quantitatively in the mathematics classroom.

Function. Perhaps no single recommendation of the National Committee has been so greatly neglected as the matter of teaching the concept of function. It should be emphasized and reemphasized in concrete situations throughout the courses by the means of tabulations, graphs, formulas and equations, and by every other means available. This is one of the most important contributions that mathematics has to make toward the understanding of our environment.

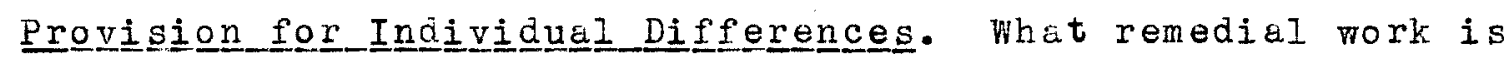
offered in the textbooks is adaptable to individual instruction. However, as has already been shown, the amount of such work is insufficient and no serious attempt to construct the drills scientifically is in evidence. The work in the textbooks is adaptable to directed study but unfortunately the unitg are, on the whole, too brief to warrant long-term assignments. In construct- 
ing new courses of study for Kentucky some attempt should be made to form larger divisions of subject matter units. Also the courses of study should be definitely planned for classes segregated according to ability.

Unit OOrganization. It has been shown that nearly all the so called "units" which appear in the textbooks are merely logical divisions of subject-matter. In planning new courses of study for Kentucky there should certainly be found some more psychological basis for organization. If conditions are such that large lifefunctioning units which disregard subject-matter lines cannot be made the basis of the junior high school curriculum then it remains for the mathematics courses of study to outline units of instruction as life-like and as inclusive as the subject itself permits. They should be centered around vital concepts.

Not only should the units be psychologically conceived but the objectives of each unit should be so definitely stated that these objectives could be used as a basis for examining the learning product. Obscure aims couched in uncertain terms are of little help. The purposes of the unit must be known not only to the teacher but likewise to the pupil.

Assuming Responsibility for Attitudes and I Ideals. The aesthetic side of mathematics has been given some attention in the textbooks, but more emphasis should be given this matter. The pupil should be brought to see the relation of mathematics to 
every worthy undertaking of society. But the responsibility for forming attitudes and ideals does not stop here. Self-reliance, cooperation, tolerance, and other traits should be definitely planned for.

Attitudes and ideals can best be developed by activity and courses of study should provide for much activity and for the exercise of much initiative on the part of the pupil. They should not overwork, as do these textbooks, the teacher-pupil relation but should provide for group activity and group cooperation. The teacher should progressively drop into the background. Pupils should be made to think about important social problems and to draw their own conclusions. This cannot be done unless there is provision on the part of the curriculum for presenting these problems and supplying the pupils with data and tools with which to work.

\author{
AN EVALUATION OF THE LOUIEVILLE CURRILULUM \\ AS KEVEALED EY THE COUREES OF STUDY
}

\title{
Introduction
}

The courses of study for grades seven, eight, and nine in general mathematics and for ninth grade algebra were analyzed in the light of the criteria. A list of these courses of study appears in the bibliography. 
Fusion

Criterion One: Are the courses offered in mathematics of the general type rather than of the type that treats of a single branch of methematics?

General mathematics is offered in grades seven, eight, and nine. It is required in the seventh and eighth and is an elective in the ninth the alternate being algebra.

Criterion Iwo: Are the algebraic formula and equation used throughout the course rather than confined to isolated chapters?

The formula and equation are confined, in the general courses, almost wholly to chapters dealing with them primarily. Some work with formulas is done in connection with percentage problems although the opportunities are by no means exhausted. In treating the three cases of percentage there is a splendio opportunity for using the equation to an advantage that has been neglected.

Criterion_Three: Are graphs and other statistical procedures used throughout the course rather than being confined to isolated chapters?

In the seventh and eighth grades there are spearate chapters devoted to graphs and the work with graphs is confined largely to these chapters. In the ninth grade the work with graphs is given principally in the unit entitled "Interpreting Large Numbers". While most of the work with graphs given in the ninth grade gen- 
eral course comes in this unit other applications of the graph are made in the unit on "Personal school and Home Problems," in the unit on "Formulas and kquations," and in the optional unit on "The Money Value of Life and Health." A spearate unit in the algebra course treats graphs of linear systems.

Criterion Four: Are the geometric figures and constructions used throughout the course rather than confined to isolated chapters?

They are confined almost wholly to isolated chapters or units. However, one or more units dealing with the geometric figures and constructions or with the geometric figures is offerer each semester throughout the entire three years in the general courses.

\section{Content}

Criterion One: Are the fundamental processes adequately provided for?

The courses of study for general mathematics for the entire three years give careful attention to the fundamentals. As a further means of guaranteeing adeduate provision for the fundamentals there is a separate course in remedial mathematics for those pupils on any level who need special attention in this regard.

Criterion Two: Is informational arithmetic stressed? 
The unit on, "Business Oses of Percentage" in the seventh grade; those on "Banks and Banking," "Investments," "Insurance," and "Taxes" in the eighth; and those on "Personal, school and Home Problems" in the ninth all treat informational topics.

Criterion Three: Is a considerable proportion of the mathematics for the three years intuitive geometry?

In the seventh grade the units on nMeasurement, " nixperimental Geometry, " and on "freas, Perimeters, and Volumesn are suggested to consume fifteen weeks out of a total of thirty-two or approximately forty-seven per cent of the time. In the eighth grade the units on "Measure of Lines and Angles" and "Measure of Areas and Volumes" are suggested to consume nine weeks or approximately twenty-eight per cent of the time, and in the ninth grade the unit on "Geometric Forms and Principles" is suggested to consume four weeks or approximately twelve and one-half per cent of the total time.

Criterion_Four: Is some trigonometry included either in the eighth or ninth grade?

The ninth grade course in general mathematics includes a unit on the right triangle which introduces the student to the tangent and sine functions. Trigonometry is omitted from the ninth grade algebra course.

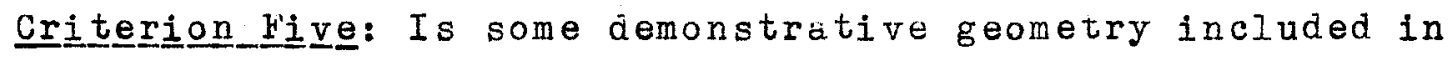


either the eighth or ninth grade?.

The ninth grade general course devotes a unit to "leometric Forms and Principles" in which some demonstration is included. Demonstrative geometry is not included in the algebra course.

Criterion_six: Is a considerable proportion of the work for the three years algebra?

Practically no algebra is taught in the seventh grade except in connection with the mensuration of geometric figures. Approximately twelve and one-half per cent of the time in the eighth grade course is devoted to algebra in the unit on "Formulas and Equations" and approximately twenty per cent of the time in the ninth grade general course is devoted to the two units, "Formulas and Equations" and Signed Numbers". The ninth grade algebra course is, to be sure, almost altogether algebra.

$$
\text { Quantitative Thinking }
$$

Qríterion One: Are significant data presented for quantitative treatnent?

Many of the graphs treat of socially significant data although as many do not. Such subjects as the distribution of Louisville taxes, fire prevention, and heulth and safety are of social value. However, many of the subjects treated such as areas of the various continents, length of rivers, amount of corn produced, etc. are of little social value. 
Criterion Iwo: Áre statistical procedures stressed?

There is a unit on "Statistics" in the ninth grade which deals with such concepts as average, median, mode, measure of central tendency, frequency distributions, etc. Graphs are taught in units in each of the three years. The criticism might be made, however, that statistical procedures are not used to a great extent except in the units particularly devoted to them.

Criterion Three: Is provision made for class discussion of socially important concepts from a quantitative standpoint?

The informational topics offer opportunity for class discussion although, as it will presently be shown, socially important concepts have been relegated to a secondary place in favor of computational techniques.

Eriterion Four: Are pupils provided with techniques for estimating answers before deriving them in order to develop "number sense?"

While numerous methods are provided for checking answers, there is comparatively little work in estimating answers before deriving them. More attention should be paid this matter.

Criterion Five: Is number sense developed by providing practice in rounding off numbers?

Rounding off numbers is included in the seventh, eighth, 
and ninth grade in connection with graphs and interpreting large numbers. More work of this kind, however, needs to be given. In an age when even the average citizen must consider numbers which run into millions this cannot be stressed too much.

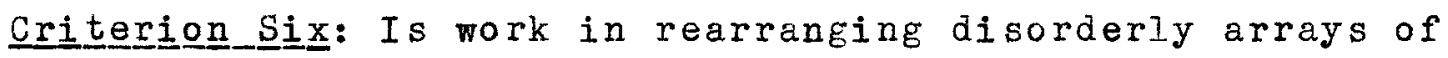
figures included?

This is definitely provided for in the seventh grade in the unit on "General Review of Fundamentals" with whole numbers, fractions and decinals. It is again stressed in the ninth grade.

Eriterion Seven: Is transposition (a purely mechanical device) taught only after the concept of balance in the equation has been stressed?

Transposition is not taught at all. The idea of balance in the equation and the concept that one process may be undone by performing the opposite process is stressed throughout all the courses which treat the algebraic equation.

\section{Dtilitarianism}

Criterion one: Have impractical materials such as the following been eliminated?

(a) Unusual weights and messures? Work is confined in the Louisville courses to the common weights and measures. Apothecaries' measures, 


\section{3}

troy weights, etc. have been eliminated. The metric system is taught but this would seem justifiable since it is largely from the appreciative point of view.

(b) Unwieldy decimals?

Decimals are confined to five places. Probably most work in decimals on the junior high school level should not be carried further than four decimal places.

(c) Unusual aliquot parts?

The aliquot parts are confined to halves, thirds, fourths, fifths, and their multiples. Unusual ones such as one-seventh, one-ninth, and others have been eliminated.

Criterion Two: Have puzzle types of problems been eliminated in teaching algebra?

Out of sixty-six problems in the unit on "Equations" in the ninth grade, only eight are of the type that make some practical application of the ecuation. The work in this unit on applications of the formula to percent is to be commended. In the algebra course many of the problems also are of the puzzle type.

Criterion Three: Are pupils encouraged to bring in problems about which they are concerned for solution?

Except for such suggestions as bringing in business forms, 
gas bills, geometric designs, etc. the pupils are not called upon to bring their own problems to class for solution.

Eriterion Four: Is the mathematics of the home stressed?

Home budgets, accounts, home management, purchasing, home supplies, home economy, and thrift are treated. Ihe criticism might be made that the work is largely from the standpoint of the adult rather than from the child as a member of the home.

Criterion Five: Is there content which is definitely useful to the student in other subjects?

Science. The simple machines are treated. The work with equations in the ninth grade contains some good material on showing the concentration of mixtures.

Social studies. The chapters on "Taxation," "Insurance," "Banking," and other informational subjects should assist the pupil to get a notion of the social factors involved. It is unfortunate, however, that these topics are treated more from the computational standpoint rather than with the idea of bringing out large quantitative concepts.

English. Except for incidental practice in oral and written expression, and in reading there is little that would contribute to English.

Shop Work, Mechanical Drawing and Domestic Arts. The practice in measurement and the work with the geometric figures ought 
to assist the pupil in his shop work. Also there are sections of exercises that deal directly with shop problems. Scale drawing and geometric constructions ought to aid the student of mechanical drawing. There are numerous problems which relate directly to economics in relation to the home. 0ther problems deal with recipes, purchasing of goods, etc.

Art and Music. The geometric designs should contribute to the art course. There are no materials that apply directly to music.

\section{Function}

Criterion $\underline{\text { nne: }}$ Is provision made for tabulation of related data in such a way as to bring out the correspondence?

Except for a fer such exercises in grade nine, this sort of tabulation has been entirely neglected.

Qritererion Two: In the formula is the affect of one variable upon another stressed?

Little direct concern has been given this matter.

Criterion Three: Are functional graphs stressed?

Functional graphs are almost entirely neglected. There is an extended treatment of them in the eighth grade textbook used in Louisville, but this work has been omitted from the course of study. Some slight attention is given functional relations ex- 
pressed graphically in the ninth grade course. Graphs of formulas and equations are functional and these are included in both ninth grade courses.

Oriterion Four: Is the dependence of one variable upon another stressed throughout the course?

It is very doubtful whether or not the pupil gets the full meaning of dependence unless it is constantly directed to his attention. This is not done in the courses of study although some teachers may do so.

Criterion Five: Is there a special unit or section of a unit devoted to dependence?

No such unit or portion of a unit appears.

\section{Individual Differences}

Criterion One: Is the remedial work readily adaptable to individual instruction?

There is a special course in remedial mathematics which is especially designed to provide the maximum of individual attention.

Eriterion Two: Is the work so arranged as to make practical directed study?

The courses are especially designed for use of the hiorrison 
technique of directed learning.

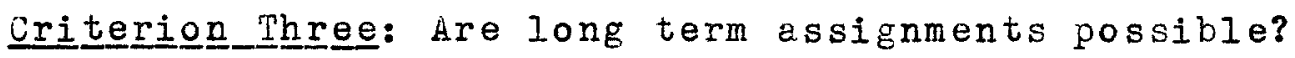

The average length of the units is between three and four weeks making possible long term assignments due to this fact and to the fact that the units are centered around some central skill or technique.

Criterion Four: Is the work adaptable to groups which have been differentiated on the basis of ability?

Special provision has been made for slow groups and for optional work for superior classes in addition to the remedial course already described.

Criterion Five: Are special classes provided for?

The junior high schools all contain special or ungraded classes in which mathematics is given careful attention.

\section{Unit Organization}

Qriterion one: Are the units of an experiential (or psychological) nature rather than logical divisions of subject matter?

All the units for the junior high school courses of study are listed below and classified. Where a unit appears on more than one level, it was entered but once in the table and the number of times it appeared is indicated in the parentheses. 
A Tabulation of the Units of Instruction in the Louisville Courses of Study According to Caswell's and Campbell's Classification.

I. Subject Matter Units (A) Topical, (B) Generalization, (c) Significant Aspect of Culture or Environment

II. Experiential Units (A') Center of Interest, (B') Pupil Purpose, (c') PupiI Need.

Name of Unit

Areas, Perimeters and Volumes $(z) \ldots . . . x$

Banking (2) $\ldots \ldots \ldots \ldots \ldots \ldots \ldots \ldots \ldots$

Business Practice (2) ................

Experimental Geometry............. x

Formulas and Equations $(3) \ldots \ldots \ldots \ldots$.

Fractions (in Equations) (I) .........

Geometric Forms and Principles (includ-

ing Demomstration) (1) ...........

Graphs (2) $\ldots \ldots \ldots \ldots \ldots \ldots \ldots \ldots \ldots$

Graphs and Linear Systems (2) ........

Insurance $(1) \ldots \ldots \ldots \ldots \ldots \ldots \ldots \ldots \ldots \ldots$

Interpreting Large Numbers (1) ........ $x$

Measurements $(2) \ldots \ldots \ldots \ldots \ldots \ldots \ldots \ldots$.

Money Value of Life and Health (1).... $x$ Multiplication, Division, Equations,

Problems (I) $\ldots \ldots \ldots \ldots \ldots \ldots \ldots \ldots$ 
A Tabulation of the Onfts of Instruction in the Louisville Courses of Study According to Caswell's and Campbell's Classification Continued.

I. Subject Matter Onits (A) Topical, (B) Generalization, (C) Significant Aspect of Culture or Environment

II. Experiential Units (A') Center of Interest, (B') Pupil Purpose, (C') Pupil Need.

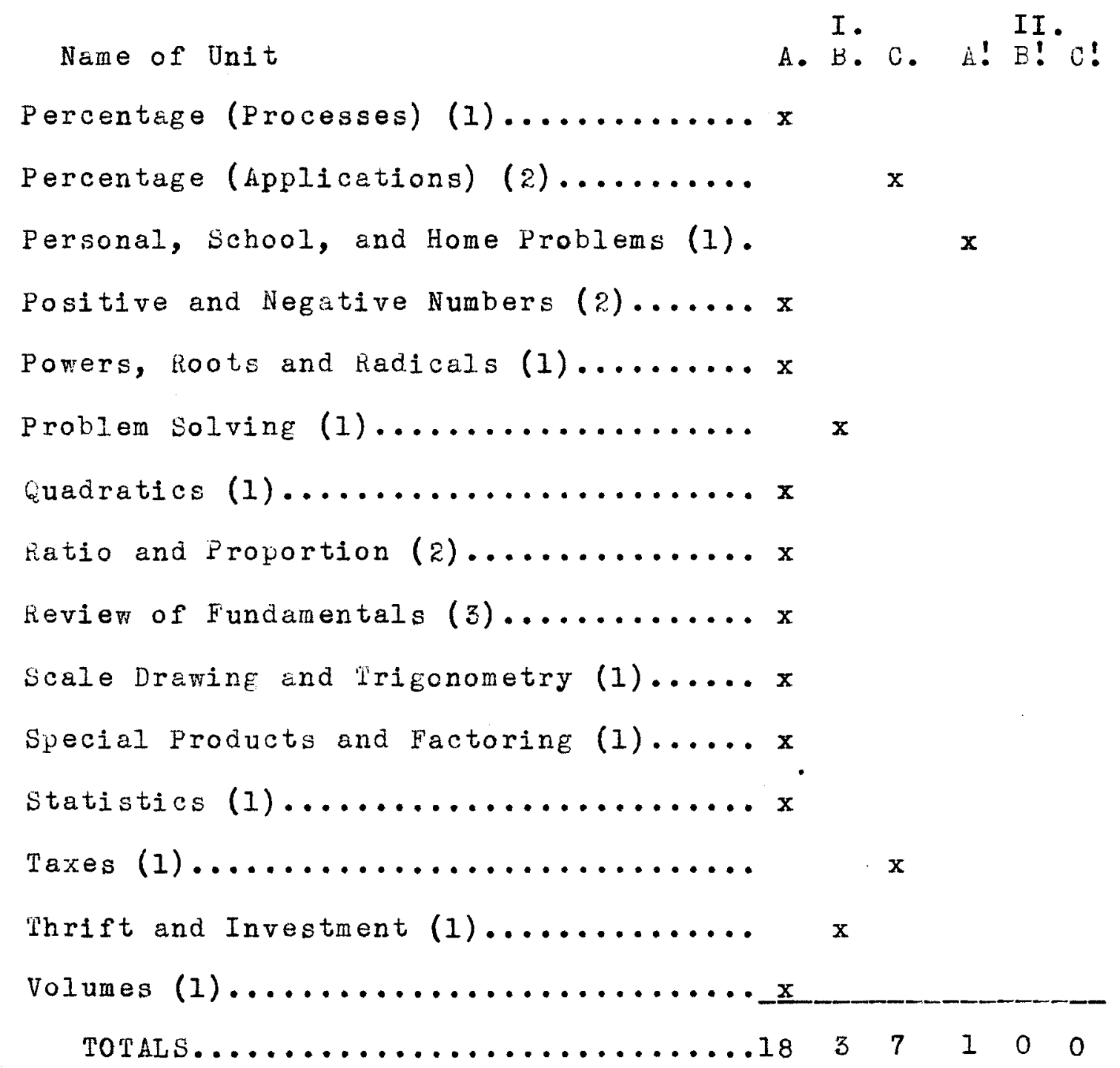


Practically all the units are of a subject-matter type. Eighteen of the entire twenty-nine units are topical. Only one unit could be classified as experiential.

Criterion Two: Are the objectives of the unit definitely stated?

Each unit contains definite objectives in terms of pupil accomplishments. In eddition, the seventh and eighth grade courses contain very detailed lists of skills and understandings which are to be commended.

Criterion Ihree: Are the units centered around some central theme or purpose?

As has already been shown nearly all of the units are of a subject-matter type and most of these are topical in arrangement. Such units while built around a central theme are usually too narrow in scope to provide for pupil purpose. It is difficult to conceive of a pupil adopting the mastery of a narrow logical division of subject matter as a goal unless he can see how it will aid some purpose already present in his mind.

Critererion Four: Can the learning products of the units be measured?

The logical type of unit is most easily measured. The tests provided would appear to measure the products of the units effectively. 
Assuming Responsibility for Attitudes and Ideals

Criterien 2ne: Is the aesthetic side of mathematics stressed by such topics as geometry in nature, in design of buildings, etc.?

Some slight attention is paid the geometry of design and geometry in nature in the general courses for grades seven, eight, and nine. In the writer's opinion more could be done along this Iine. Hore concrete examples lifted bodily from the courses in applied arts could be included.

Criterion Iwo: Is attempt made to shom how mathematics has contributed in the past and is contributing to the progress of mankind?

There is a brief account of the history of geometry in the ninth grade general course and several references to the part mathematics has played in the development of civilization throughout all the general courses. Opportunities, however, have by no means been exhausted. Almost every unit provides a setting for bringing out the social contributions of mathematics.

Criterion Three: Is pupil initiative stressed by providing optional or honor work?

Nearly all the units present material to be covered only by the exceptional student, and there are several entire units intended only for the accelerated pupil. 
Criterion Four: Is the work adaptable to group cooperation?

The teacher-pupil relation has been considerably overworked. The work-sheet technique which is emphasized in the Louisville courses is subject to this danger. Few real cooperative projects for the class as a whole are provided.

Criterion Five: Are important social problems presented in such a way as to encourage the pupil to think for himself?

There are too few socially significant problems offered and many of these are treated largely from the computational standpoint. Such major problems as unemployment, prevention of war, old age security, etc. are not considered and hence the pupil is not encouraged to think about such issues. It may be argued that these problems are for the social studies rather than for mathematics, but they all contain cuantitative relations which would seem best conceived of with the aid of mathematical techniques.

Criterion Six: Is there material simple enough so that the slow pupil may experience a reasonable degree of success and, at the same time, is the superior pupil supplied with work that will challenge his best effort?

While the material offered has not been subjected to controlled experimentation thus determining its difficulty, a wide range of difficulty is provided and especial provision has been made for the slow pupil in the remedial course which consists 
almost entirely of drill work in the fundamentals. For the exceptionally bright pupil, it is questionable whether or not equal provision has been made in the general courses. However, as a rule these pupils are encouraged to take algebra instead of the generel course in the ninth grade. The present testing program which has been in operation for several years is supplying data which can eventually be used as a gauge of the difficulty of the material offered.

SUMAARY OF THL LOUISVILLE LURRICULUM

Eusion. Louisville offers general courses throughout the three years of the junior high school period. In the ninth grade there is a choice between general mathematics and algebra.

The general courses are not, however, examples of complete fusion. The various branches of mathematics should be more completely interwoven.

Content. The fundamentals are adequately provided for. Much informational material is provided which is, however, treated too largely from a computational standpoint. The proportions by which the various branches of mathematics are represented compare favorably with practice elsewhere. Less algebra is offered in the seventh and eighth grades than is typical.

Quantitative Thinking. There should be included more data of a nature that is socially significant. Statistical procedures 
should be used throughout the courses rather than merely appearing in segregated units. More attention should be paid techniques for estimating answers in order to develop "number sense." Other means toward this end have been carefully included.

Utilitarianism. Wiliminations of obsolete terms, impractical measures, and unwieldy decimals have been made although some problems call for the use of five decimal places. The puzze type of algebraic problem appears too frequently. The applications of the formula in percentage is commendable. Pupils should be encouraged to bring in more problems of their own for solution. Mathematics of the home has been given considerable attention, but it is suggested that the work might be more from the standpoint of the child. Some correlation between mathemetics and the other subjects is apparent but more could be done along this line.

Function. While function is implied in many cases it is important that definite emphasis should be given this concept if the pupils are to come to understand its significance.

\section{Provision for Individual Differences. The remedial work} has been designed with the individual in mind. Long term assignments are provided for and optional work and special classes all assist in adjusting the work to the individual pupil.

Unit organization. Nearly all the units are of a topical nature. A more psychological approach is desirable. "the objectives are, none the less, definitely stated; the units are cen- 
tered around some central theme, and the outcomes are measurable.

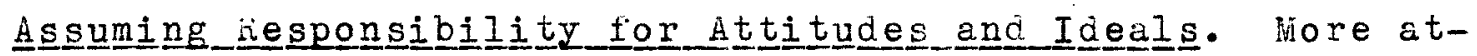
tention should be given the aesthetic side of mathematics and more stress laid on the importance of mathematics to mankind. Pupil initiative has been provided for through optional work. Less emphasis should be placed upon the pupil-teacher relation and more upon class cooperation. More significant social problems should be presented. There is a wide range in the difficulty of the work offered which tends to provide for the low pupils and at the same time challenge the best efforts of the superior pupils. It is believed that a more scientific gauging of the difficulty of the work can be achieved after the present tesing program has been in operation somewhat longer. 
CHAPTER VIII

GONGLUSIONS 
CHAPTER VIII

CONULUSIUNS

Introduction

The purpose of this study has been to evaluate the present mathematics curriculum in the junior high schools of Kentucky and to suggest ways for its improvement. In order to accomplish this purpose a backgroung was first presented which consisted of a brief history. of junior high school mathematics; of the opinions of experts in the field; and of a presentation of practices of forward looking schools elsewhere. As a complement to this background a questionnaire study was made of the conditions of organization under which mathematics is being taught in Kentucky. The final step was to evaluate the curriculum of Kentucky and of Louisville by means of analyses of textbooks, courses of study, and comments made by the teachers on the questionnaires.

Conclusions Drawn from the History of Junior High School Mathemstics

From the historical sketch the following conclusions were gleaned regarding junior high school mathematics. First, there has been a gradual pushing down to the secondary level mathematics which was taught formerly only in higher education. Second, this necessitated a new approach in the teaching of mathematics 
and hence fused or general courses came into being. Third, obsolete topics in arithmetic were replaced with intuitive geometry and simple algebra. Fourth, the junior high school was the institution which most readily adopted these changes.

\section{Conclusions Drawn from the Guestionnaires}

Regarding the Organization and the Teachers of Mathematics

From the guestionnaire study of the conditions of organization under which mathematics is being taught in the junior high schools of kentucky the following facts were gleaned.

Twenty-two junior high schools were found which qualify under the definition assumed in the first chapter. The enrollment of fourteen of these schools exceeds 500 pupils. Lighteen of the schools practice homogeneous grouping. Only three of them are limited to grades seven and eight while the remaining schools contain these grades and, in adition, grade nine. All of these data indicate that the general organization of these schools is such as to make feasible the operation of a thoroughly revised mathematics curriculum.

General mathematics is at present offered in grades seven and eight in all but one of the schools and is recuired of all pupils. It is obvious that in planning new courses of study for the state that general mathematics should be the offering provided for these levels. In the ninth grade there is less uniformity since the schools are ecually divided between offering 
only algebra and offering a choice between algebra and general mathematics. If only one course is to be planned for the ninth grade it would appear that general mathematics is preferable for the majority of students. Perhaps it will be necessary to plan for both courses at this level, however, in view of the present emphasis upon algebra.

Forty-five and fifty minute periods of instruction are typical, so that in constructing new courses of study it would appear advisable to go upon this assumption.

Teachers of mathenatics have had sufficient training both in general preparation and in education and mathematics in particular to warrant their being able not only to utilize a modern course of study but also to assist in the construction of such. Only six teachers reporting on the questionnaire have less training than that represented by the Bachelors degree and a consiaerable number have reached the Masters level. Not only heve the teachers had this training but have also had considerable experience in teaching mathematics as sixty-nine per cent of them have had more than five years experience.

Also the responses of these teachers to the ten issues of secondary education indicate that they are alert to the problems confronting education today.

Conclusions Conerning the Curriculum

From the writings of experts and from accounts of curricu- 
lum practices from forward looking schools throughout the country certain tendencies in junior high school mathematics were noted, and these were used as a busis for evaluating practice in Kentucky.

It is recognized that analyses of textbooks and of courses of study do not give a complete picture of the curriculum but they would appear to supply the best description obtainable. It is further admitted that the evaluation which has been made of the curriculum is limited by the sources from which the criteria were obtained, namely from the writings of experts and from the practices of forward looking schools in other localities.

Fuㅗiㅡㅁㅡ: First among these is the tendency toward fusion. It was found that expert opinion and contemporary prectice in exceptional schools favor general courses rather than specialized courses in arithmetic, algebra, geometry, etc. for the entire three years of the junior high school period. some authorities advocate a further step and urge that subject matter lines themselves be disregarded and that large areas of instruction be set up which draw upon all subjects as they cen contribute to end in view. Such a plan has been put into operation in such schools as those of the state of Virginia. The Kentucky curricuIum leaves much to be desired in this regard. As has already been shown, only ten schools offer general mathematics in the ninth grade and in none of these schools is it required of all students. None of the schools has gone so far as to fuse math- 
ematics vith other subjects. Where fusion has taken place in the form of general courses it has been more or less of a superficial nature. A more genuine fusion is to be desired.

Content: Certain definite tendencies were also noted regarding the content materials for the courses offered in the junior high school. Both expert opinion and contemporary practice point to the trend of including arithmetic, intuitive and demonstrative geometry, algebra, trigonometry, and statistics. 'Hese various branches of mathemsics are represented in the Kentucky curriculum in about the same proportion as was revealed by titclormick's study of textbooks used generally throughout the nation. For example, intuitive geometry consumes approximately nineteen and one-fifth per cent of the space in the eighth grade textbooks used in Kentucky while Mccormick found the percentage to be twenty-one and one-half per cent for the texts he analyzed. The Kentucky textbooks devote about twenty per cent of their space to algebra on the same level which also compares favorably with national studies. The major criticism that may be made against the content of the curriculum as revealed by an analysis of the textbooks is that there is inadeouate provision for the fundamentals. In this regard the Louisville curriculum is a notable exception.

Quantitative Thinking: Another tendency established as a trend is the emphasis upon quantitative thinking and avey from mechanical manipulation. The curriculum in Kentucky as revealed 
by an analysis of the textbooks shows that neither has there been presented significant social problems about which the student may think nor has there been the technigues provided with which to attack these problems. Even the Louisville courses leave much to be desired in this regard.

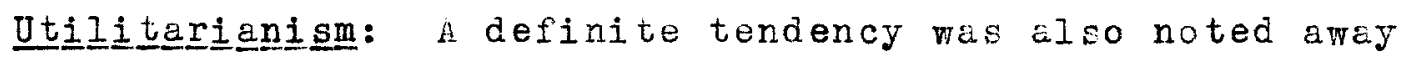
from disciplinary ains and in the direction of utilitarianism conceived of in its broader sense. The consensus of opinion of authorities and better practice agree that work should not be merely difficult for difficulty's sake but that it should have real social utility. The Kentucky curriculum woulc be greatly improved if there were femer of the "puzzlel tyre of problems especially in algebra, and more practical work of a social nature were introduced. AIso there should be a great wealth of problem material from other studies, particularly science, social studies, and the applied arts.

Function: Lxperts have advocated for over a cuarter of a century the making of the functional relation the one unifying concept in junior high school mathematics. None the less, practice has been slow to follow theory and in this kentucky and Louisville are no exceptions. It cannot be emphasized too strongIy that in this day of rapia change the dependence of one factor upon another is of great importance and is perhaps the one outstanding contribution that mathematics has to offer toward the understanding of our environment. 


\section{2}

Individual Differences: Writers have long emphasized the necessity for providing for the individual. The National survey of Secondary Education declared that in the schools surveyed the three most widely used means of providing for individual differences are homogeneous grouping, some form of the unit assignment, and special classes. In Kentucky eighteen of the twenty-two schools practice homogeneous grouping. Only half of the schools maintain special classes. Hxcept for the Louisville courses of study there was little evidence of long term unit assignments. This feature should be included in constructing new courses of study for Kentucky. Also it is urgent that remedial mork be planned in such a way as to be readily.adaptable to individual instruction.

Unit Organization: There is wide diversity of opinion and a multiplicity of practices regariing what should rightfully be considered a unit of instruction. Conceived of in its broadest sense a unit is a mere logical division of subject matter but in a stricter sense it constitutes a new attempt to teach the child rather than to teach subject materials. It was shown that the curriculum in Kentucky at large and in Louisville has been organized according to the unit plan only on the former sense. Real life-functioning units which start with the needs anc interests of the pupil are almost non-existant. Only complete and revolutionary reorganization of the curriculum can manifest the best traits of the tendency toward real unit instruction. 


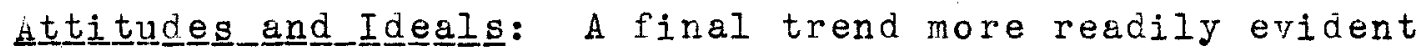
in theory than in practice advocates the assumption by the school of the responsibility for something more than the teaching of facts and declares that the school should also attempt to construct in the pupils emotionalized attitudes and ideals. While almost all educators would subscribe to this ioea, it was found that practically all the emphasis in the Kentucky curriculum in mathematics for the junior high school is upon facts and little attention has been given to the forming of attitudes and iadas which will contribute to the social well being. The teacherpupil relation is greatly overworked. keal initiative on the part of the pupil and wholesome cooperation among pupils are not provided for.

The above summary contains only the more general recommendations and criticisms. The more detalled comments appear in the various chapters which constitute this thesis.

\section{Indirect conclusion}

Aside from the conclusion directly in line with the purpose of this sudy the following indirect conclusion may be drawn. This study supplies evidence that textbooks are not to be relied upon for having had incorporated in them tre most recent ideas about the curriculum. Phis is a resonable inference since textbooks are designed to meet the needs of a wide range of teaching situations and cannot, therefore, be too progressive 


\section{Suggestions for Further study}

This thesis has concerned itself with the mathematics curriculum as it relates only to the junior high schools of Kentucky. Since it is probable that schools on the traditional eightfour plan will use the same courses of study for grades seven, eight, and nine as are used by the junior high schools, a simiIar study might well be made of the present curriculum for these grades in such schools.

This study has organized criteria which should be useful in making a comparative study of junior high school textbooks in mathematics or of courses of study.

It was the assumption of this thesis that the criteria for evaluating the curriculum should be drawn from two sources. These are the opinions of experts and accounts of practices in schools elsewhere. Since these are not the only sources from which criteria can be obtained, it would be very much worth while if a similar study could be made with criteria obtained from such a source as the mathematical needs and interests of children of the junior high school age. 
BIBLIOGRAPHY 


\section{BIBLIOGRAPHY}

Books and Monographs

Billet, Roy 0., Provision for Individual Differences. Marking and Promotion, Bulletin 1932, No. 17, Monograph No. 13, U. S. Office of Luducation, Washington, D. C.

Briggs, Thomas H., The_Juni으_High_School, Houghton Mifflin Company, Eoston, 1920 .

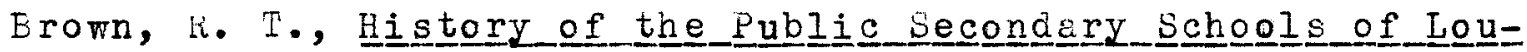
isville, Kentucky, 8 master's thesis on file at the University of Kentucky, Lexington, Kentucky, 1935 .

Cajori, F., Ihe leaghing and History of Onited states, U. S. Bureau of Education, Washington, D. C., 1890 .

Campbell, W. T., Observatienal Geometry, American Book Company, New York, 1899 .

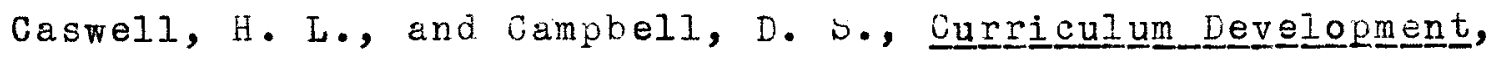
American Book Company, New York, 1935 .

Colburn, Warren, 트 Intróduction to AIgebra Upon the Inductive Methoㅁ, Hilliard and Company, Boston, 1825.

Davies, Charles, 티 ementenary Algebra․ A. S. Earnes and Company, 
New York, 1854

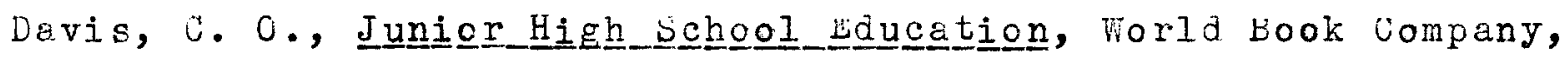
New York, 1925 .

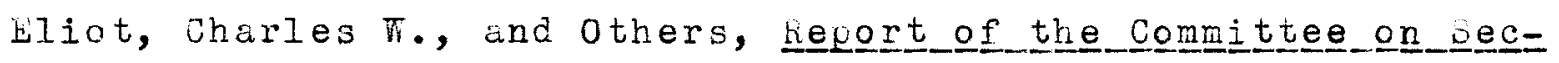
ondary schhool_studies, Bureau of Hucation, Tashington, D. G., 1893 .

Failor, I. N., InventioneI Geometry, A. S. Earnes \& Company, New York, 1904 .

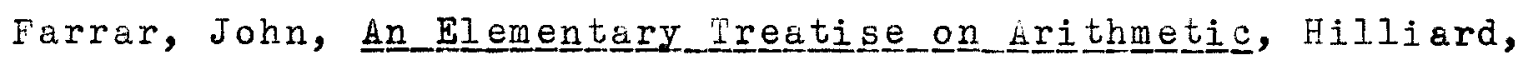
Gray and Company, Boston, 1834.

Harap, Henry, Ihe I'echnicue of iurriculum I an Company, Nev York, 1928.

Judy, R. P., Ihe Reorganization of jecondary Eaucationg, a master's thesis on file at the University of Kentucky, Lexington, Kentucky, 1929 .

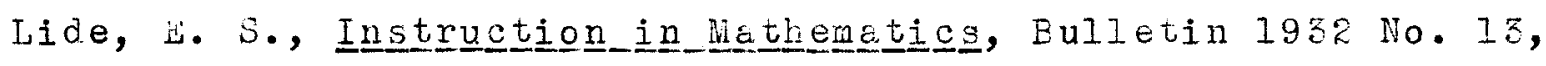
Monograph No. 17, U. S. Office of tuducation, Fashington, D. U.

Mclormick, Clarence, Ihe Teaching of lieneral Nathemitice in the

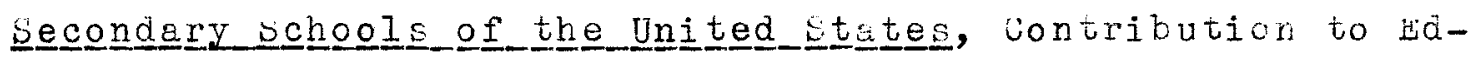
ucation No. 386, Bureau of Publications, Uolumbia University, New York, 1929. 


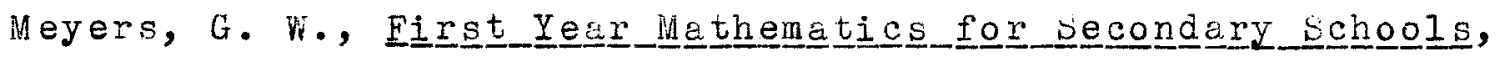
University of Uhickgo Press, Uhicago, 1906.

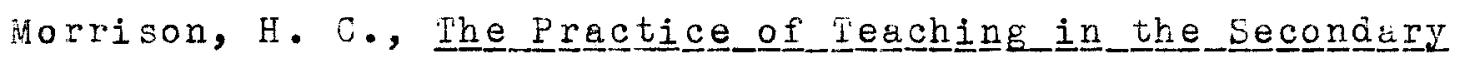

School , The University of Chicago Press, Chicego, second Edition, 1931.

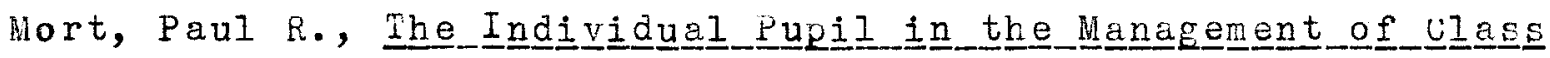
and $\underline{\text { sech }}$ 으으, American Book Company, New York, 1928.

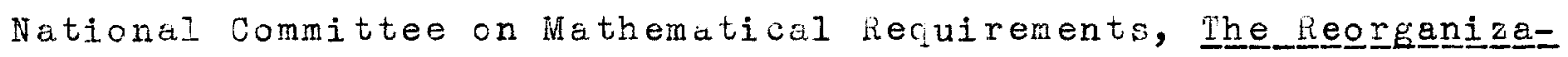

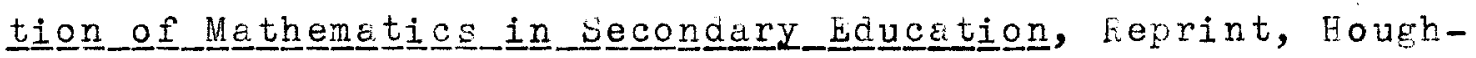
ton Mifflin Com any, New York, 1927.

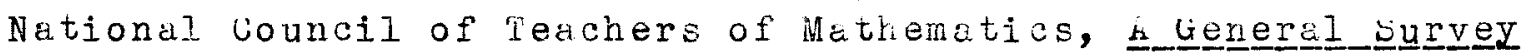

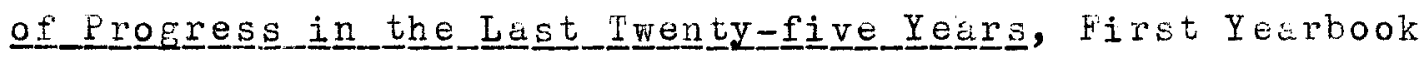
of the National Council (1926) (Now out of print.) Eureau of Publications, Columbia University, New York.

National Council of Teachers of Mathematics, Deleected Toneics_in

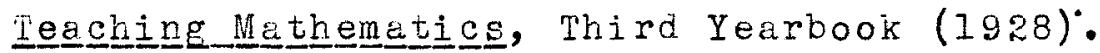

National Council of Teachers of Mathematies, SiEnificant Changes

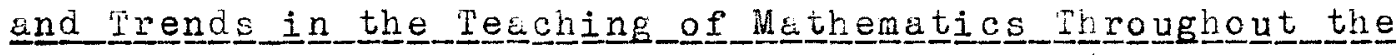
World Since 1910, Fourth Yearbook (1929).

National Council of l'eachers of Mathematics, Kelational_End Eunctional Ihinking, Ninth Yeerbook (1934).

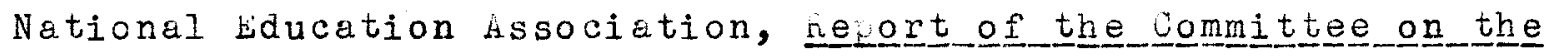


Orientation 으르음ondary Education: Eulletin of the Depar tement of Secondary School Principals, $x x: 59$ (January, 1936).

National iducation hsociation, Five Unifying Factors ingermeri=

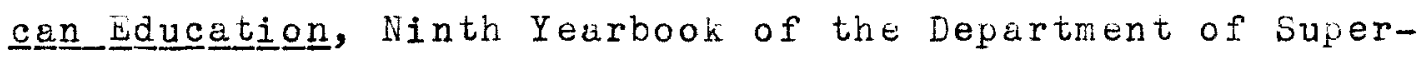
intendence, (1931).

National society for the btudy of bucation, Minimum Essentials in_Elementa표 Schoogl Subjects, Part I, Fourteenth Yearbook, (1915) .

North-Central Association of Colleges and Decondary Schools,

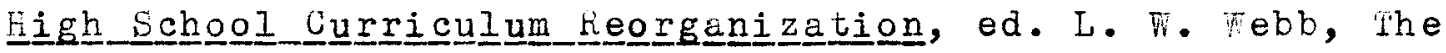
Association, Ann Arbor, ilichigan, 1935.

otto, Henry J., Elementary scchool Organizagtion, Appleton-Jontury co. iven Youk, 1034.

Progressive Lducation Association, 道年hematics, Eulletin No. 591, Committee on Evaluation in the kight-Year study, Ohio state University, Columbus, Ohio, 1936.

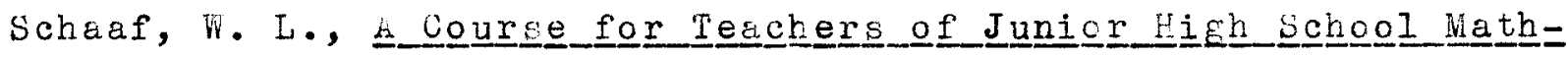
ematics, Contribution to Education No. 313, Eureau of Publications, lecchers College, Columbia University, New York, 1928.

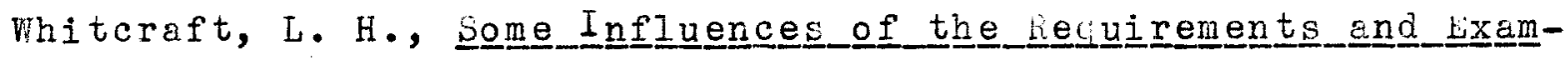
inations of the College Entrance Examination Eoa 


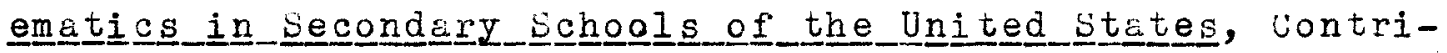
bution to Education No. 557, Bureau of Publications, I'eachers lollege, Volumbia University, New York, 1933.

inagazine Articles

Ammerman, Charles, and Others, "Yreliminary keport of the committee of the Central Association on Algebre in the secondary School," School Science and Mathematics, VII (Sept. $1907) \cdot \mathrm{pp} \cdot 674-85$.

Atherton, Charles kussell, "The Place of Mathematics in the

Curriculum of the Progressive School," The Mathematic

Teㅡ르르, XXVIII:I ( Jan. 1935) pp. 48-55

Breslich, H. R., "The Unit in Mathemetics, " Junniogr-Eenior High

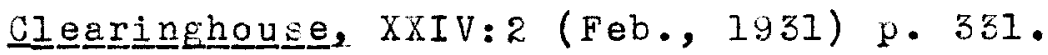

Breslich, E. R., "Junior High School hathematics," School XXVIII: 5 (May, 1920) p. 374.

Bresiich, E. n., "Mathematics for Grades Seven, Light, and Nine",

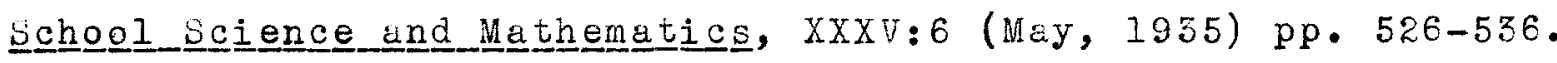

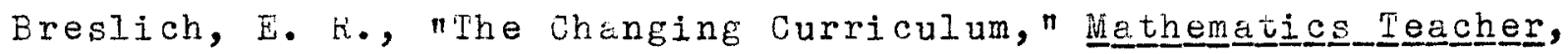
XXVI: 6 (oct., 1933) p. 345 . Erim, Orville G., "Basic Realities and the Activity Movement," 므ogressive Educacation XI:6 (0ct., 1934) pp. 328-333. Davis, Mrs. David $\hat{\mathrm{A}}$., "A Comparative Study of Textbooks in Junior High School Mathematics," Ihe High school, VIII:2 (Feb. I2, 1936) pp. 103-104. 
Gugle, Marie, "Revision of College Preparatory Mathematics, " Mathematics iegacher, XV:7 (Nov., 1922) pp. 381-91. Hedrick, E. K., "Crises in Economics, Education, and

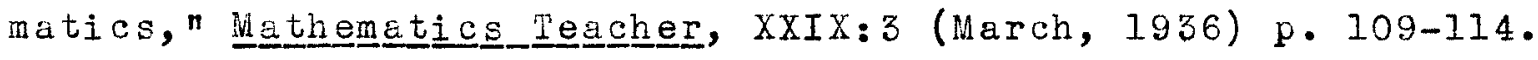
Johnson, J. T., "Adapting Instruction in Mathematics to Individual Differences in Learning," Mathematics Teacher, XXVI:4 (Apr., $1933), \mathrm{pp} \cdot 193-196$

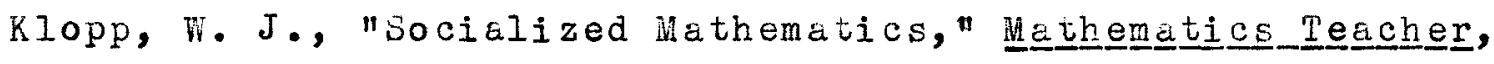
XXIII: 3 (March, 1930), pp. 16I-163.

Langley, W. R., "The Function Concept in Algebra," Mathenatics Peachene, XXVI:1 (Jan., 1933), pp. 5-9.

Long, Edith, "Correlation of Algebra, Geometry, and Physics," Schhogol zevien, XXIV (0ct., 1902), pp. 209-21. Palmer, Katherine Ball, "Mathematics in the Home," Matheaㅡ를 Peecher, XXIV: 6 (0ct., 1931), pp. 355-36z.

Reeve, N. D., "The Case for General Mathematics," 煎 theinatics Tescher, XV:7 (Nov., 1922), pp. 381-391. Roser, J.T., "The social Qualities of Mathematics," Mathematic․ㅡ Feacher, XXVII:2 (Feb., 1954), pp. 82-85.

Schaaf, William Leonard, NMathematical Iraining for Economic

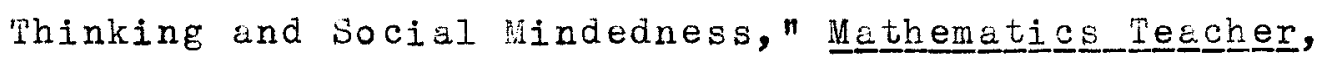
XXVII: 8 (Dec., 1934), pp. 373-380.

Zant, James H., "Mathematics in the Integrated Curriculum," Hathematics Teacher, XXVII: 8 (Dec., 1934), pp.38I-389. 
Courses of study

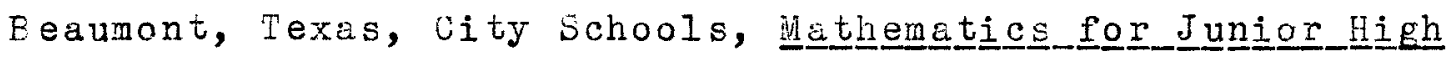
도느요토, 1932 .

Eoston Public schools, Mathematics 2 Gragdes_VII=VIII, EeVised, 1930.

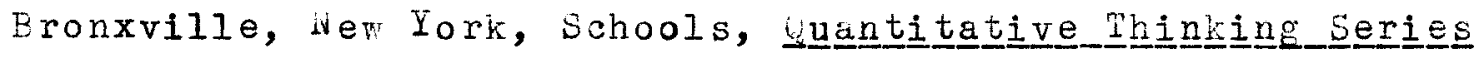

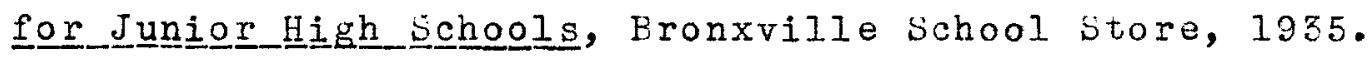

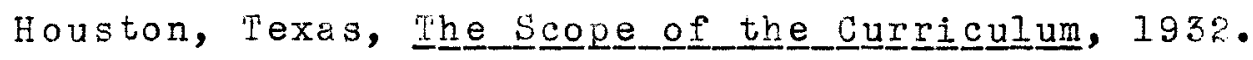
Indianapolis, Indiana, Public schools, ouseㅗ of

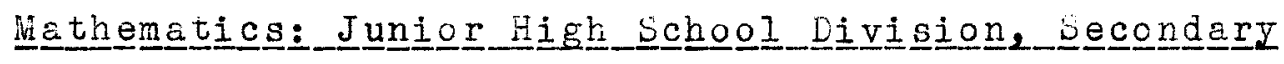
S드으으토, 1934 .

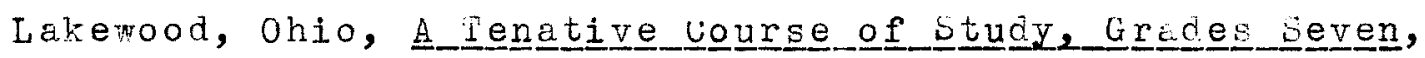

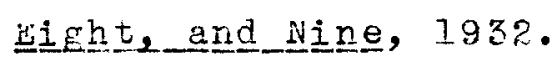

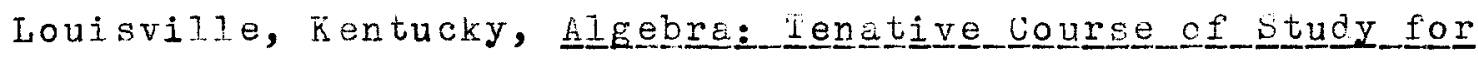
Ihe Junior High Bchools, (First Revision), 1932.

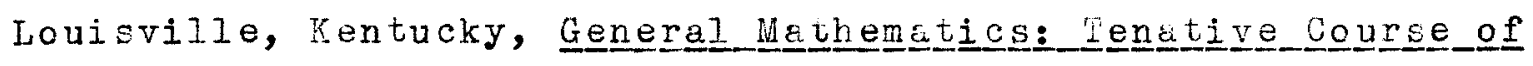

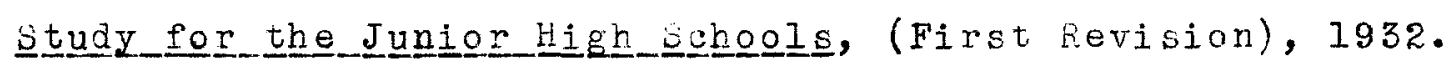

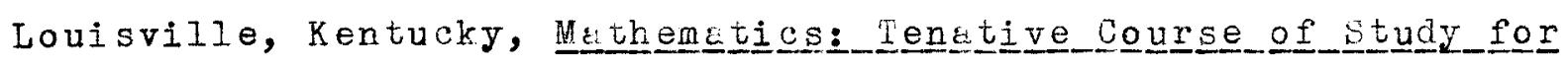

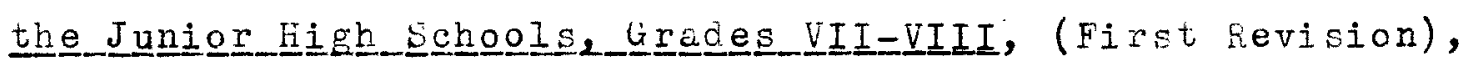
1933.

Louisville, Kentucky, Lemedial Mathematics foror_Junior High Schools, 1935 .

Ohio State University, Lxperimental school, Equcetional_hesegrch Bulletiㅡ, February 12, 1936 .

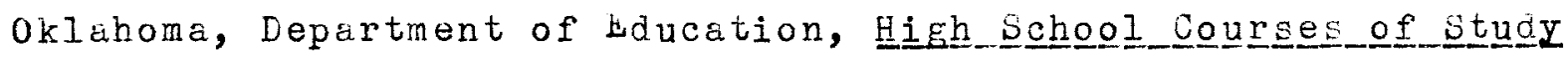




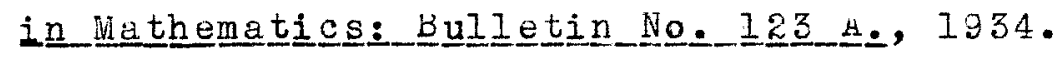

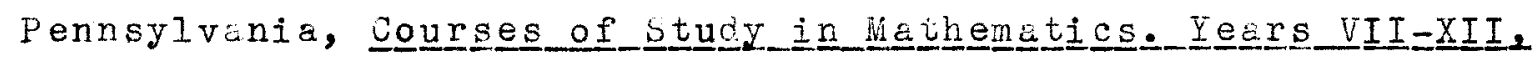
1927.

South Dakota, Mathematics for Secondary Schools: Cour se

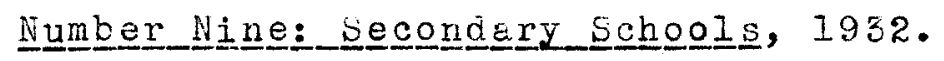

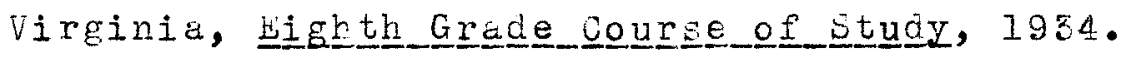

Washington, Stute of, A_P 1 an Fon ther the Regranization of $H i g h$

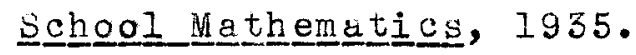

Mathematics Textbooks Used in the Junior High Schools of $k$ entucky

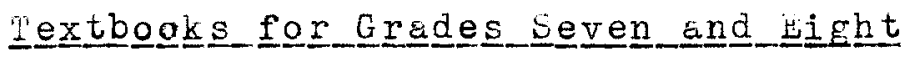

Betz, William, Junior Mathematics for Ioda․ Books one and Two,

Ginn and company, Boston, 1934. Used in two schools. Hemilton, samuel, Bliss, talph F., and Kupfer, Lillian, Essen-

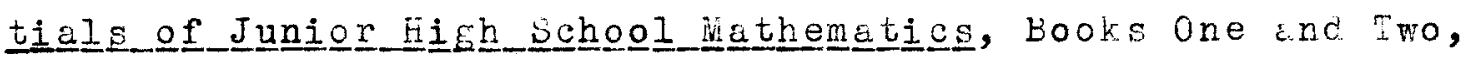
Ginn and Company, Eoston, 1927. Used in two schools.

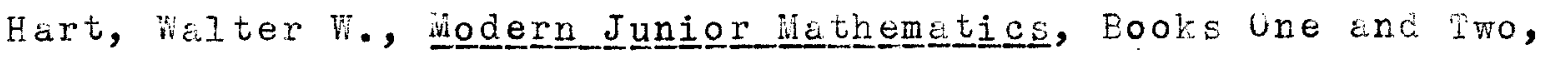
D. O. Heath and Company, Boston, 1931. Used in three schools. Stone, John l., The New H. Sanborn and compeny, Uhicsgo, 1927. Used in eight schools. Strayer, George D., and Upton, Clifford B., Arithmetic for Higher Grades, American Book Uompany, New York, 1928. Used in one school.

Strayer, George V., and Upton, Ulifford B., Juningr Mathematics, 
American Book Company, New York, 1929. Used in four schools.

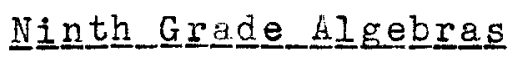

Hart, Walter W., Progressive First Algebra, D. C. Heath and company, Boston, 1934. Used in fourteen of the schools. Hamilton, Samuel, Bliss, kalph P., and Kupfer, Lillian, Junior High School Mathemetics, Book Three, American Book Lompany, New York, 1927. Used in two schools. Hawkes, Herbert E., Luby, Nilliam A., and Touton, Frank U., New

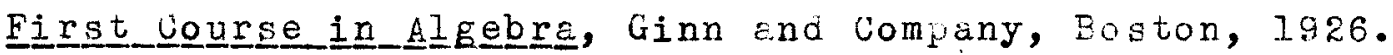
Used in two schools. Nyberg, Joseph, kirst Gourse in New York, revised in 19z2. Used in one school.

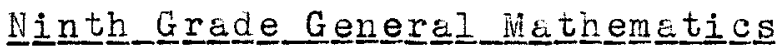

Betz, William, Junior Mathematics, Book lwo, Ginn and Company, Eoston, 1934. An eighth grade book used on the ninth grade level in one school.

Lasley, Sidney J., and hudd, ingrtle F., The New fpplied liathematics, Prentice Hall, Incorporated, New York, 1934. Used in one school. 
APPENDIX 


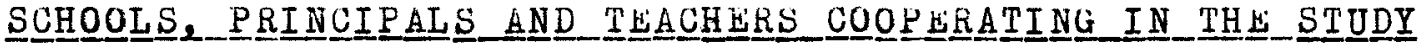

\begin{abstract}
ASHLAND

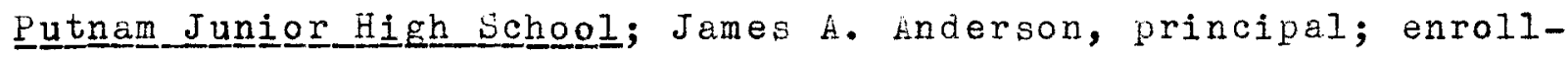
ment, 803; Edith cNeal, Margaret Melcher and four other teachers cooperating.
\end{abstract}

\section{EOFLIHG GREEN}

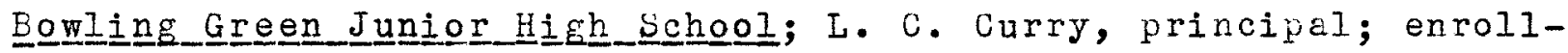
ment, 450; Orme Doolin, Edwina Jones, A. G. Ross and one other teacher cooperating.

\section{ERYAN STATION}

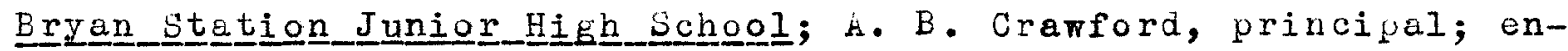
rollment, $300 ;$ W. K. Evans, Buena $C$. Mathis and three other teachers cooperating.

\section{COVINGTON}

Holmes_Junior High_schhool; enrollment, 1273; Edith R. McCandiess, W. M. Shearer, the principal and two other teachers cooperating.

\section{HARLAN}

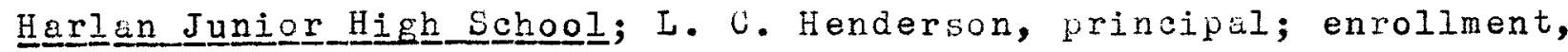
335; Vivian Nash, Grayson Hackney, Cloyd McDowell, Lélánci Wilson and one other teacher cooperating.

\section{HLNDERSON}

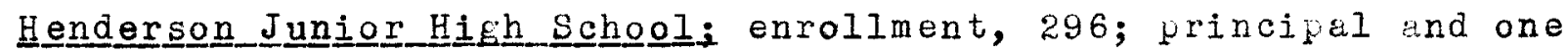


teacher cooperating.

\section{LEXINGTON}

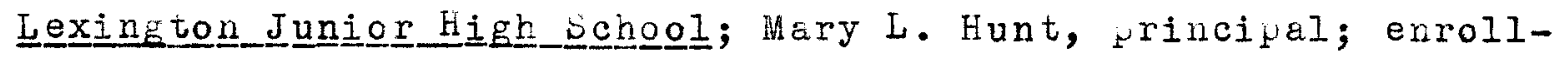
ment, 672; Ina Kay Smith, Elmer T. Gibbs and two other teachers cooperating.

Morton Junior High Schooli J . M. Deacon, principal; enrollment, 602; Tomie Bronson, Katherine kankin, L. E. Grover and two other teachers cooperating.

\section{LOUISVILLE}

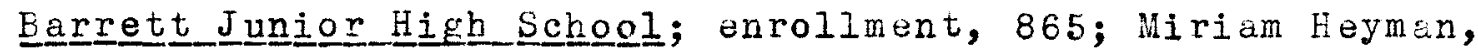
Robert Turner and one other teacher cooperating. Eastern Junior High School; enrollment, 580, one teacher cooperating.

Halleck Hall (Louisville Junior High School); enrollment, z209; Laura Bassett, Philip Clements, Carl V. Fronabarger, Aurelius h. Mooney, William D. Shelby and one other teacher cooperating.

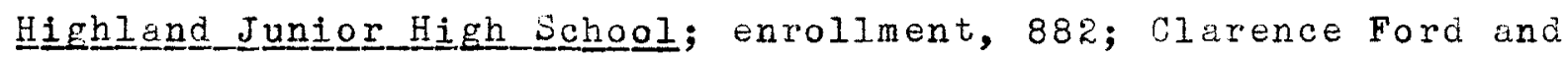
one other teacher cooperating.

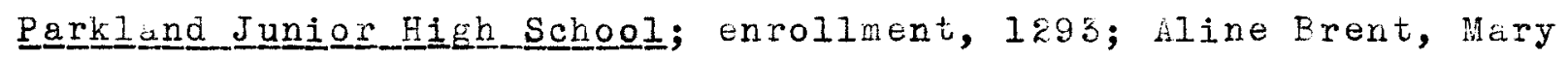
Catharine Ryan, arthur J. Ries, and three other teachers cooperding.

Shawnee Junnior High School; enrollment, 1192; Sue G. Schroeder, P. W. Raine, Davis S. Fields, Harold S. Keeling and one other teacher cooperating. Southern Junior High Schoogl; enrolzment, 1553; Sarah Boggs, 
Daniel N. Hammond, Charles Youmans and two other teachers cooperating.

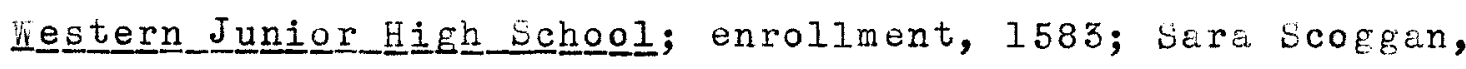
Willard C. Taylor, and two other teachers cooperating.

\section{MADISONVILLE}

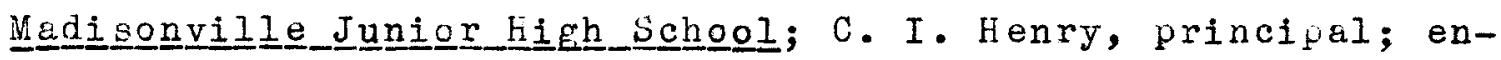
rollment, 350 ; one teacher cooperating.

\section{MAYSVILLE}

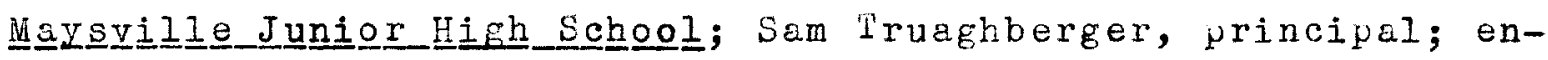
rollment, 164; three teachers cooperating.

OWENSBOHO

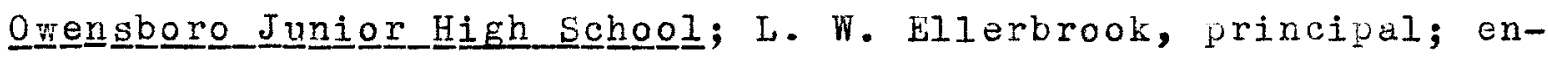
rollnent, 683 ; four teachers cooperating.

\section{PADU $\cup A H$}

토드므므_Junior High_School; hdah L. Brazelton, princifal; enrollment, 200; Emily Schroeder and one other teacher cooperating.

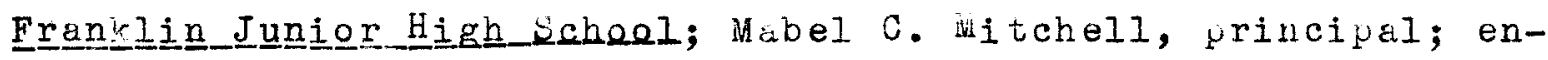
rollment, 292; Shirley Durham, Herman Miller cooperating. Washington Junior High_SchooI; D. Ialmadge Cooper, principal; enrollment, 575; Mary McGuire, Pattie Petway, Belle Stanley cooperating. 
THE TOPICS WHICH APPEAR IN THE TEXTBOOKS BOT WHICH TWO OR MORE TEACHERS OMIT AS INDICATED ON THE QUESTIONNAIRES

\author{
TOPIC NUMBER OF TEACHERS
}

Grades Seven and Eight:

Making Formulas

Mensuration of Solid Figures -

Metric Measures -

St.tistics -

Study of Position

Taxation of Income

Unusual Measures (including Metric) ----- 4

Ninth Grade General Mathematies:

Trigonametry

Ninth Grade Algebra:

Imaginary Numbers -

Trigonometric Functions -

Variation - 
QUESTIONNAIRE FOR IHDIUIDUAL TEACHERS

OF

JUNIOE HIGH SOHGOL METHEMAIICS

Check: Male Female

1. Name of teacher:

(If you prefer not to have your name mentioned in the report check here: _._. ).

2. School where employed:

z. Number of years of tétching experience: (include present year).

4. Numer of years experience teaching mathenatics: (include present yeźr).

5. Number of years experience in junior high schools: clude present year).

6. Level of training: (Degree or semester hours).

7. Number of semester hours in mithematics:

8. Number of semester hours in education:

9. What subjects or duties other than mathematics do you now have?

10. College major subject: Minor subject:

11. Do you use the supervised or directed study plan of teaching extensively in your mathematies classes? no some.

12. Do you use the unit method (including pretest, presentation, assimilation, organization, etc. or some similar arrangement) extensively in your mathematics classes? yes no some.

13. Do you use the contract plan of lesson assignment extensively? __nes_no_no some.

14. Do you use the group plan of instruction extensively? (dividing up the class into groujs accordine to interests or progress) yes no some.

15. Please describe belor and on the back of this sheet any unusual practices in method, materials or ideas of any kind that you have used successfully in junior high school mathematics. 
Note: Belaw are some statements concerning highly controversial issues. There is, perhaps, no "right" or "wrong" answer to many of these issues. What is sought is your opinion as a class-room teicher.

Dírections for maxking: Be sure to mark each statement in one of the foliowing ways:

(x) ( ) ( ) If you are in full agreement with tie statement.

() (x) ( ) If you agree with the statenent but with a few reservations.

()()$(x)$ If you agree with the statenent vith many reservations.

(-) ( ) ( ) If you wholly disagree with the staterent.

( ) (-) ( ) If you aisagree with tre statement but with a few reservations.

( ) ( ) (-) If you disagree with the statement with many reservátions.

\section{1 .}

() ( ) ( ) The junior high school mathenctics curriculum should be planned with the aim of providing for all normal individuals and not merely for a select group.

\section{2 .}

( ) ( ) ( ) The work of certain pupils, who because of inability or indifference do not shov progress after every effort has been made to adjust the curriculum to their needs, shoula be terminated with a completion of the fundamentals.

3.

( ) ( ) ( ) The junior high school mathemetics curriculum should be based on the common needs of the studerts rather than on their differentiated needs.

4.

( ) ( ) ( ) The junior high school mathematice courses should exploit every opportunity to provide for vocational training and not be coufined to training that might come under the heading of "generel educetion".

5.

( ) ( ) ( ) The junior high school mathemetics curriculum should be primarily directed toward preparation for advanced courses rather than directed primarily toward the vaiue of its own courses. 
( ) ( ) ( ) It would be wise to organize the experiences of the
junior high sohol period of eduction around life-
functioning aims such as socio-sivic, econonic,
health, leisure time, etc. rather than to adhere to.
the tradional subject-matter civisions such as
matheratics, English, etc.

7 .

( ) ( ) ( ) Junior high school mathematics shouia present merely orcanized facts aná shoula not assume responsibility for attitudes andideals.

8.

( ) ( ) ( ) The junior high school mathematics curriculum should have as its aim merely the adjustment of students to prevailing social ideals and should not seek the reconstruction of these ideals.

9.

( ) ( ) ( ) Junior high school matheratics shoula be thoukht of as a distinct but closely articulating part of the entire mathematics progran of the schools rather than as a mere phase of that program with few or no distinguishing charecteristics of its own.

10.

( ) ( ) ( ) Junior high school mithematics should be concerned only with the welfare ana progress of the individual rather than with those only as they promise to contribute to the welfare and progress of society.

Note: Belon are some practical questions about what ycu believe the junior high school mathematics curriculum shoula contein. Again it is your opinion that is sought.

1. Do you believe that practically all pupils are capable of a reasonable degree of nastery of algebra and that therefore it should be a recuired subject in the ninth grade? _._yes ___yes with reservations no.

2. To what extent do you believe that the present needs and interests of chilaren woula form an adequate basis for selecting material for the junior high school mcthemetics curriculum? wholly, _. largely, __ to a considerable extent, __to a very limiteci extent, not at all.

3. Assuming that a course of study for each year would take into account 180 class periods plecse irdicate below the number of class periods which you believe should be devoted to each 


\section{1}

topic. Fill in the blank. lines with any additional topics you feel are important.

TOPIC:

NNUNBER OE_CLESS EEEIOED:

7 th grade 8th. grade 9th. grade course: course: general mathenctics course:

Fundamentil processes of arithmetic including whole numbers, fractions, decimals, and percents:

Informational arithmetic inciuding, taxation, insurance or similar informational materiel:

Intuitive geometry including simple constructions, areas, volumes, etc.:

Algebraic equations including simple problems:

History and eppreciation of the importance of mathematics:

Statistics ana statistical graphs:

NumericaI trigonometry:
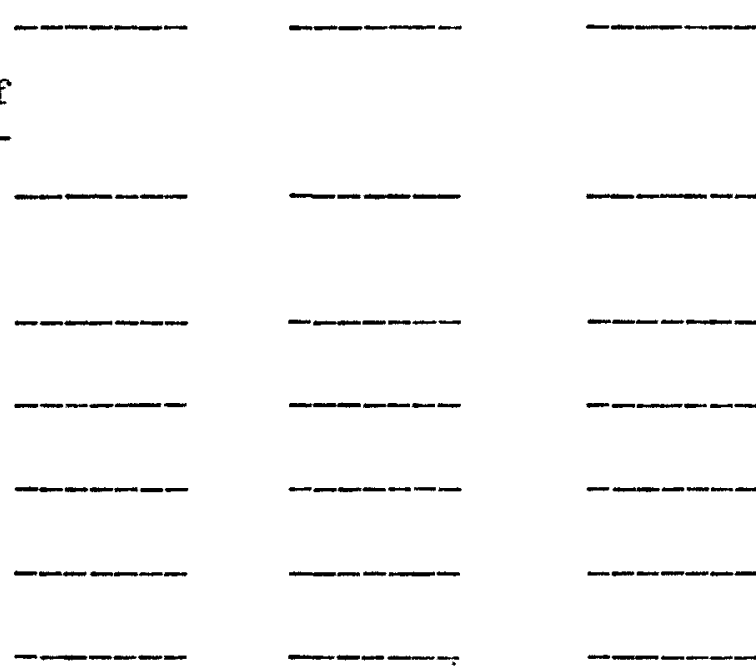

Note: Use beck of this sheet for still additional topics and time allotments. 
Please fill in the following information for the courses that you a a

1. Eeventh Grade Mathematics Please list any topics in the basic text used in your school which you omit:

Please list below any topics not in the basic text which are included in your seventh grade course:

2. Eighth Grade Mathematics Please list any topics in the basic text used in your school which you omit:

PIease list below any topics not in the basic text which are included in your eighth grade course:

3. Ninth Grade Genergl Mathematics Please list any topics in the basic text used in your school wich you omit:

Please list below any topics not in the basic text which are included in your ninth grade general mathematico course:

4. Ninth Grade Algebra Plecse list any topics in the besic text used in your school which you omit:

Please list below any topics not in the basic text which are included in your course: 
Note: If mathematics courses other than the ones mentioned above are offered and tzught by you please list the same information for these courses on the bacir of this sheet. 


\section{QUESTIONNAIRE ON REPEIATICS \\ IN THE}

JUNIOR HIGH SCHOOLS OF KENSUCKY

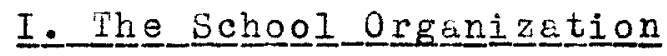

1. Name of the junior high school:

2. Address:

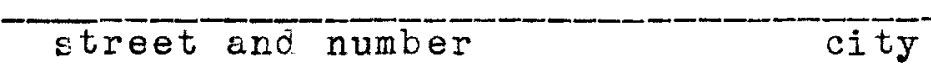

3. Name of principal:

Note: If principal prefers not to have his name mentioned check:

4. This junior high school is composed of grades:

5. Is this junior high school an integral part of a six-year secondary school? yes no. (Plesse check before the proper response.)

6. Enroliment for the present year is pupils.

7. Number of school months normally in session per year:

8. Do you segregate classes according to ability? (check).

9. How many periods per week are devoted to mathematics? 7 th grade: periods 8th grade: periods gth grade: periods.

10. The average length of each of these periods in minutes is: 7 th grade: minutes 8 th grade: minutes gth grae: minutes.

II. The Mathematics Cي̣riciculum

11. Is seventh grade methematics required of aII students? ___yes __._no.

12. Is eighth grade mathematics reguired of all students? yes __no. 
13. List the mathematics courses offered in the ninth graoe:

14. Underscore one of the following statements which describes best your mathematical recuirements for the ninth grace or if none of these apply state your requirements:

(a) algebra required of all (b) general methematics required of $a I I$

(c) no mathematics required (d)

15. Does general mathematics count as a unit towara graduetion from senior high school when taken in the ninth grade?

____yes ___no.

16. Does comercial arithmetic count as a unit toward graudation from senior high school when taken in the ninth grade?

-_-_yes no.

17. Does your school have a printed, mimeograhed, or otherwise recorded course of study for mathematics?

for 7 th grade:___yes__no, for 8 th grade:___yes__no. for 9 th grade generai mathematics:___yes__no, for $\overline{9} \overline{t h}$ grade algebra: ___ yes__no, any others:____________

18. Do you have a coaching class, opportunity class, or ungraded class to provide for slow pupils in mathematics in your school? yes no.

19. Do you have a separate course of study for slow pupils who are not assigned to the above mentioned coaching class? yes no.

20. What basic texts are used for junior high school methematics in jour school?

Seventh grade basic text:

Highth grade basic text:

Ninth grade algebra text:

Ninth grade general mathematics basic text:

Basic texts for other mathematics courses: 
Vita

The writer was born at Smith's Grove, Kentucky on Februsry the eighth, 1909. He received his elementary and secondary education in various public and private schools of Kentucky and was graduated from Lawrenceburg City High School in June, 1926. Having attended Kentucky Tesleyan College and the University of Kentucky, he matriculated at the University of Louisville in January, 1930 and was graduated in August, 1931.

His first position was teaching in the Harris Branch School, Clark County, Kentucky. In september, 1931 he was employed as teacher of mathematics in Parkland Junior Hich School of Louisville, Kentucky, which position he now occupies. He has served on several committees for revision of the curriculum in junior high school mathematics in Louisville and is at present a member of the Kentucky Mathematics Curriculum Comittee for Grades Seven to Nine. 